\title{
GESTÃO DO RISCO DE GRANIZO PELO SEGURO E OUTRAS ALTERNATIVAS: ESTUDO DE CASO EM \\ POMARES DE MAÇÃ DE SANTA CATARINA
}

\author{
HENRIQUE MASSARU YURI
}

Dissertação apresentada à Escola Superior de Agricultura "Luiz de Queiroz", Universidade de São Paulo, para obtenção do título de Mestre em Ciências, Área de Concentração: Economia Aplicada.

P I R A C I C A B A

Estado de São Paulo - Brasil

Novembro - 2003 


\title{
GESTÃO DO RISCO DE GRANIZO PELO SEGURO E \\ OUTRAS ALTERNATIVAS: ESTUDO DE CASO EM \\ POMARES DE MAÇÃ DE SANTA CATARINA
}

\author{
HENRIQUE MASSARU YURI \\ Engenheiro Agrônomo
}

Orientador: Prof. Dr. FERNANDO CURI PERES

Dissertação apresentada à Escola Superior de Agricultura "Luiz de Queiroz", Universidade de São Paulo, para obtenção do título de Mestre em Ciências, Área de Concentração: Economia Aplicada.

P I R A C I C A B A

Estado de São Paulo - Brasil

Novembro - 2003 
Dados Internacionais de Catalogação na Publicação (CIP) DIVISÃO DE BIBLIOTECA E DOCUMENTAÇÃO - ESALQ/ USP

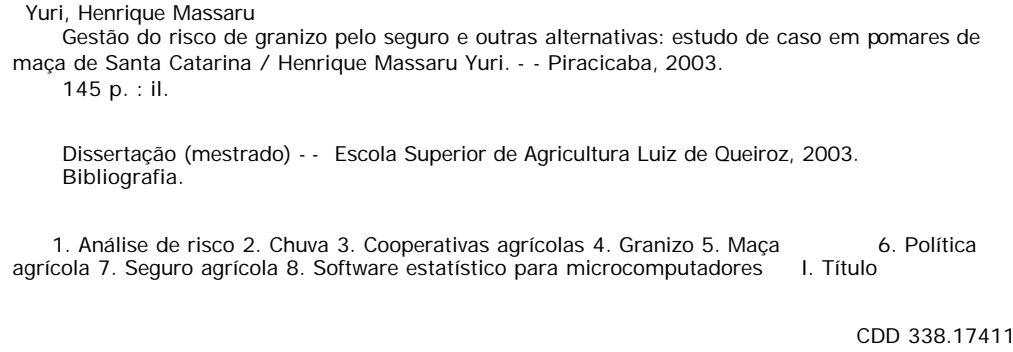

1. Análise de risco 2. Chuva 3. Cooperativas agrícolas 4. Granizo 5. Maça agrícola 7 . Seguro agrícola 8 . Software estatístico para microcomputadores

I. Título

6. Política

CDD 338.17411

"Permitida a cópia total ou parcial deste documento, desde que citada a fonte - $\mathrm{O}$ autor" 
Dedico este trabalho aos meus avós:

Tadaomi Yuri (in memorian),

Hisako Yuri,

Jutei Tsuhako,

Tsuru Tsuhako (in memorian). 


\section{AGRADECIMENTOS}

Registro aqui meus sinceros agradecimentos à minha esposa Larissa, aos meus pais, irmãos, tios e amigos pelo inabalável companheirismo e incomensurável apoio que sempre me ofereceram em todos os momentos da elaboração deste trabalho, ao Prof. Adriano Azevedo-Filho pelo seu esforço e empenho no apoio e co-orientação do desenvolvimento deste trabalho e, a todos os demais professores, colegas e funcionários do Departamento de Economia, Administração e Sociologia - ESALQ-USP por suas valiosas e incentivadoras sugestões e críticas, conselhos e serviços. Meus agradecimentos também aos cooperados da SANJO - Cooperativa Agrícola de São Joaquim, à CLIMATERRA Assessoria Planejamento Agronomia Ltda., à LIRASEG Corretora de Seguros, à AGF - Anti Granizo Fraiburgo Ltda., à AFF - Associação de Fruticultores de Fraiburgo, à EPAGRI - Empresa de Pesquisa Agropecuária e Extensão Rural de Santa Catarina S.A., ao INPE - Instituto Nacional de Pesquisas Espaciais por suas participações, informações técnicas, comentários e sugestões disponibilizadas, fundamentais para o desenvolvimento e conclusão deste trabalho, e ao FAPGREP/FEALQ - Fundo de Apoio à Pesquisa em Gerenciamento de Riscos e Economia da Produção, coordenado pelo Prof. Adriano Azevedo-Filho, pela bolsa de estudos e cobertura de custos da pesquisa realizada. 


\section{SUMÁRIO}

Página

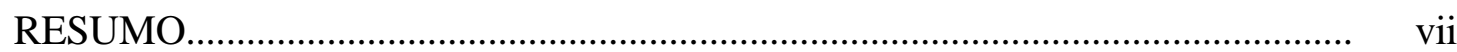

SUMMARY

1 INTRODUÇÃO ................................................................................... 1

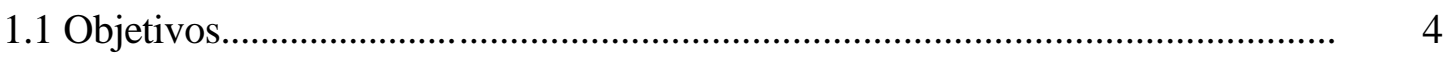

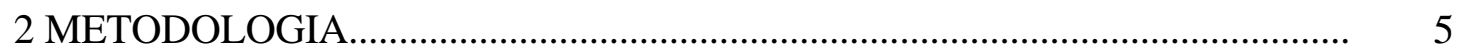

3 REVISÃO E CARACTERIZAÇÃO DE ALTERNATIVAS ................................ 11

3.1 Revisão bibliográfica.................................................................................... 11

3.2 Alternativas para o gerenciamento do risco de chuvas de granizo........................ 13

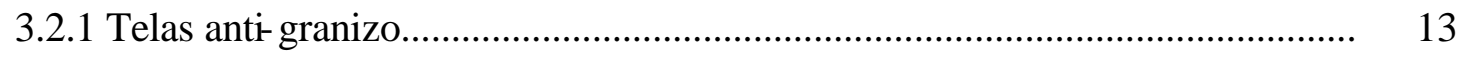

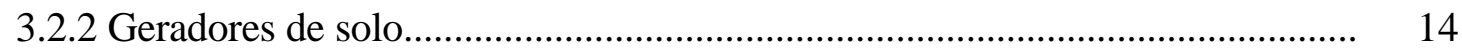

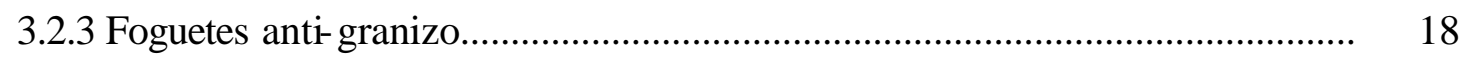

3.2.4 Pulverização das nuvens com utilização de aviões............................................. 18

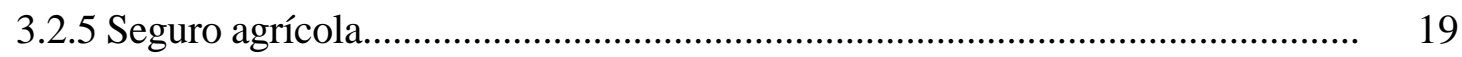

3.2.6 Diversificação espacial................................................................................. 21

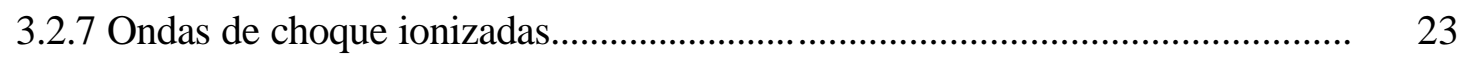

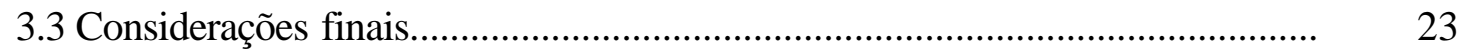

4 RESULTADOS E ESTUDO DE CASO ………............................................... 25

4.1 Considerações iniciais.................................................................................... 25

4.2 Ocorrência e avaliação da intensidade das chuvas de granizo em SC …............. 25

4.3 Alternativas historicamente utilizadas em São Joaquim e Fraiburgo .................. 27

4.4 Diagrama de decisão e modelo computacional................................................. $\quad 30$

4.5 Análise dos dados coletados através de questionário.......................................... 35 
4.5.2 Questionário aplicado à empresa prestadora de serviços em meteorologia agrícola....... 41

4.5.3 Questionário aplicado aos produtores de maçã.................................................... 45

4.6 Aplicação, em planilha de cálculo, dos resultados do levantamento ................... 55

5 CONCLUSÕES............................................................................................. 62

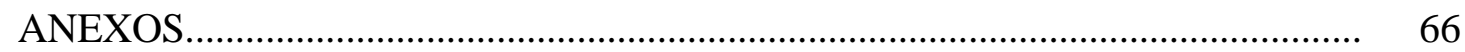

REFERÊNCIAS BIBLIOGRÁFICAS.............................................................. 124

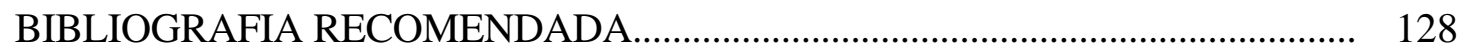




\title{
GESTÃO DO RISCO DE GRANIZO PELO SEGURO E OUTRAS ALTERNATIVAS: ESTUDO DE CASOEM POMARES DEMAÇÃ DE SANTA CATARINA
}

\author{
Autor: HENRIQUE MASSARU YURI \\ Orientador: Prof. FERNANDO CURI PERES
}

\section{RESUMO}

O prejuízo causado por chuvas de granizo é um dos principais problemas enfrentados pelos produtores de maçã no Brasil e em outros países. O trabalho apresenta, a partir de uma revisão abrangente da literatura e pesquisas de campo realizadas em região produtora do Estado de Santa Catarina, uma caracterização do problema e das alternativas existentes para a definição de estratégias ótimas para o gerenciamento do risco existente. As alternativas consideradas incluíram: seguro comercial, seguro mútuo, diversificação espacial, telas anti-granizo, foguetes anti-granizo e geradores de solo. $\mathrm{O}$ trabalho utiliza um modelo conceitual, especificado num diagrama de decisão e dados levantados na pesquisa, para evidenciar a relação qualitativa e quantitativa existente entre as diferentes alternativas consideradas e as variáveis mais relevantes para caracterização do problema. O modelo definido no diagrama de decisão foi implementado em software, em planilha eletrônica, de forma a facilitar o processo de seleção das melhores alternativas para gestão do risco de granizo, a partir da situação existente com relação a preços, custos e outras informações relevantes. Esse software foi 
utilizado em estudo de caso realizado junto a uma cooperativa de produtores de maçã de São Joaquim, SC, para a análise quantitativa das alternativas levantadas. O trabalho visa fornecer subsídios técnicos que auxiliem os agricultores no processo de tomada de decisão quanto à estratégia mais adequada para a administração do risco de chuvas de granizo em seus pomares, auxiliem as empresas de seguro na elaboração de novos contratos em suas carteiras agrícolas e, também, o governo no desenvolvimento de novas políticas voltadas ao setor agropecuário. 


\section{HAIL RISK MANAGEMENT USING INSURANCE AND OTHER ALTERNATIVES: CASE STUDY ON APPLE ORCHARDS IN SANTA CATARINA, BRAZIL}

Author: HENRIQUE MASSARU YURI Advisor: Prof. FERNANDO CURI PERES

\section{SUMMARY}

The damage caused by hailstorms is one of the most important problems faced by the apple producers, in Brazil, and in other countries. This work presents, from a literature review and local surveys within the apple producing region in Santa Catarina State, Brazil, a characterization of the hail risk problem and an evaluation of existing alternatives for risk management. The alternatives considered in the risk management process included: commercial insurance, mutual insurance, spatial diversification, antihail nets, hail rockets and ground burners. Besides, the research presents a conceptual model that uses decision diagrams to describe the qualitative relationship among the different alternatives for administration of the hail risk and the most important variables for the problem. The decision diagram guided the development of a software tool designed to help the selection of the best combination of alternatives for hail risk management. This software tool, implemented in a spreadsheet, was used in a case study involving an association of apple producers in São Joaquim, SC. The intention of this work is to aid apple producers in the selection of the most appropriate strategy for the 
administration of the risk of hailstorms in their orchards, aid the insurance companies in the design of new contracts in your agricultural portfolio and, also, aid the government in the development of new agricultural policies. 


\section{INTRODUÇÃO}

Em todo o mundo a cultura da maçã se desenvolve usualmente dentro de regiões temperadas ou em altitudes elevadas. As características climáticas típicas dessas regiões beneficiam a produção e qualidade dos frutos, que demandam um longo período com baixas temperaturas para um desenvolvimento fisiológico apropriado. Ocorre, contudo, que essas mesmas características climáticas propícias ao desenvolvimento da cultura favorecem a ocorrência freqüente de chuvas de granizo, com prejuízos significativos aos agricultores.

No Brasil, os pomares de maçã estão localizados, predominantemente, nos Estados de SC e RS (Figura 1), ocupando uma área aproximada de 30 mil hectares e envolvendo cerca de 2.200 produtores, o que gerou, na safra 99/2000, quando foram produzidas 960.mil toneladas da fruta, uma renda bruta próxima a US\$ 300 milhões (Associação. Brasileira dos Produtores de Maçã - ABPM, 2001).

O expressivo crescimento do investimento na produção interna de maçã, que já atende $95 \%$ do consumo brasileiro, ao longo da última década, motiva o interesse por métodos que possam aprimorar o gerenciamento do problema do granizo nessas regiões. Ao longo das safras de 99/2000 e 2000/01, cresceu o uso do seguro e outros mecanismos de gerenciamento, pouco utilizados no passado recente. Segundo Lima (2000) ${ }^{1}$, no caso do seguro comercial, na safra 2000/01, em algumas regiões produtoras, as áreas protegidas, predominantemente de pequenos e médios produtores, superaram $50 \%$ da área total cultivada.

\footnotetext{
${ }^{1}$ LIMA, A.H.V. (LIRASEG Corretora de seguros, São Joaquim). Comunicação pessoal, 2000.
} 


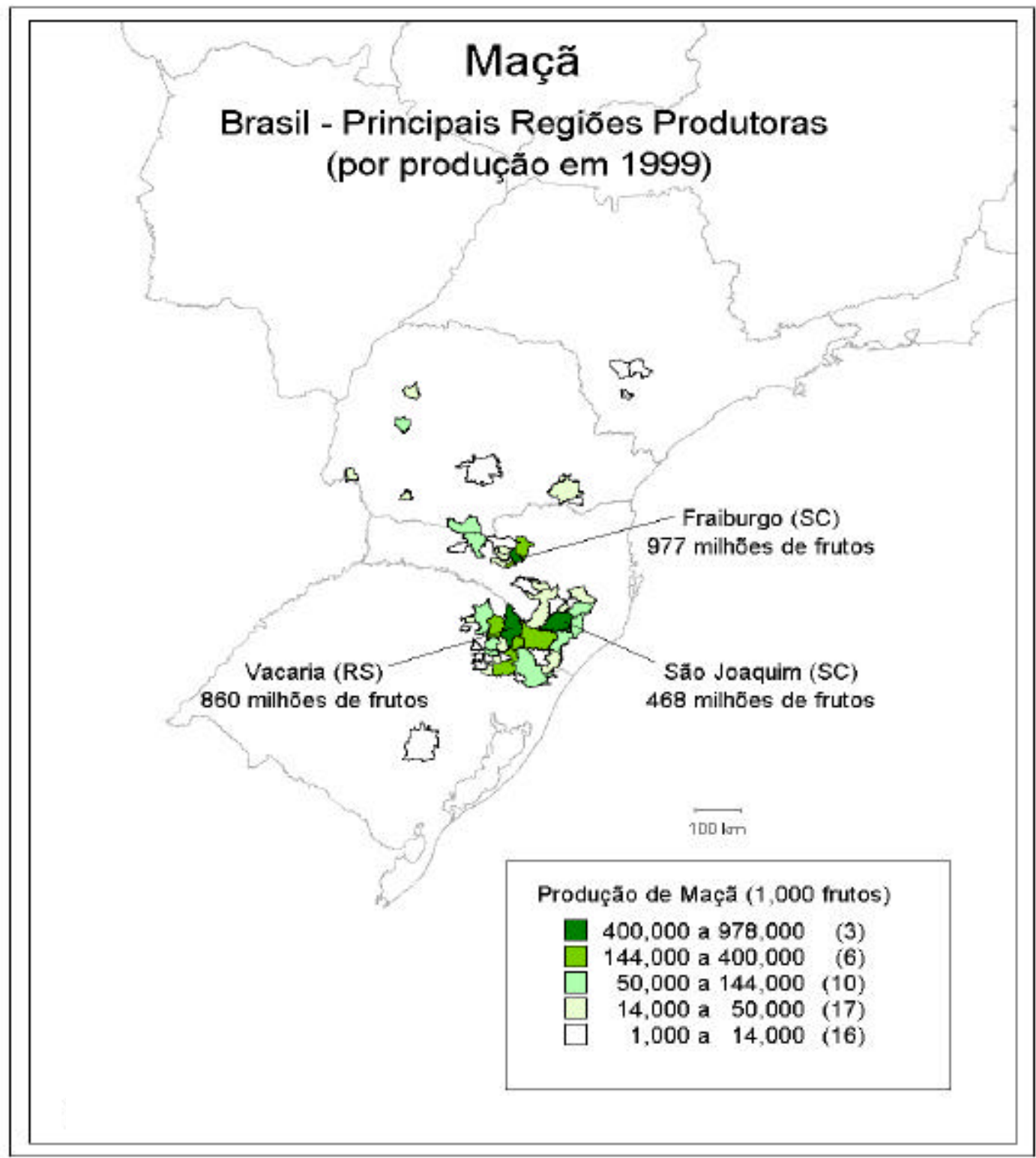

Figura 1 - Principais regiões produtoras de maçã no Brasil.

Fonte: Dados básicos do Instituto Brasileiro de Geografia e Estatística - IBGE elaborados na pesquisa (2001) 
O granizo é um fenômeno que ocorre de forma localizada, não atingindo grandes áreas. Em todo o mundo, o prejuízo causado por granizos intensos em pomares de maçã pode ser devastador, especialmente para pequenos e médios produtores, em função dessa característica peculiar da distribuição espacial desse fenômeno climático (Dessens, 1986a; Changnon-Junior, 1984). A natureza dos prejuízos causados pelo granizo envolve conseqüências econômicas de curto e de longo prazo. O prejuízo direto é resultante do impacto das pedras de granizo - que podem superar o tamanho de um ovo às frutas e às árvores. Ess e impacto pode ocasionar significativa redução na qualidade e quantidade dos frutos destinados à comercialização, assim como dano às árvores em formação e em produção. Isso pode causar não só a perda de receitas diretas, mas também, dificuldades para atend imento de contratos. São essas consequiências e a crescente procura dos consumidores por frutas de qualidade que estão tornando a adoção de alternativas para a administração do risco de chuvas de granizo em pomares de maçã, cada vez mais, indispensável.

Em muitos países produtores de maçã, como França, Itália e EUA, é expressivo o esforço de pesquisa que visa estabelecer o desenho econômico ideal do programa de gerenciamento dos riscos de granizo através da combinação adequada dos métodos disponíveis, tendo em vista as características regionais e a eficiência relativa das diferentes alternativas. No Brasil, contudo, não só os esforços desenvolvidos em outros países são pouco conhecidos, como são escassos os estudos nacionais sobre esse assunto. 


\subsection{Objetivos}

O trabalho teve como objetivos específicos:

(I) Análise do problema do risco de granizo em pomares de maçã, levantando e caracterizando as alternativas existentes para seu gerenciamento, a partir da literatura existente e pesquisas de campo realizadas com produtores, técnicos e especialistas em meteorologia, em regiões produtoras de maçã de Santa Catarina;

(II) Elaboração de um modelo conceitual e sua implementaçãocomputacional, a partir da utilização de técnicas de análise de decisão, que possa contribuir para o entendimento qualitativo e quantitativo do problema em estudo, facilitando o desenho e análise de estratégias para o gerenciamento do risco de granizo;

(III) Implementação do modelo em estudo de caso envolvendo a cooperativa SANJO de produtores de maçã, de São Joaquim - SC, para avaliação das alternativas mais adequadas. 


\section{METODOLOGIA}

O atendimento ao objetivo (I) da pesquisa, definido na seção anterior do trabalho, considerou uma revisão abrangente da literatura na área e pesquisas de campo nas regiões produtoras. A revisão da literatura enfatizou os trabalhos sobre o problema de granizo em pomares de maçã e os métodos utilizados para gerenciamento do problema. A literatura existente consultada é predominantemente multidisciplinar de fontes internacionais, especialmente da França, Itália, Alemanha, EUA e Iugoslávia.

A revisão considerou três fases distintas:

1. Pesquisa abrangente nas bases de dados disponíveis para localização dos trabalhos relacionados ao tema;

2. Ordenação, classificação e análise dos títulos mais promissores;

3. Obtenção física dos trabalhos considerados mais relevantes à pesquisa.

O desenvolvimento dessa terceira etapa exigiu um esforço considerável em contatos internacionais com universidades, instituições de pesquisa e autores dos trabalhos, em função da não disponibilidade de muitos desses trabalhos relevantes nas bibliotecas nacionais.

A aquisição de conhecimentos sobre o problema, feita através da revisão bibliográfica, foi complementada com um levantamento realizado predominantemente no município de São Joaquim - SC, uma das principais regiões produtoras nacionais. O levantamento considerou numerosos contatos com agentes envolvidos na produção e 
comercialização de maçã com o objetivo de esclarecimento de aspectos relevantes do problema do granizo na região. Contou com o valioso apoio da direção e membros da Cooperativa SANJO de produtores de maçã, de uma corretora de seguros especializada em seguro de pomares de maçã, e empresas locais prestadoras de serviços na área de meteorologia. Também foram realizados, com o apoio do INPE (Instituto Brasileiro de Pesquisas Espaciais), trabalhos de caracterização geográfica dos municípios de São Joaquim e Fraiburgo, SC.

As entrevistas realizadas com membros da cooperativa enfatizaram:

(a) Informações técnicas sobre a cultura da maçã, o problema do granizo e alternativas de gerenciamento disponíveis;

(b) Perspectivas dos agricultores quanto à importância do problema do granizo frente a outros problemas enfrentados na fase de produção das maçãs;

(c) Problemas causados pelo granizo que possam dificultar o desenvolvimento de contratos para comercialização da safra.

Na entrevista realizada na corretora de seguros foram levantadas:

(a) Questões sobre os contratos de seguro agrícola existentes e sua evolução recente;

(b) Competitividade do seguro comercial frente a outras alternativas existentes.

A entrevista na empresa prestadora de serviço na área de meteorologia considerou:

(a) Perspectivas sobre o granizo na região;

(b) Efetividade e custo das alternativas como "geradores de solo" e foguetes antigranizo destinadas à redução da freqüência e intensidade do granizo. 
Os trabalhos de caracterização geográfica realizados tiveram como objetivo visualizar a distribuição espacial dos pomares de maçã nos municípios de São Joaquim e Fraiburgo (SC), assim como o relevo regional; identificar as regiões de maior ocorrência de granizo, e também auxiliar no direcionamento adequado das atividades necessárias para o cumprimento das próximas etapas do trabalho.

O cumprimento do objetivo (II) do trabalho considerou a utilização de técnicas de análise de decisão, para caracterização qualitativa do problema de decisão associado à combinação ótima de alternativas para gerenciamento do problema do granizo. Esse esforço foi desenvolvido com o intuito de facilitar um melhor entendimento do problema, através de técnicas específicas, algo que vem sendo enfatizado na literatura recente em análise de decisões (Haiffa et. al. 1998a, 1998b) como altamente recomendável para que se evitem esforços na busca da "solução ótima para o problema errado".

A técnica utilizada, denominada Diagrama de Decisão ou Diagrama de Influência foi desenvolvida originalmente por R. Howard (Howard \& Matheson 1984, Howard, 1990) e formalizada por R. Shachter (Shachter 1986, Shachter 1987). É uma metáfora conveniente para representação de problemas complexos de decisão através de uma linguagem gráfica relativamente inteligível por pessoas envolvidas com o problema, sem grande treinamento em métodos quantitativos. Essa representação é totalmente fundamentada na teoria de decisão e na teoria de probabilidades, sendo conveniente para implementação em software através de técnicas computacionais. Os diagramas de decisão utilizam os elementos gráficos ilustrados na Figura 2, que representam decisões, variáveis, conseqüências, dependências probabilísticas entre variáveis e decisões, e a informação disponível no momento da decisão. O diagrama pode ser utilizado em diferentes etapas no processo de análise da decisão. Nas fases iniciais é usado como uma ferramenta para análise qualitativa, visando facilitar o entendimento do problema pelos agentes envolvidos e, nas fases finais, para análise quantitativa, a partir da especificação das variáveis em termos de valores, probabilidades e relações funcionais. Essa fase usualmente envolve a especificação das preferências e indicadores utilizados para 
avaliação dos méritos das alternativas (em muitos casos esse indicador será a esperança matemática da utilidade).

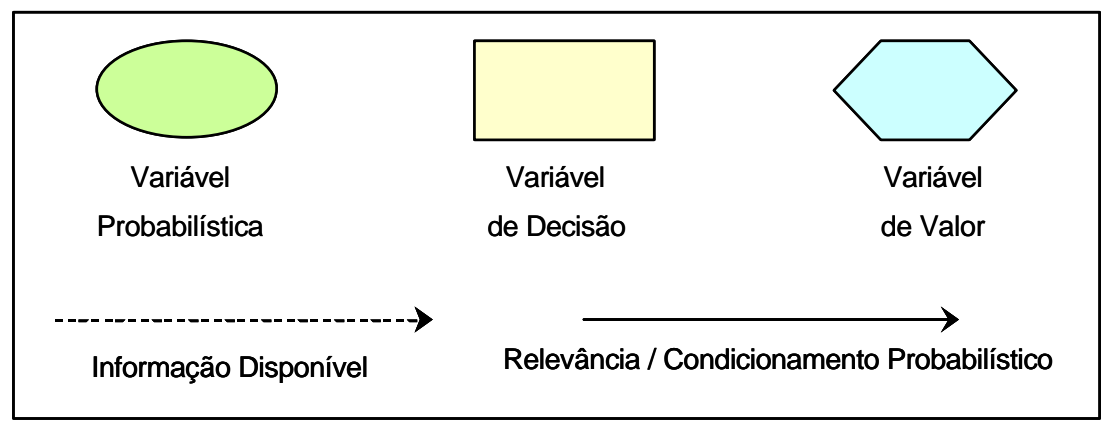

Figura 2 - Elementos gáficos utilizados nos diagramas de decisão. Fonte: Howard (1990)

Todo diagrama de decisão, totalmente especificado, espelha uma distribuição conjunta de probabilidade. Em problemas que utilizam variáveis discretas, é possível converter um diagrama de decisão em uma árvore de probabilidades (ou árvore de decisão) e vice-versa (muitos programas existentes no mercado apresentam esse recurso para facilitar a modelagem). $\mathrm{Na}$ árvore de probabilidades/decisão a estrutura do problema fica escondida dentro da árvore, o que pode dificultar a modelagem em problemas com muitas variáveis (o que torna a representação por árvores relativamente intratável do ponto de vista prático - Figura 3). No diagrama de decisão a estrutura do problema fica facilmente disponível para observação e manipulação, o que acaba tornando essa metáfora conveniente para a representação em interfaces gráficas de programas desenvolvidos para apoio à análise de decisão.

Dentro deste trabalho a técnica é utilizada como uma ferramenta qualitativa de análise. Tem o objetivo de produzir um ponto de partida para a verificação das relações existentes entre as variáveis do problema, promovendo um embasamento para a continuidade do trabalho de refinamento e quantificação, visando o melhor entendimento dos méritos das possíveis alternativas consideradas. 


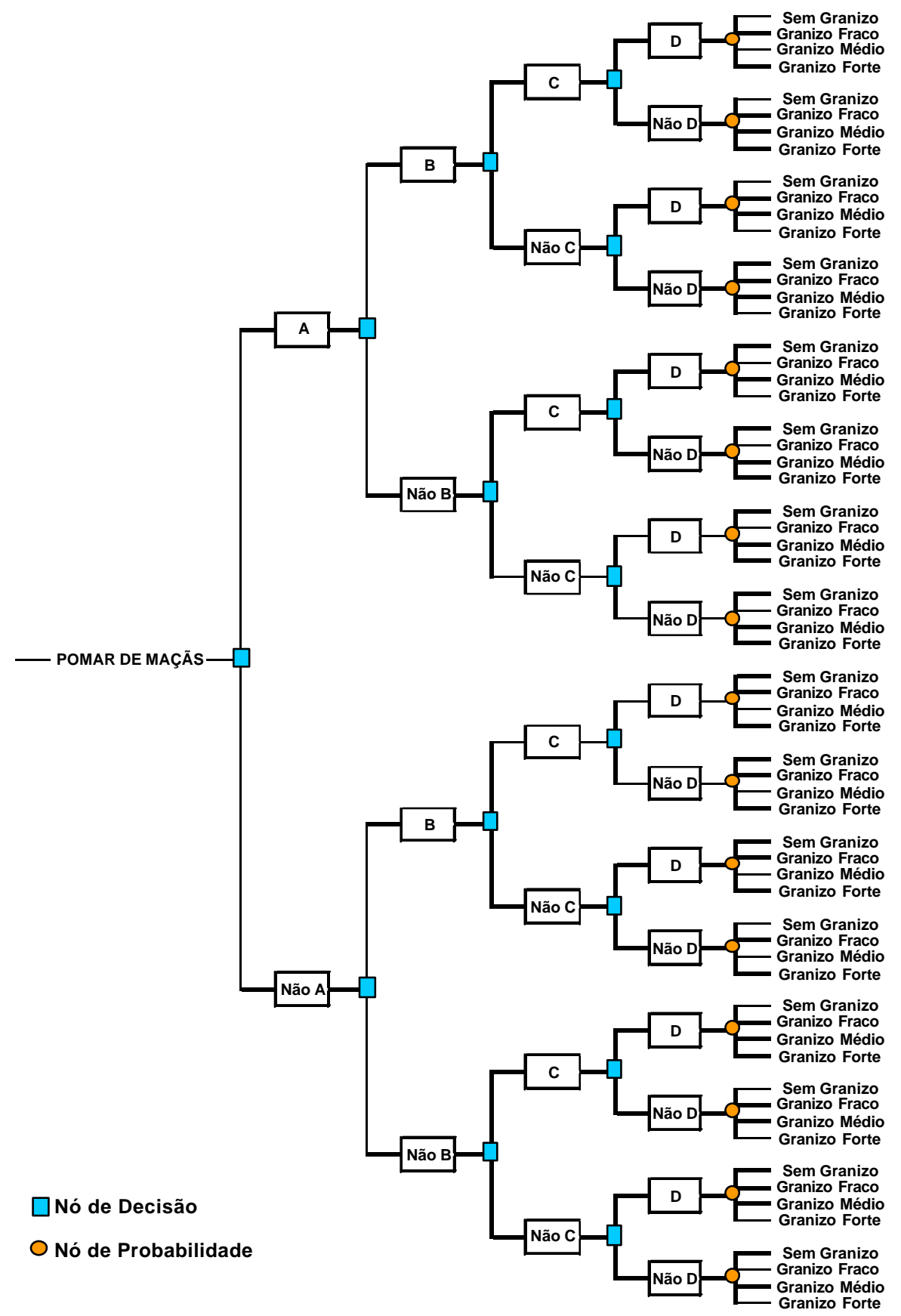

Figura 3 - Árvore de decisão: esquema básico para visualização das possíveis alternativas em um processo de tomada de decisão para gerenciamento do risco de chuvas de granizo em pomares de maçã.

Fonte: Resultado da pesquisa. 
Para o cumprimento do objetivo (III) do trabalho, contamos com o apoio da SANJO, principal cooperativa de produtores de maçã do município de São Joaquim, da CLIMATERRA Assessoria Planejamento Agronomia Ltda. (empresa prestadora de serviços na área de meteorologia agrícola) e da LIRASEG Corretora de Seguros. Realizou-se um levantamento formal, através de questionários (ANEXOS A, B e C), de informações complementares necessárias no processo de refinamento do modelo prévio desenvolvido a partir do diagrama de decisão e na avaliação das alternativas mais adequadas para administração do risco em estudo. Foram, principalmente, levantadas informações e dados técnicos sobre o sistema de produção utilizado, preços, produtividade e intensidade de prejuízo esperado, visando caracterizar as preferências dos produtores. Com a agregação das informações obtidas em todas as etapas do trabalho, com a aplicação do modelo, realizou-se a avaliação das alternativas mais adequadas. 


\section{REVISÃO E CARACTERIZAÇÃO DE ALTERNATIVAS}

\subsection{Revisão bibliográfica}

$\mathrm{Na}$ revisão bibliográfica realizada constatou-se que os trabalhos nacionais sobre problema das chuvas de granizo em pomares de maçã ou mesmo em áreas agrícolas são pouco numerosos, frente à importância do problema. Os trabalhos levantados da literatura nacional incluem: Antunes (1986); Berlato et al. (2000); Conti (1981); Costa et al. (2000); Leite et al. (2000); Yuri \& Azevedo-Filho (1999). Em países como França, Itália, EUA e Alemanha, que estão entre os principais produtores mundiais de maçã, o assunto é abordado na literatura com maior freqüência. Na Europa, não só a cultura da maçã, mas toda a agricultura enfrenta problemas consideráveis com o granizo, o que acaba justificando um número significativo de trabalhos sobre o assunto nesse continente. O Quadro 1 apresenta o resultado da revisão bibliográfica, classificando os trabalhos de acordo com o tema abordado e seu país de publicação. A Figura 4 mostra a relação entre a produção de maçã de alguns países selecionados e o número de trabalhos obtidos na revisão bibliográfica.

A revisão de literatura mostrou que as alternativas utilizadas nas principais regiões produtoras de maçã para gerenciamento do problema, usualmente incluem: (a) cobertura com telas anti-granizo; (b) geradores de solo, (c) foguetes anti-granizo, (d) pulverização das nuvens com a utilização de aviões e, (e) seguro agrícola. Essas alternativas serão discutidas resumidamente ao longo das próximas páginas, considerando, também, as informações obtidas no levantamento de campo realizado. 


\begin{tabular}{|c|c|c|c|c|c|c|c|c|c|c|c|}
\hline \multirow{2}{*}{$\begin{array}{l}\text { Assunto } \\
\text { principal do } \\
\text { trabalho }\end{array}$} & \multicolumn{11}{|c|}{ Numero de trabalhos obtidos por Pais e assunto } \\
\hline & França & Itália & $\begin{array}{l}\text { Alema- } \\
\text { nha }\end{array}$ & EUA & $\begin{array}{l}\text { lugos- } \\
\text { lávia }\end{array}$ & Brasil & $\begin{array}{l}\text { Éspa- } \\
\text { nha }\end{array}$ & Suíça & $\begin{array}{l}\text { Argen- } \\
\text { tina }\end{array}$ & Outros & Total \\
\hline $\begin{array}{l}\text { Granizo: } \\
\text { caracterização } \\
\text { climatológica }\end{array}$ & 12 & 4 & 4 & 10 & 3 & 3 & 0 & 0 & 0 & 8 & 44 \\
\hline Tela anti-granizo & 6 & 13 & 8 & 0 & 0 & 0 & 1 & 1 & 0 & 8 & 37 \\
\hline $\begin{array}{l}\text { Seguro } \\
\text { comercial }\end{array}$ & 9 & 3 & 4 & 2 & 0 & 0 & 0 & 1 & 1 & 6 & 26 \\
\hline Seguro mutuo & O & $T$ & 0 & O & O & 0 & O & O & O & $T$ & 2 \\
\hline $\begin{array}{l}\text { Foguete anti- } \\
\text { granizo }\end{array}$ & 0 & 1 & 0 & 1 & 2 & 0 & 0 & 0 & 0 & 0 & 4 \\
\hline $\begin{array}{l}\text { Metodos de } \\
\text { controle - geral }\end{array}$ & 17 & 12 & 1 & 8 & 0 & 2 & 2 & 1 & 0 & 1 & 44 \\
\hline $\begin{array}{l}\text { Comparaçao } \\
\text { entre os } \\
\text { métodos }\end{array}$ & 0 & 2 & 0 & 0 & 0 & 0 & 0 & 0 & 0 & 0 & 2 \\
\hline $\begin{array}{l}\text { Risco climatico / } \\
\text { Quantificação } \\
\text { de prejuízo }\end{array}$ & 11 & 2 & 2 & 5 & 2 & 1 & 1 & 0 & 0 & 15 & 49 \\
\hline Total & 55 & 38 & 19 & 26 & 7 & 6 & 4 & 3 & 1 & 39 & 198 \\
\hline
\end{tabular}

Quadro 1 - Resultado da revisão bibliográfica, trabalhos classificados de acordo com o tema principal e o país de publicação.

Fonte: Dados da revisão bibliográfica realizada na pesquisa.

* Espanha, Bélgica, Holanda, Rep. Tcheca, México, Austrália, China, Coréia, Japão, África do Sul, Tunísia, Nepal, Hungria.

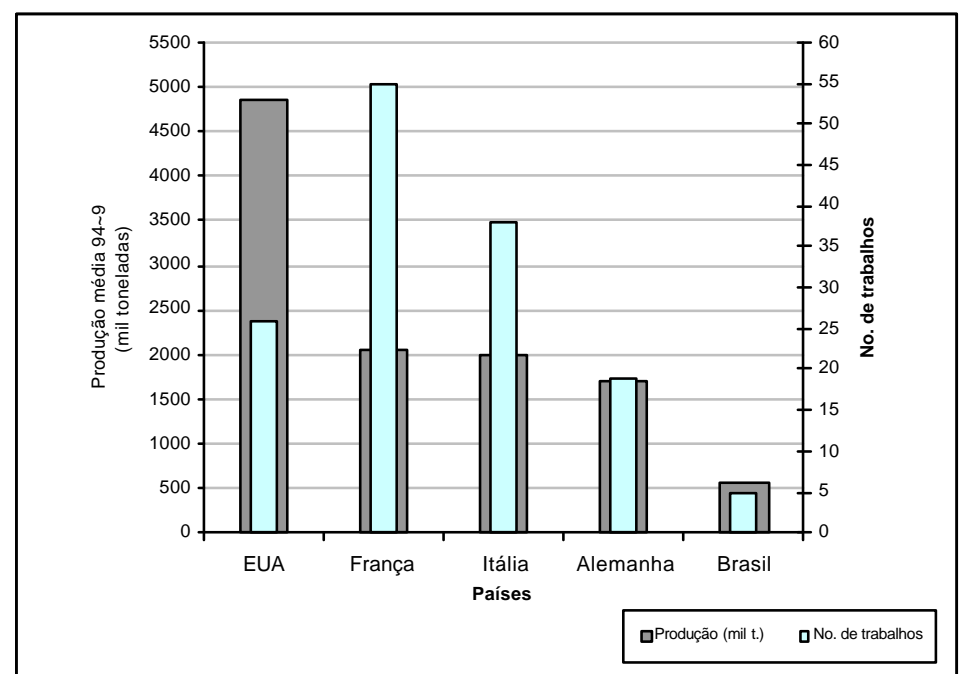

Figura 4 - Produção média de maçãs (1994 1998) e número de trabalhos relevantes obtidos na revisão bibliográfica, do Brasil e de alguns dos principais países produtores dessa fruta.

Fonte: ABPM (2001) para produção, e dados da revisão bibliográfica realizada na pesquisa. 


\subsection{Alternativas para o gerenciamento do risco de chuvas de granizo}

\subsubsection{Telas anti-granizo}

Sistema que consiste na cobertura das macieiras com telas plásticas sustentadas por estrutura de postes e arames. Essas telas servem como uma barreira física para o granizo, impedindo que as árvores, flores ou frutos sejam danificados na ocorrência desse evento climático. Atualmente, no Brasil, apesar de existirem poucas áreas protegidas por esse sistema, a adoção dessa alternativa de proteção contra possíveis prejuízos vem se ampliando significativamente.

A tela antigranizo realmente protege os pomares contra as pedras de granizo mas, segundo Battaglia \& Tassara (1992), reduz em 25\% a entrada de energia solar nos pomares e também reduz a energia que sai dos pomares durante a noite. Isso acaba por provocar uma variação nas condições micro-climáticas do cultivo, com modificações especialmente das temperaturas máximas durante o dia e mínimas durante a noite, implicando em uma amplitude térmica menor. Modificam-se também outros fatores como a luminosidade, a evaporação e o vento, com provável redução do risco de danos por geadas na primavera, um efeito favorável.

No trabalho de Leite et al. (2000), são apresentados resultados de experimento realizado em pomares de Fraiburgo - SC, com as cultivares Gala e Fuji, durante 4 anos (safras 95/96 98/99). Os níveis de sombreamento das telas utilizadas nesse experimento foram de 12, 18 e 30\% para a cultivar Gala e 12 e 18\% para a cultivar Fuji. Foram avaliadas as seguintes variáveis: crescimento dos ramos e frutos; firmeza e pH dos frutos; sólidos solúveis totais e degradação de amido nos frutos; percentagem de coloração vermelha e de russeting ${ }^{2}$ nos frutos; teores de nutrientes nos futos e também em folhas.

\footnotetext{
${ }^{2}$ Distúrbio fisiológico que se caracteriza por uma aspereza da casca da maçã, resultante da formação de camadas de células suberizadas (cortiças), provocadas por estresse externo (condições climáticas, produtos químicos etc.) ou, então, ser uma característica varietal (Iuchi et al., 2001).
} 
A cor vermelha foi a variável que apresentou maior influência do sombreamento provocado pela tela, 11,3 a 14,2\% de redução na cultivar Gala e 2,8 a 7,2\% na cultivar Fuji. Na cultivar Gala houve, também, maior incidência de Colletotricum $^{3}$ na área protegida por tela. Com o aumento do sombreamento, reduzitrse a incidência de russeting nos frutos. Nesse experimento os efeitos do sombreamento sobre as variáveis de produção variaram, de ano para ano, dependendo das condições climáticas.

A cobertura de telas pode, também, prejudicar o processo de polinização das flores das macieiras, que requerem polinização cruzada. No experimento realizado por Anderson et al. (1997), no Estado americano de Utah, no período de plena florada, as telas foram recolhidas para que o trabalho de polinização fosse realizado pelas abelhas.

O uso de telas anti-granizo é entendido pelos produtores como o mais garantido (em termos de evitar o prejuízo com o granizo) entre os sistemas de proteção, porém tem como desvantagens o alto custo de implantação (aproximadamente $\mathrm{R} \$ 10.000,00 / \mathrm{ha}$ em valores de 1997) e as poucas informações (positivas e negativas) existentes sobre a influência que o sombreamento causado pode apresentar no comportamento agronômico e fisiológico da planta no longo prazo (Leite et al., 2000).

\subsubsection{Geradores de solo}

Forma química de combate ao granizo e que demanda um trabalho em grupo dos agricultores. Consiste na adição de Iodeto de Prata, na forma de gás, através de aparelhos denominados "geradores de solo", nas nuvens potencialmente causadoras de granizo. Esses aparelhos são compostos, basicamente, por um recipiente contendo ar comprimido, outro contendo solução de Iodeto de Prata e acetona, e uma peça onde ocorre a combustão dessa solução e conseqüente vaporização do sal.

\footnotetext{
${ }^{3}$ Fungo causador da doença conhecida como "Mancha da Gala". O patógeno causa lesões necróticas deprimidas nas maçãs das variedades Gala, Golden Delicious e os descendentes que herdaram os genes desta última. Além disso, causa manchas necróticas nas folhas e posterior queda das mesmas. (Boneti \& Katsurayama, 1999).
} 
Nesse sistema, vários geradores de solo são distribuídos pela área a ser protegida e, na previsão de ocorrência do granizo, esses aparelhos são acionados conjuntamente.

Existe atualmente no Brasil, especificamente em Fraiburgo - SC, um programa de combate ao granizo baseado nesse sistema, auxiliado por um radar meteorológico. A Figura 5 é um mapeamento desse programa; apresenta a distribuição espacial dos pomares das principais empresas produtoras de maçã deste município, a localização do radar meteorológico, dos aparelhos de gerador de solo e dos granizômetros (equipamento de medição de ocorrência e intensidade das chuvas de granizo).

A Figura 6 apresenta os resultados da verificação da ocorrência e medição da intensidade das chuvas de granizo na safra 1999/2000, realizados através dos granizômetros, na mesma área representada na Figura 5. Na Figura 6, os círculos mais escuros e maiores representam chuvas de granizo de maior intensidade. Verifica-se que na área dos pomares, que corresponde à área protegida pelo sistema de geradores de solo, a frequiência e a intensidade média do granizo foram menores.

No Sudoeste da França, em três décadas de observações (1965 1982), a taxa média de prejuízo devido ao granizo, em área protegida por um sistema de geradores de solo, diminuiu em $41 \%$ em comparação com o restante do país (nível de significância de $1 \%)$. Nesse mesmo período, os danos devido ao granizo não tiveram mudanças significativas nas áreas não protegidas, vizinhas às áreas protegidas, ou em áreas com clima e agricultura semelhantes (Dessens, 1986b). 


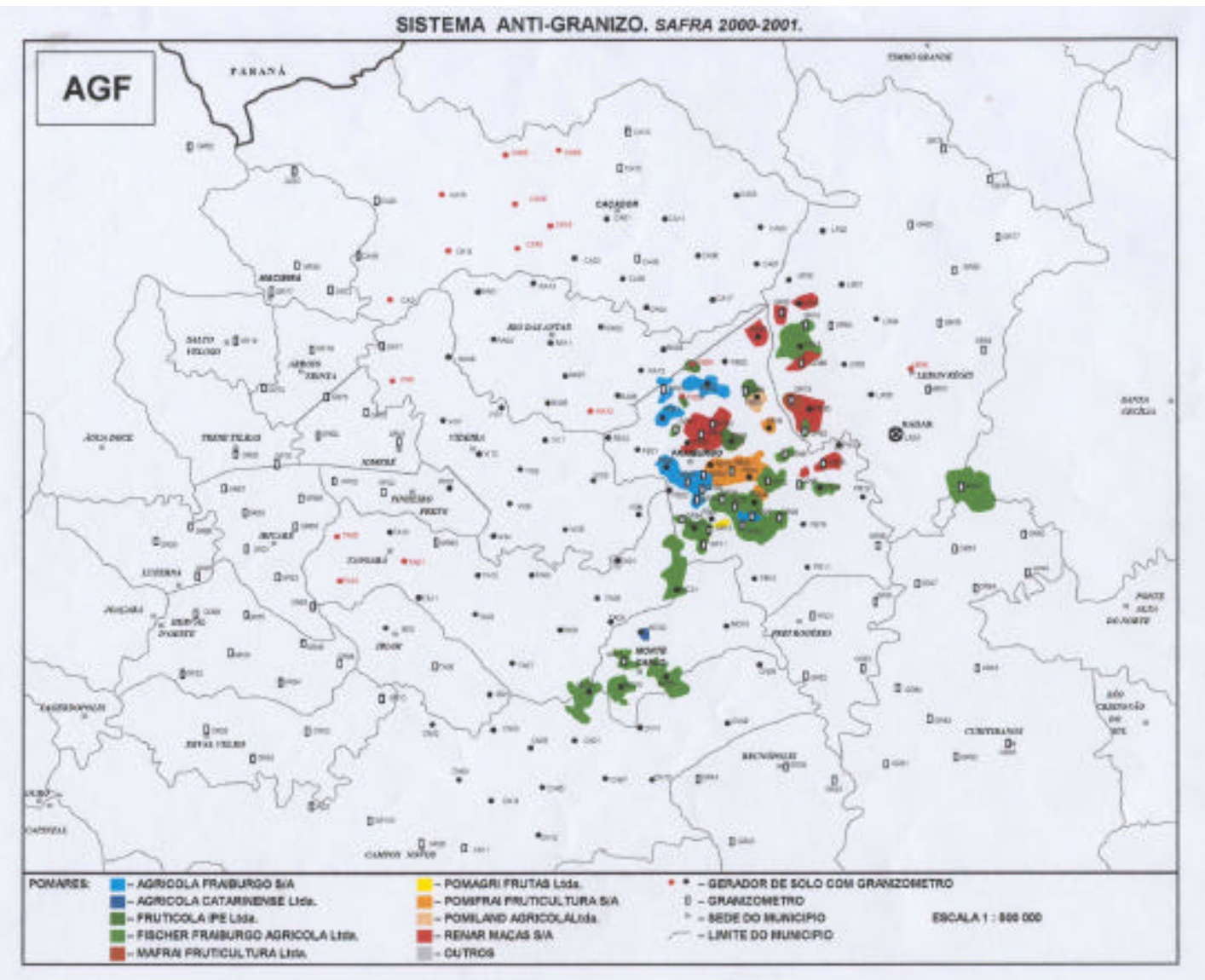

Figura 5 - Mapa do programa de combate às chuvas de granizo através do sistema de geradores de solo em Fraiburgo - SC: localização dos pomares, geradores de solo e granizômetros (safra 2000/2001).

Fonte: Iliine $(2000)^{4}$

${ }^{4}$ ILIINE, V. (AGF - Anti-Granizo Fraiburgo Ltda., Fraiburgo). Comunicação pessoal, 2000. 


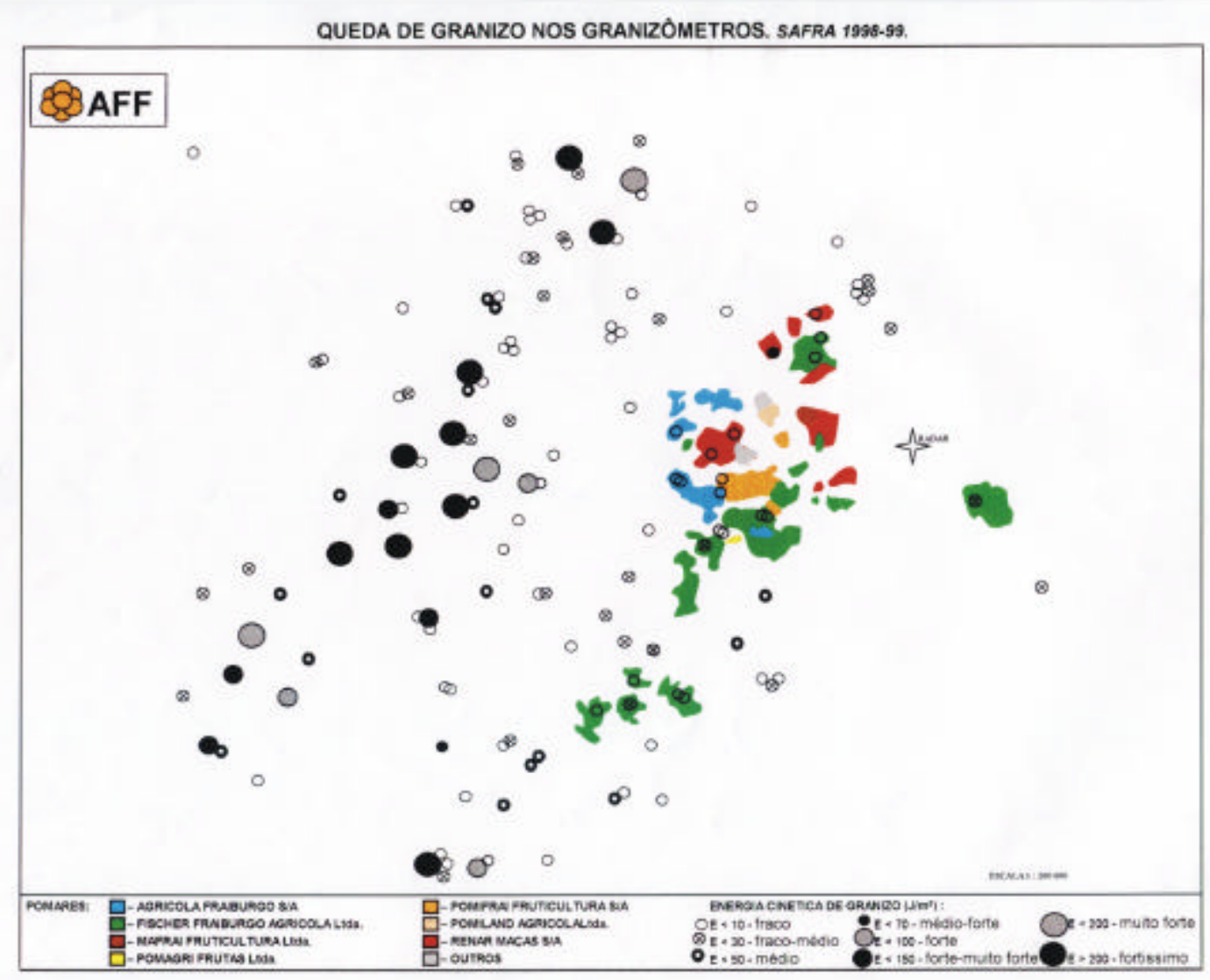

Figura 6 - Medição da ocorrência e intensidade do granizo na safra 1999/2000 em pomares de Fraiburgo - SC através do uso de granizômetros.

Fonte: Gutierrez Neto $(2000)^{5}$

$\overline{5}$ GUTIERREZ NETO, F. (AFF - Associação de Fruticultores de Fraiburgo, Fraiburgo). Comunicação pessoal, 2000. 


\subsubsection{Foguetes anti-granizo}

Sistema que, assim como os geradores de solo, utiliza o Iodeto de Prata no combate às chuvas de granizo. Baseia-se no lançamento de foguetes contendo cápsulas deste sal na direção de nuvens potencialmente causadoras desse evento climático. Existiram, no Brasil, na década de 80, com a utilização de foguetes nacionais, experiências com esse sistema, porém sem o resultado técnico esperado. Entre 1989 e 1995, os foguetes nacionais foram substituídos por foguetes russos de maior eficiência, porém, devido ao alto custo desse equipamento e muitas dificuldades operacionais, o sistema foi desativado. Os pontos negativos desse sistema são o seu alto custo, imprecisão nos lançamentos dos foguetes, perigo da queda de pedaços da carcaça dos foguetes sobre residências, instalações agrícolas, rebanhos ou pessoas e impossibilidade do uso desse sistema em área onde exista tráfego aéreo. Curiosamente, numa das primeiras experiências com esse foguete, um caminhão que trafegava localmente foi atingido.

\subsubsection{Pulverização das nuvens com a utilização de aviões}

Utilizando princípio semelhante ao dos sistemas de geradores de solo e de foguetes anti granizo, com a utilização de aviões, é pulverizada uma solução de Iodeto de Prata na nuvens potencialmente causadoras de granizo. Não existem relatos da utilização desse sistema na agricultura brasileira.

O North Dakota Cloud Modification Project (NDCMP) supervisionado pelo North Dakota Weather Modification Board é o mais antigo programa no mundo que realiza a pulverização de Iodeto de Prata nas nuvens através do uso de aviões, desde 1976.

Utilizando dados do seguro contra o granizo do período de $1924 \sim 1988$, verificou-se que, no período a partir do início do projeto, houve uma queda média de 
45\% nos prejuízos causados pelo granizo na região de atuação desse sistema (Boe et al., 1997)

Tanto o sistema de geradores de solo, quanto o de foguetes anti-granizo, ou ainda, de pulverização das nuvens com a utilização de aviões, visam a alteração climática em uma microregião para reduzir a chance ou intensidade do prejuízo. Segundo Sonka et. al. (1978), existem duas razões econômicas para o homem alterar o clima. Uma seria reduzir as perdas causadas por desastres climáticos e, a outra razão seria tornar o clima benéfico para uma maior e melhor produção de algum bem. Haragan (1974), no entanto, alerta que existem consideráveis controvérsias científicas em torno da potencial geração de benefícios das modificações climáticas. Esta diversidade de opiniões pode ser atribuída a dois tipos de incerteza. Uma seria a dificuldade em estabelecer claramente se a tecnologia utilizada está realmente afetando a característica climática de interesse. A outra seria se os resultados benéficos são realmente consideráveis frente a alguma possível consequiência indesejável.

\subsubsection{Seguro agrícola}

A indústria do seguro é baseada na aleatoriedade de eventos, tanto no tempo como no espaço. Seguradoras normalmente não oferecem seguro contra riscos concentrados espacialmente porque o valor do prêmio não seria atrativo para potenciais clientes. O mercado ideal seria baseado em um risco onipresente, potencialmente devastador e, de muito baixa probabilidade de ocorrência. Nesta situação, muitas pessoas comprariam o seguro, porém, muito poucas precisariam ser indenizadas (Etkin \& White, 1997).

Ainda segundo Etkin \& White (1997), pode-se considerar os riscos naturais como um jogo. Uma vez que as regras são conhecidas, a estratégia de vitória pode ser arquitetada. Os eventos extremos, no entanto, afetam esse jogo alterando suas regras, a 
qualquer momento, e sem aviso prévio, podendo, dessa forma, ocasionar até mesmo a falência de companhias de seguro. O consenso científico de que em um futuro próximo o mundo experimentará mudanças climáticas e, a maior frequiência com que eventos extremos vêm ocorrendo, têm feito com que seguradoras rapidamente adequiem os custos dos prêmios dos seguros.

Duas modalidades de seguro são desenvolvidas atualmente, no Brasil, no setor produtivo da cultura da maçã: seguro privado comercial e seguro mútuo informal.

O modelo atual de seguro comercial agrícola contra o granizo em pomares de maçã está disponível, aos produtores brasileiros, desde a safra 1998/1999. Essa modalidade de seguro é semelhante ao seguro convencional de automóveis no qual temos um prêmio a ser pago na contratação do seguro e, em caso de sinistro, há o ressarcimento do prejuízo, descontado o valor da franquia.

No seguro mútuo informal, um grupo de pessoas com interesse comum (nesse caso específico, produtores de maçã) formam um grupo dentro do qual os prejuízos decorrentes das chuvas de granizo serão rateados.

O seguro agrícola, apesar de interessante para o agricultor pelo fato de minimizar os seus prejuízos financeiros, não traz grandes benefícios para a oferta de alimentos em um país, uma vez que não garante a quantidade e a qualidade dos produtos agrícolas (Etkin \& White, 1997).

Nas pesquisas de campo e consultas à internet, além das alternativas para gerenciamento do risco de granizo relatadas na literatura, outros dois sistemas de combate a esse evento climático foram levantados: a diversificação espacial e o sistema de combate ao granizo através de ondas de choque ionizadas. 


\subsubsection{Diversificação espacial}

Alternativa que vem sendo considerada atualmente no processo de replantio dos pomares e no aumento de escala na atividade, que ocorre na cultura da maçã, principalmente em São Joaquim, onde predominam pequenos e médios produtores.

Pela característica geográfica da ocorrência do granizo, áreas relativamente distantes têmprobabilidade pequena de serem atingidas simultaneamente.

No levantamento realizado, nas principais regiões brasileiras produtoras de maçã, ficou claro que a organização da produção desta fruta segue duas tipologias principais:

(a) pequenos e médios produtores, organizados em cooperativas;

(b) produção de grandes empresas.

As regiões de São Joaquim e Fraiburgo, em SC, exemplificam, respectivamente, as tipologias (a) e (b), detalhadas no Quadro 2.

\begin{tabular}{|c|c|c|}
\hline & \multicolumn{2}{|c|}{ Municipio } \\
\hline & Sao Joaquim & Fraiburgo \\
\hline $\begin{array}{l}\text { Início da } \\
\text { pomicultura } \\
\text { comercia }\end{array}$ & $\begin{array}{l}1974 \text { com a instalação de núcleo da Cooperativa Agrícola } \\
\text { de Cotia. }\end{array}$ & 1973. \\
\hline $\begin{array}{l}\text { Extensão dos } \\
\text { pomares }\end{array}$ & $\begin{array}{l}\text { Predominam os pequenos e medios }(10 \sim 40 \text { ha }) \text {, o relevo } \\
\text { acidentado não permite o cultivo de grandes áreas } \\
\text { contínuas. }\end{array}$ & Grandes pomares acima de 1000 ha. \\
\hline $\begin{array}{l}\text { Organização dos } \\
\text { produtores }\end{array}$ & $\begin{array}{l}\text { Pequenos e medios produtores, a maioria organizados em } \\
\text { cooperativas, as principais: SANJO - Cooperativa Agrícola } \\
\text { de São Joaquim; Cooperserra - Cooperativa Regional } \\
\text { Agropecuária Serrana Ltda; Cooperativa Agrícola Frutas } \\
\text { de Ouro. }\end{array}$ & $\begin{array}{l}\text { Grandes empresas: Fischer Fraiburgo Agrícola } \\
\text { Ltda.; Agrícola Fraiburgo S.A.; Renar Maçãs } \\
\text { S.A.; Pomifrai Fruticultura S.A.. }\end{array}$ \\
\hline $\begin{array}{l}\text { Iniciativas no } \\
\text { gerenciamento } \\
\text { do risco de } \\
\text { chuvas granizo }\end{array}$ & $\begin{array}{l}\text { Na década de } 80 \text {, lançamento de foguetes anti-granizo, } \\
\text { sem sucesso. Na safra 2000/2001, segundo informações } \\
\text { de corretor de seguros, aproximadamente } 50 \% \text { da área } \\
\text { produtora de maçã coberta por seguro. Atualmente, } \\
\text { existência de algumas áreas com cobertura de telas, } \\
\text { desenvolvimento de programa informal de seguro mútuo } \\
\text { na principal cooperativa de produtores e, diminuição } \\
\text { considerável da área coberta por seguro privado. }\end{array}$ & $\begin{array}{l}\text { Na década de } 80 \text {, instalação de radar } \\
\text { meteorológico para monitoramento de chuvas de } \\
\text { granizo na região e lançamento de foguetes anti- } \\
\text { granizo, sem sucesso. Atualmente, uso de } \\
\text { "geradores de solo", também com auxílio do } \\
\text { radar. }\end{array}$ \\
\hline
\end{tabular}

Quadro 2 - Caracterização da cultura da maçã nos principais municípios produtores do Estado de Santa Catarina.

Fonte: Informações obtidas na pesquisa. 
Para uma melhor visualização da distribuição espacial dos pomares nesses dois municípios e entendimento da maneira como ela pode influenciar no desenvolvimento de estratégias para a gestão do risco em estudo, realizourse, para o caso de São Joaquim, um trabalho de caracterização geográfica regional através do uso de imagens de satélite e de aparelhos de GPS (Global Position System). Em Fraiburgo, esse mapeamento dos pomares já é feito pela AGF (Anti-Granzo Fraiburgo Ltda.), a qual nos forneceu dados e informações.

A Figura 7 apresenta a imagem de satélite do município de São Joaquim no mês de novembro de 2000 (cópia reduzida do original colorido). A distribuição espacial dos pomares no município de Fraiburgo pode ser observada na Figura 5 apresentada anteriormente.

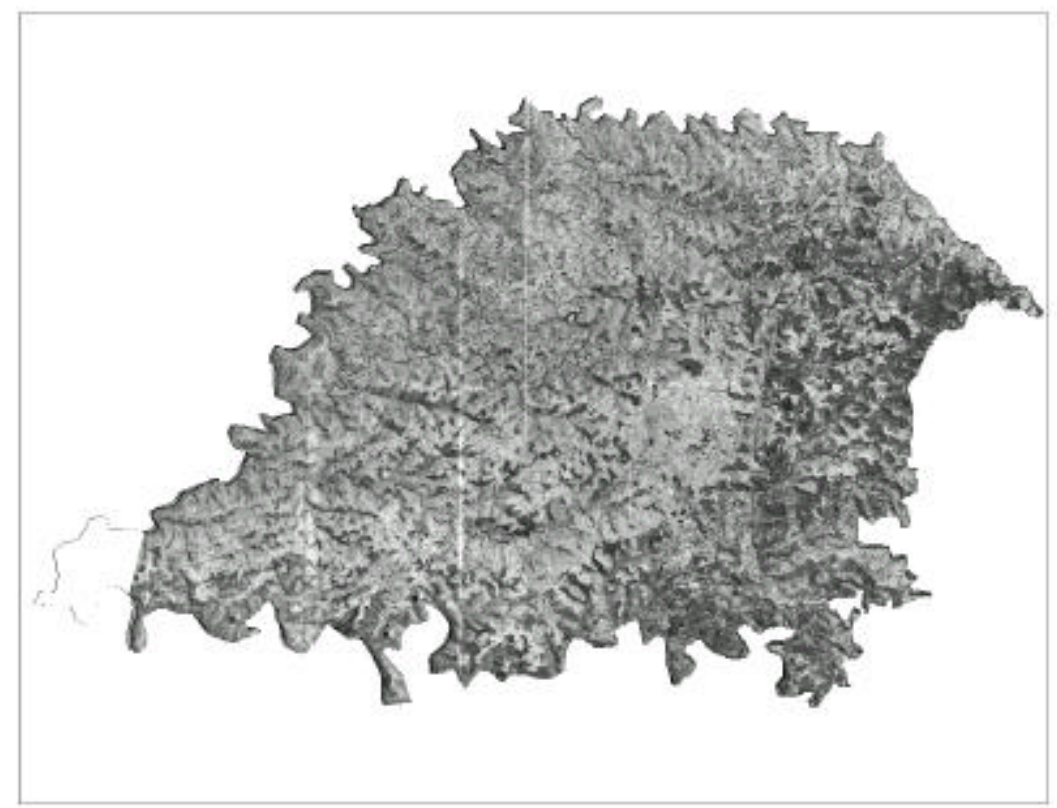

Figura 7 - Imagem de satélite do município de São Joaquim - SC, novembro/2000. Fonte: Rudorff (2001) ${ }^{6}$

\footnotetext{
${ }^{6}$ RUDORFF, B. (INPE, DSR. Instituto Nacional de Pesquisas Espaciais, Departamento de Sensoriamento Remoto, São José dos Campos). Comunicação pessoal, 2001.
} 


\subsubsection{Ondas de choque ionizadas}

Com a utilização de gás liquefeito (acetileno ou propano), de alto poder detonante, realiza-se uma seqüência de fortes explosões, produzindo ondas sonoras de choque que provocam uma acumulação de vibrações e ressonâncias que geram, no ambiente micro-físico da nuvem, perturbações que interferem no processo de cristalização (congelamento) das gotas de água em suspensão. Na zona protegida, isso faz com que o granizo não ocorra ou, pelo menos, sua intensidade seja minimizada (Cyberambiental, 2002).

Nesse sistema são utilizados aparelhos (móveis ou fixos) compostos basicamente por um ionizador/mesclador (torre tubular de 6 metros de altura), que possui na sua base entradas de aeração, injetores de gás e eletrodos de ignição. Pode funcionar com energia solar armazenada em baterias, controle remoto e opcionalmente com auxílio de radar meteorológico. O custo desse sistema está em torno de US\$ 35,00/hora (Hail Stop Equipments Inc., 2002). Cada equipamento isoladamente protege uma área aproximada de 100 hectares (Cyberambiental, 2002).

Não há conhecimento sobre o desenvolvimento, no Brasil, de programas de combate ao granizo que fizessem uso dessa alternativa. Em países como Argentina, Austrália, Áustria, Bélgica, Canadá, França, Alemanha, Itália, México, Marrocos, Nova Zelândia, Portugal, África do Sul, Espanha, Suíça e EUA existem áreas protegidas por esse sistema (Sapoi S.A., 2002).

\subsection{Considerações finais}

São muitas as possibilidades existentes para gerenciamento do risco de granizo. Todas elas, contudo, acabam tendo prós e contras que dificultam a escolha da melhor alternativa ou combinação de alternativas. Para facilitar a caracterização desses prós e contras, são apresentadas, no Quadro 3, as principais características das alternativas consideradas na pesquisa face a diferentes intensidades de granizo. 


\begin{tabular}{|c|c|c|c|c|}
\hline \multirow{3}{*}{$\begin{array}{l}\text { Alternativas } \\
\text { Simples }\end{array}$} & \multirow{3}{*}{$\begin{array}{c}\text { Custos da } \\
\text { alternativa e } \\
\text { características }\end{array}$} & \multicolumn{3}{|c|}{ Consequèncias fisiológicas / econömicas } \\
\hline & & \multicolumn{3}{|c|}{ Estados da natureza } \\
\hline & & Sem granizo & Granizo fraco & Granizo forte \\
\hline $\begin{array}{c}\text { Sem } \\
\text { Proteção }\end{array}$ & Sem custo direto & $\begin{array}{l}\text { Sem efeito do } \\
\text { granizo } \\
\text { Situação ideal }\end{array}$ & $\begin{array}{l}\text { Danos superticialis em folhas, } \\
\text { flores ou frutos. Possível } \\
\text { recuperação parcial dos frutos } \\
\text { Prejuízo econômico moderado } \\
\text { (qualidade) }\end{array}$ & $\begin{array}{l}\text { Quebra de galhos, danos em } \\
\text { folhas, flores ou frutos, pode } \\
\text { causar perda total da safra } \\
\text { Prejuízo significativo }\end{array}$ \\
\hline $\begin{array}{l}\text { Seguro } \\
\text { Comercial }\end{array}$ & \begin{tabular}{|l|} 
Franquia de $10 \%$ ou \\
$20 \%$, os prêmios \\
variam de $4,1 \%$ a $7 \%$ \\
do valor esperado da \\
produção (contrato \\
$2000 / 2001$ - Porto \\
Seguro Cia de \\
Seguros Gerais)
\end{tabular} & $\begin{array}{l}\text { Sem etelto do } \\
\text { granizo } \\
\text { Despesas com } \\
\text { prêmio }\end{array}$ & $\begin{array}{l}\text { Danos supenticials em tolhas, } \\
\text { flores ou frutos. Possível } \\
\text { recuperação parcial dos frutos } \\
\text { Prejuízo parcialmente } \\
\text { compensado dependendo da } \\
\text { intensidade do granizo. Em } \\
\text { função da franquia pode não } \\
\text { haver indenização } \\
\text { Despesas com prêmio }\end{array}$ & $\begin{array}{l}\text { Quebra de galhos, danos em } \\
\text { folhas, flores ou frutos, pode } \\
\text { causar perda total da safra } \\
\text { Prejuízo parcialmente } \\
\text { compensado. Garantia parcial da } \\
\text { renda do produtor, mas sem } \\
\text { amenização de prejuízos de } \\
\text { longo prazo } \\
\text { Despesas com prêmio }\end{array}$ \\
\hline $\begin{array}{c}\text { Seguro } \\
\text { Mútuo }\end{array}$ & $\begin{array}{l}\text { Prêmio menor que } \\
\text { do seguro comercial } \\
\text { e dependente de } \\
\text { acordo em grupo }\end{array}$ & $\begin{array}{l}\text { Sem efeito do } \\
\text { granizo } \\
\text { Despesas com } \\
\text { prêmio ou não, } \\
\text { dependendo do } \\
\text { contrato }\end{array}$ & $\begin{array}{l}\text { Danos supenticials em tolnas, } \\
\text { flores ou frutos. Possível } \\
\text { recuperação parcial dos frutos } \\
\text { Indenização somente se produtor } \\
\text { comprovadamente não obtiver } \\
\text { receita suficiente para pagamento } \\
\text { do financiamento bancário } \\
\text { Despesas com prêmio }\end{array}$ & $\begin{array}{l}\text { Quebra de galinos, danos em } \\
\text { folhas, flores ou frutos, pode } \\
\text { causar perda total da safra } \\
\text { Indenização somente se produtor } \\
\text { comprovadamente não obtiver } \\
\text { receita suficiente para pagamento } \\
\text { do financiamento bancário. Não } \\
\text { ameniza prejuízos de longo prazo } \\
\text { Despesas com prêmio }\end{array}$ \\
\hline $\begin{array}{l}\text { Diversificação } \\
\text { Espacial }\end{array}$ & $\begin{array}{l}\text { Custos e dificuldades } \\
\text { decorrentes da } \\
\text { administração de } \\
\text { áreas não contíguas }\end{array}$ & $\begin{array}{l}\text { Sem eletio do } \\
\text { granizo }\end{array}$ & $\begin{array}{l}\text { Redução da tração altinglda em } \\
\text { função da pulverização do risco. } \\
\text { Dificilmente duas áreas } \\
\text { relativamente distantes serão } \\
\text { atingidas simultaneamente numa } \\
\text { mesma safra }\end{array}$ & $\begin{array}{l}\text { Requção da traçáa attnglda em } \\
\text { função da pulverização do risco. } \\
\text { Dificilmente duas áreas } \\
\text { relativamente distantes serão } \\
\text { atingidas simultaneamente numa } \\
\text { mesma safra }\end{array}$ \\
\hline $\begin{array}{c}\text { Tela } \\
\text { de Proteção }\end{array}$ & $\begin{array}{l}\text { Instalação: custo } \\
\text { aproximado de } \\
\mathrm{R} \$ 12.000,00 / \mathrm{ha}(\mathrm{em} \\
\text { valores de 2000) } \\
\text { Vida útil aproximada: } \\
8 \text { anos }\end{array}$ & $\begin{array}{l}\text { Possivels } \\
\text { problemas de } \\
\text { polinização, perda } \\
\text { de qualidade (cor) } \\
\text { Investimento no } \\
\text { sistema }\end{array}$ & $\begin{array}{l}\text { Sem danos fisiologicos e } \\
\text { econômicos causados pelo } \\
\text { granizo } \\
\text { Possíveis problemas de } \\
\text { polinização e perda de qualidade } \\
\text { (cor) } \\
\text { Investimento no sistema }\end{array}$ & $\begin{array}{l}\text { Sem danos ilsiologicos e } \\
\text { econômicos causados pelo } \\
\text { granizo } \\
\text { Possíveis problemas de } \\
\text { polinização e perda de qualidade } \\
\text { (cor) } \\
\text { Investimento no sistema }\end{array}$ \\
\hline $\begin{array}{c}\text { Foguete } \\
\text { Anti-granizo } \\
\\
\text { (Aplicador de } \\
\text { lodeto de Prata) }\end{array}$ & $\begin{array}{l}\text { Investimento no } \\
\text { sistema + custo dos } \\
\text { foguetes } \\
\text { Gerenciamento é } \\
\text { complicado } \\
\text { Usados no } \\
\text { passado, mas não } \\
\text { mais }\end{array}$ & $\begin{array}{l}\text { So utilizados na } \\
\text { perspectiva de } \\
\text { ocorrência de } \\
\text { granizo } \\
\text { Investimento no } \\
\text { sistema }\end{array}$ & $\begin{array}{l}\text { Possivel amentzaçá na } \\
\text { intensidade do evento e do } \\
\text { prejuízo (questionável) } \\
\text { Problemas com queda da carcaça } \\
\text { de foguetes e com controle dos } \\
\text { lançamentos. } \\
\text { Investimento no sistema + custo } \\
\text { do foguete }\end{array}$ & 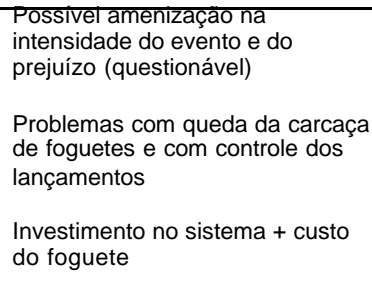 \\
\hline $\begin{array}{c}\text { Sistema } \\
\text { Regional de } \\
\text { Geradores } \\
\text { de Solo } \\
\text { (Aplicador de } \\
\text { lodeto de Prata) }\end{array}$ & $\begin{array}{l}\text { Investimento no } \\
\text { sistema + custo } \\
\text { operacional } \\
\text { Problema de rateio } \\
\text { do custo } \\
\text { Efeitos ambientais }\end{array}$ & $\begin{array}{l}\text { So utilizados na } \\
\text { perspectiva de } \\
\text { ocorrência de } \\
\text { granizo } \\
\text { Investimento no } \\
\text { sistema }\end{array}$ & $\begin{array}{l}\text { Possivel reaução na intenstdade } \\
\text { e freqüência do granizo ( } 30 \sim \\
50 \% \text { ). Até } 8 \% \text { de eficiência na } \\
\text { proteção das árvores. } \\
\text { Investimento no sistema + custo } \\
\text { operacional }\end{array}$ & $\begin{array}{l}\text { Possivel redução na intensidade } \\
\text { e freqüência do granizo ( } 30 \sim \\
50 \% \text { ). Até } 80 \% \text { de eficiência na } \\
\text { proteção das árvores. } \\
\text { Investimento no sistema + custo } \\
\text { operacional }\end{array}$ \\
\hline
\end{tabular}

Quadro 3 - Síntese dos custos e conseqüências das alternativas utilizadas no Brasil para gerenciamento do risco de granizo, de acordo com os estados da natureza.

Fonte: Informações obtidas na pesquisa. 


\section{RESULTADOS E ESTUDO DE CASO EM SANTA CATARINA}

\subsection{Considerações iniciais}

Neste capítulo são apresentados os principais resultados do trabalho, envolvendo o modelo proposto e o estudo de caso dentro do qual o modelo é aplicado. Inicialmente, é discutida a caracterização e quantificação da chance e intensidade das ocorrências de granizo na região de interesse: São Joaquim (SC). A seguir, é discutido o uso das alternativas caracterizadas no capítulo anterior, dentro das regiões produtoras de Santa Catarina, a partir dos levantamentos realizados. Finalmente, é apresentado o modelo desenvolvido e o estudo de caso realizado.

\subsection{Ocorrência e avaliação da intensidade das chuvas de granizo em SC}

Segundo Berlato et al. (2000), para a agricultura, melhor do que o conhecimento das ocorrências médias dos diferentes elementos meteorológicos, é o conhecimento das probabilidades de ocorrência dos mesmos. As probabilidades fornecem índices de chance de ocorrência de determinados níveis ou valores críticos de fenômenos meteorológicos que são de grande utilidade no planejamento da agricultura.

No caso de granizo, as distribuições de Poisson e binomial negativa são as que apresentam melhor ajuste (Arruda et al. (1996), Dale (1976) e Thom (1966), citados por Berlato et al., 2000). Segundo Thom (1966), a distribuição de Poisson ajus ta-se bem 
quando a frequiência de ocorrência de granizo não é muito alta e quando a média se aproxima da variância. A distribuição binomial negativa é indicada no caso contrário.

A quantificação dos riscos de ocorrência de granizo nas diferentes regiões ecoclimáticas é útil no planejamento da agricultura, especialmente nos casos de zoneamento agroclimático; pode servir de subsídio para efeito de seguro agrícola e, ainda, pode orientar projetos que visam a proteção dos cultivos dessa adversidade climática (Berlato et al., 2000).

De acordo com o levantamento realizado, o problema das chuvas de granizo nas regiões de São Joaquim e Fraiburgo é mais sério durante os meses entre novembro e março, período crítico que compreende as fases de frutificação, maturação e colheita das maçãs, e que acaba coincidindo com a época de maior ocorrência desse evento climático. O Quadro 4 sumariza algumas informações importantes sobre o granizo nessas regiões, incluindo estimativas preliminares da frequiência do fenômeno realizadas a partir de entrevista com especialista local em meteorologia, baseadas, em parte, nas informações levantadas através de radar meteorológico localizado em Fraiburgo.

\begin{tabular}{|c|c|c|c|c|c|}
\hline \multirow{3}{*}{ Regiões } & \multirow{3}{*}{$\begin{array}{l}\text { Chuvas de } \\
\text { granizo. } \\
\text { Número } \\
\text { médio/ano }\end{array}$} & \multicolumn{4}{|c|}{ Fases fenológicas da macieira } \\
\hline & & Dormência & Floração & Frutificação & Colheita \\
\hline & & Abr Mai Jun Jul Ago & Set Out & Nov Dez Jan & Fev Mar \\
\hline $\begin{array}{l}\text { São Joaquim e } \\
\text { Fraiburgo, SC }\end{array}$ & 38 & $\begin{array}{c}1 \sim 2 \text { chuva de } \\
\text { granizo/mês (média) }\end{array}$ & $\begin{array}{l}2 \sim 3 \text { chuvas de } \\
\text { granizo/mês } \\
\text { (média) }\end{array}$ & $\begin{array}{l}\text { 5 6 chuvas de } \\
\text { granizo/mês } \\
\text { (média) }\end{array}$ & $\begin{array}{l}\text { 4 5 chuvas de } \\
\text { granizo/mês } \\
\text { (média) }\end{array}$ \\
\hline
\end{tabular}

Quadro 4 - Ocorrência média de chuvas de granizo, por fase fenológica da macieira, nas principais regiões produtoras de maçã do Estado de Santa Catarina.

Fonte: Informações obtidas na pesquisa.

As informações obtidas na revisão de literatura e no levantamento realizado sobre as principais alternativas para gerenciamento do risco de chuvas de granizo em áreas agrícolas no Brasil, bem como o custo do sistema e efeitos fisiológicos e/ou econômicos esperados, de acordo com a intensidade do fenômeno e o uso da alternativa de gerenciamento especificada, estão sumarizadas no Quadro 3, apresentado no capítulo 
anterior. É importante salientar, contudo, que o processo de gerenciamento pode, eventualmente, considerar a combinação de mais de uma dessas alternativas.

Como citado anteriormente, não existiram no Brasil, até hoje, experiências com o sistema de pulverização das nuvens com a utilização de aviões nem com o sistema baseado na emissão de ondas de choque ionizadas.

Com relação à avaliação da intensidade e danos causados pelo granizo, existem programas de combate ao granizo e trabalhos encontrados na literatura que se baseiam em dados do seguro agrícola para a realização de comparações e avaliação de eficiências relativas. Essa metodologia talvez não seja a mais adequada devido aos inúmeros modelos de programa de seguro, contratos de seguro e formas de avaliação dos danos.

Segundo Dessens (1986a), o uso de dados de seguro em estudos climatológicos é certamente não perfeitamente correto, mas apenas uma maneira de calcular (numericamente) a severidade do granizo em uma área e em vários anos.

Quanto aos projetos que realizam a semeadura de Iodeto de Prata nas nuvens, seja através de aviões, foguetes ou geradores de solo, é necessária uma avaliação física da eficiência desses sistemas. A utilização de dados do seguro contra granizo para comparações entre períodos com e sem a semeadura das nuvens é uma técnica rejeitada pelo World Meteorological Organization (WMO) (Dessens, 1998).

De acordo com Changnon (1971), o grau de perdas causadas pelo granizo pode ser estimado usando-se um ou dois parâmetros: a freqüência de pedras de granizo com diâmetro maior que $0,64 \mathrm{~cm}(0,25$ polegadas $)$ e a energia total transmitida pelo granizo. Esses parâmetros físicos são medidos através da utilização de granizômetros (hailpads).

\subsection{Alternativas historicamente utilizadas em São Joaquim e Fraiburgo, SC}

O Quadro 5 faz uma caracterização das experiências desenvolvidas em São Joaquim e Fraiburgo, principais regiões produtoras de maçã em Santa Catarina, com o uso das diferentes alternativas para a administração do risco de granizo. A importância 
relativa das diferentes alternativas nessas regiões é motivada, em larga medida, pela natureza da organização existente em cada caso (veja Quadro 2).

\begin{tabular}{|c|c|c|}
\hline \multirow{2}{*}{ Alternativa } & \multicolumn{2}{|c|}{ Municipio } \\
\hline & São Joaquím & Fraiburgo \\
\hline $\begin{array}{l}\text { Diversificação } \\
\text { espacial }\end{array}$ & $\begin{array}{l}\text { Existe algum conhecimento sobre as areas do } \\
\text { município onde a freqüência de chuvas de } \\
\text { granizo é maior e isso tem sido levado em } \\
\text { consideração no processo de implantação de } \\
\text { novos pomares e aumento de escala da } \\
\text { atividade. }\end{array}$ & $\begin{array}{l}\text { Devido a caracteristica das chuvas de granizo, } \\
\text { que ocorrem em focos isolados, dentro da área } \\
\text { dos grandes pomares já existe certa diluição de } \\
\text { riscos. Com o auxílio do radar, porém, pode-se } \\
\text { determinar de forma mais precisa as áreas } \\
\text { onde a ocorrência do evento é mais freqüente. }\end{array}$ \\
\hline $\begin{array}{l}\text { Seguro privado } \\
\text { agrícola }\end{array}$ & $\begin{array}{l}\text { Oferecida aos produtores de maça, por uma } \\
\text { única empresa, desde a safra } 1998 / 1999 \text {, tem } \\
\text { como principal proposta a garantia da renda do } \\
\text { produtor e não șomente o pagamento do } \\
\text { custeio da saf ra. É uma alternativa importante } \\
\text { para os pequenos agricultores, porém, } \\
\text { considerada de alto custo. }\end{array}$ & $\begin{array}{l}\text { Quase Inexistēncla de areas cobertas por } \\
\text { seguro nesse município. Com a predominância } \\
\text { das empresas que, de certa forma, já diluem o } \\
\text { risco do granizo em suas grandes áreas, essa } \\
\text { alternativa não foi adotada de forma } \\
\text { significativa neste município. }\end{array}$ \\
\hline Seguro mútuo & $\begin{array}{l}\text { Alternativa que existe na maior cooperativa do } \\
\text { município desde a safra } 1998 / 1999 \text {, desativado } \\
\text { apenas na safra } 2000 / 2001 \text {, quando houve a } \\
\text { opção da maioria dos cooperados pelo seguro } \\
\text { privado. É um seguro informal. }\end{array}$ & $\begin{array}{l}\text { Nao ha informaçoes sobre a existencia de } \\
\text { grupos de seguro mútuo agrícola nesse } \\
\text { município. }\end{array}$ \\
\hline $\begin{array}{l}\text { Telas anti- } \\
\text { granizo }\end{array}$ & $\begin{array}{l}\text { Apesar do seu alto custo, pelo tato de garantir } \\
\text { a oferta da maçã ao final da safra, esse } \\
\text { sistema constitui uma alternativa interessante } \\
\text { para auxiliar o cumprimento de contratos } \\
\text { comerciais pelas cooperativas. As áreas } \\
\text { protegidas por esse sistema vêm aumentando } \\
\text { ano a ano. }\end{array}$ & $\begin{array}{l}\text { Nao eram utillzadas pelas empresas desse } \\
\text { município. No entanto, atualmente estão sendo } \\
\text { desenvolvidos alguns projetos para a proteção } \\
\text { de pomares através desse sistema. }\end{array}$ \\
\hline $\begin{array}{l}\text { Geradores-de- } \\
\text { solo }\end{array}$ & $\begin{array}{l}\text { Devido a necessidade do trabalho em } \\
\text { associações, existem certas dificuldades para a } \\
\text { sua implantação no município. A presença de } \\
\text { muitos pequenos produtores nesse município } \\
\text { dificulta o acordo sobre a forma como seriam } \\
\text { divididos os custos do sistema. }\end{array}$ & $\begin{array}{l}\text { Contando com o auxilio do radar meteorologico, } \\
\text { essa alternativa já vem sendo adotada no } \\
\text { município desde } 1996 \text {. } \\
\text { O fato de quase a totalidade das maçãs do } \\
\text { município ser produzida por poucas empresas } \\
\text { facilitou o acordo sobre a forma como os custos } \\
\text { do sistema seriam divididos entre elas. }\end{array}$ \\
\hline $\begin{array}{l}\text { Foguetes anti- } \\
\text { granizo }\end{array}$ & $\begin{array}{l}\text { Sistema de altos custos, testado no passado, } \\
\text { não apresentou resultados satisfatórios. }\end{array}$ & $\begin{array}{l}\text { 19/8 1988: (foguete nacional) nao apresentou } \\
\text { resultados técnicos satisfatórios. } \\
1989 \text { e 1995: (foguete russo com o auxílio de } \\
\text { radar meteorológico) apesar de apresentar } \\
\text { resultados satisfatórios, foi abandonado devido } \\
\text { aos altos custos. }\end{array}$ \\
\hline
\end{tabular}

Quadro 3 - Experiências com o gerenciamento do risco de granizo em São Joaquim e Fraiburgo.

Fonte: Informações obtidas na pesquisa.

O programa de Fundo de Apoio Agrícola que vem sendo desenvolvido pela Cooperativa SANJO de São Joaquim desde a safra 1998/1999, nos moldes de um seguro mútuo (Azevedo-Filho, 2000), tinha como finalidade suprir a carência de um seguro agrícola por parte de seus associados. Nesse programa, os cooperados interessados, no início do ano agrícola, depositavam certo valor monetário, proporcional à sua produção média dos três anos anteriores, em um fundo administrado pela cooperativa. Após a 
colheita, durante a comercialização da safra ou próximo ao vencimento dos empréstimos, esses produtores que aderiram ao programa e que, devido à ocorrência de chuvas de granizo, comprovadamente não obtiveram receita suficiente para saldar suas dividas de custeio da safra, recebiam auxílio proveniente desse fundo acumulado. A partir dessa mesma safra, no entanto, surgiu, no mercado, o seguro privado contra granizo em pomares de maçã. Na safra 2000/2001, através de acordo entre os cooperados, o seguro privado, que apresentava uma proposta financeiramente interessante, foi adotado pela cooperativa e o programa do Fundo de Apoio Agrícola desativado, porém, na safra 2001/2002, com um aumento considerável do valor do prêmio do seguro privado, houve a reativação do programa de seguro mútuo com algumas modificações na forma de cálculo da cota de participação.

Com a adoção de programas de combate ao granizo, considerando que esses programas tenham certa eficiência, haverá um aumento na qualidade e na quantidade ofertada dos produtos agrícolas dessas regiões protegidas, o que trará, como possível conseqüência, a diminuição no preço desses produtos. Os agricultores que cultivam os mesmos produtos dessas áreas protegidas, porém em áreas nas quais não foram adotadas medidas de combate ao granizo, passarão a ter desvantagens por dois motivos: não ocorrerão aumentos de qualidade e quantidade nas suas produções e, terão que comercializar suas produções a um preço menor (Sonka et. al., 1978). 


\subsection{Diagrama de decisão e modelo computacional ${ }^{7}$}

Com as informações provenientes da revisão de literatura e levantamento de campo, sobre as principais características de cada sistema e as experiências já realizadas nos municípios de São Joaquim e Fraiburgo, partiu-se para a elaboração de um diagrama de decisão (apresentado na Figura 8) que pudesse especificar o modelo conceitual das relações entre as variáveis envolvidas, de forma a facilitar um melhor entendimento do problema e impactos causados pelas alternativas disponíveis. A preocupação, nesta fase da pesquisa, foi a representação qualitativa das relações entre as diferentes variáveis.

O diagrama de decisão foi útil para o desenvolvimento de um modelo preliminar que, baseado nas relações qualitativas, auxiliou no desenvolvimento de um programa computacional de cálculo e análise quantitativa da eficiência relativa de cada alternativa estudada e dos potenciais prejuízos causados pelo granizo. A Figura 9 apresenta o modelo prévio desenvolvido com o auxílio do programa Netica 2.06.

\footnotetext{
${ }^{7}$ O modelo e os programas foram desenvolvidos com forte apoio e orientação do Prof. Adriano Azevedo Filho.
} 


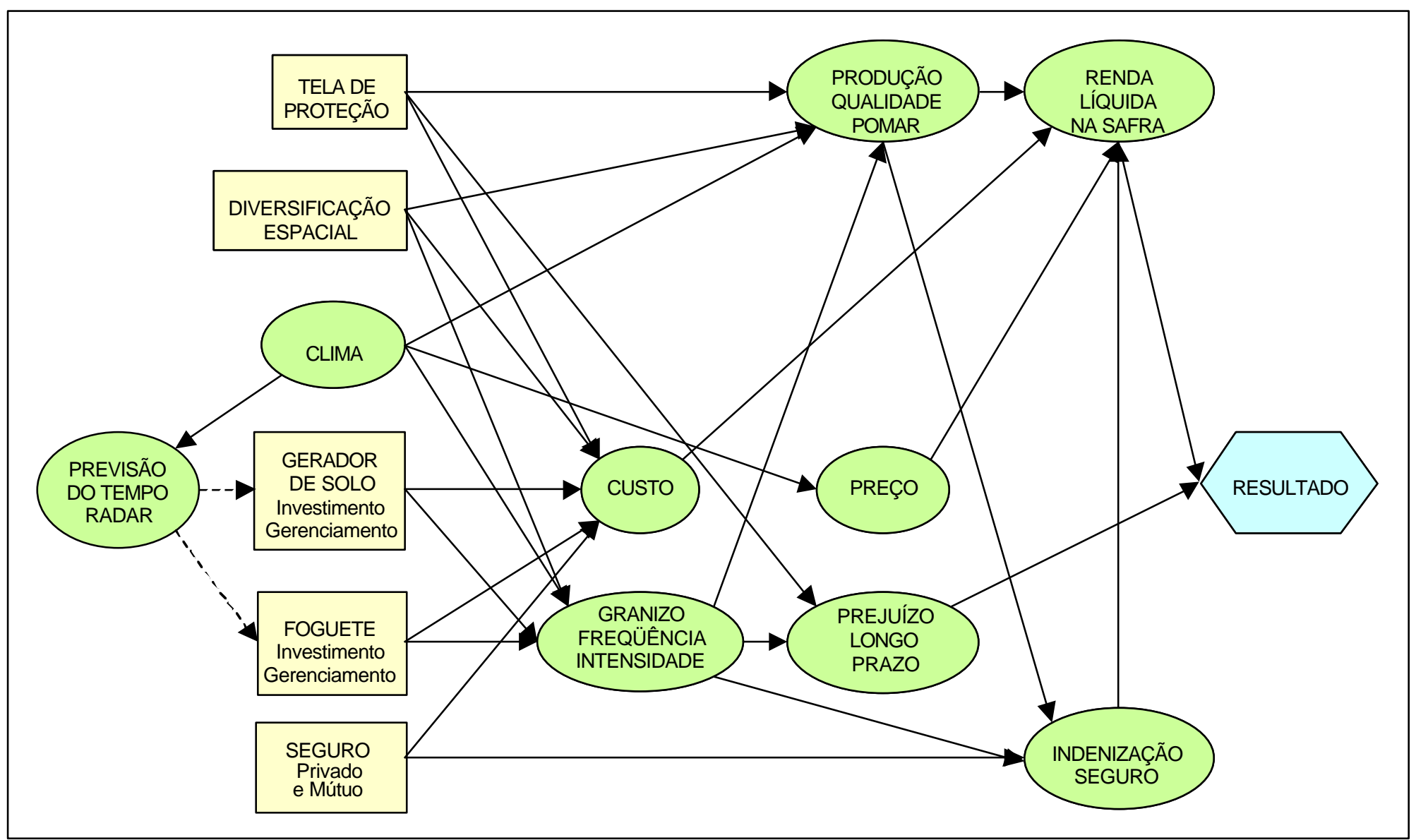

Figura 8 - Diagrama de decisão considerando as alternativas existentes para o gerenciamento do risco de chuvas de granizo em pomares de maçã e as incertezas.

Fonte: Resultado da pesquisa. 


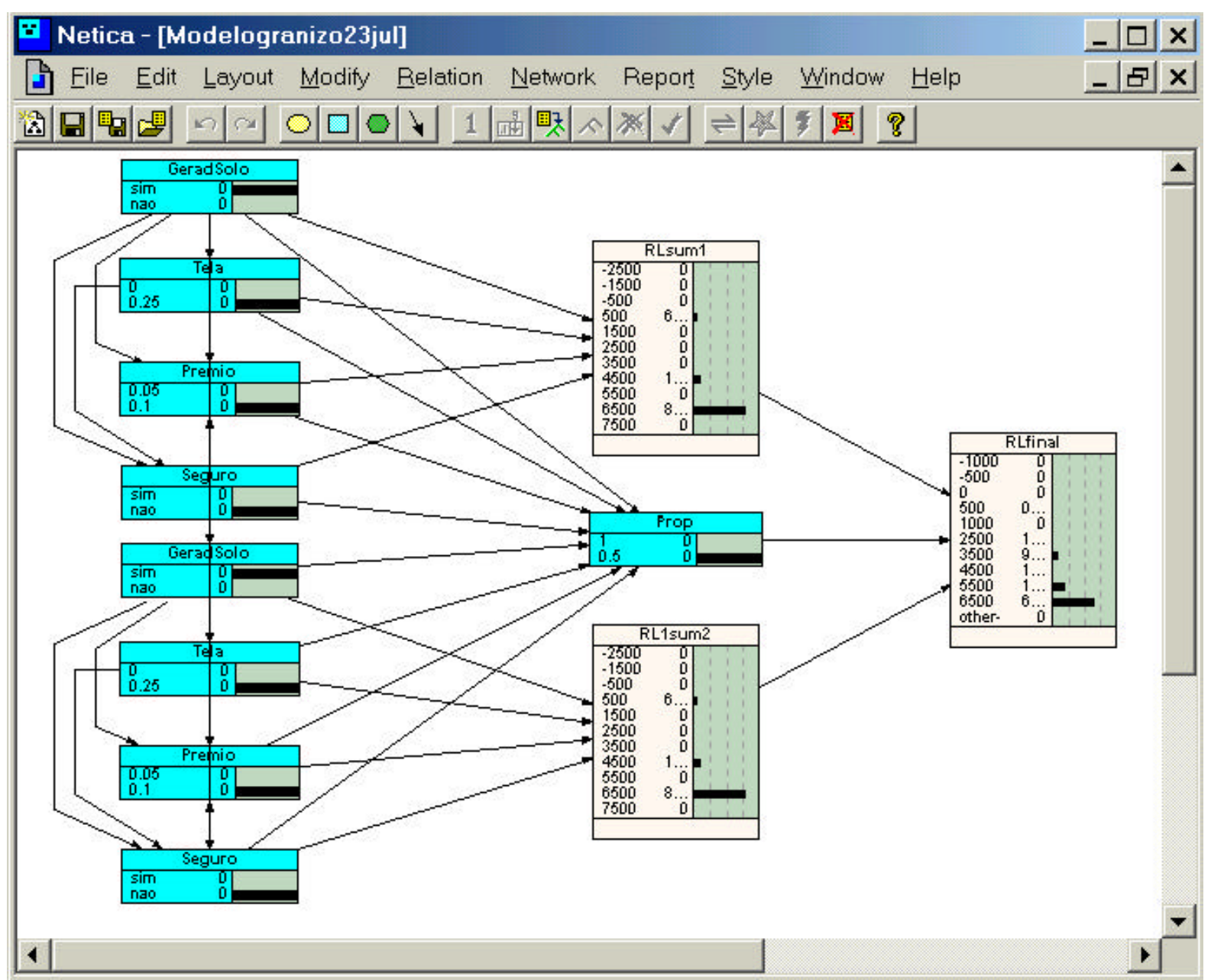

Figura 9 - Modelo prévio desenvolvido no Netica 2.06 a partir do diagrama de decisão.

Fonte: Resultado da pesquisa. 
O software "GranizoMGMT" (ANEXO D), implementados na planilha eletrônica Microsoft Excel, a partir do modelo previamente descrito, faz a análise quantitativa dos méritos das alternativas com base em alguns valores médios de preço, produtividade e intensidade dos prejuízos esperados pelo tomador de decisão. A interface desse programa com o usuário é feita através de estruturas do tipo "box" (Figura 10 e 11). A Figura 12 apresenta a planilha na qual são inseridos os valores esperados.

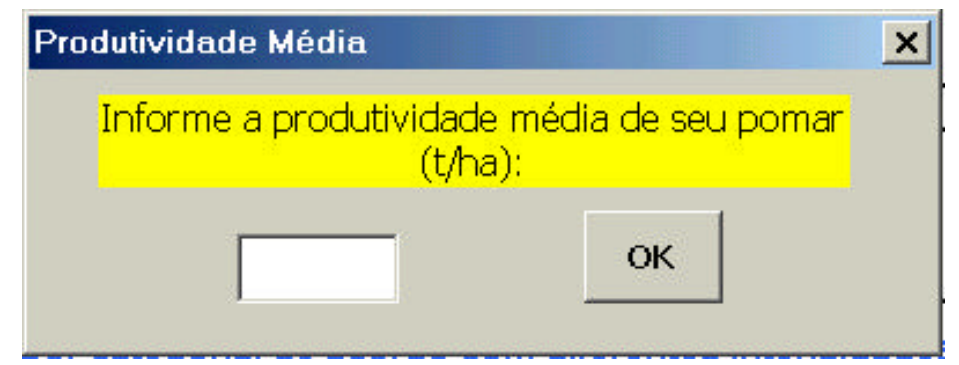

Figura 10 - Programa de cálculo e análise quantitativa - "box" para informação de valor esperado (1).

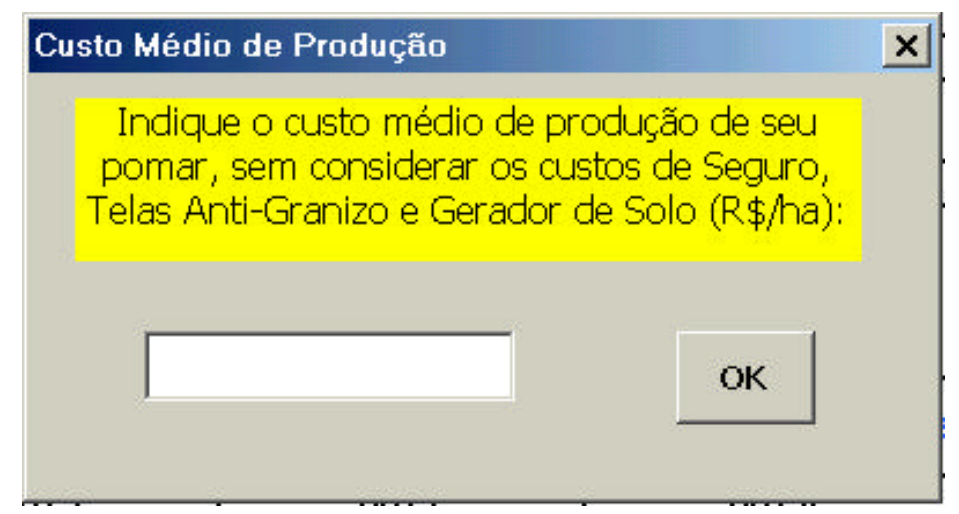

Figura 11 - Programa de cálculo e análise quantitativa - "box" para informação de valor esperado (2). 


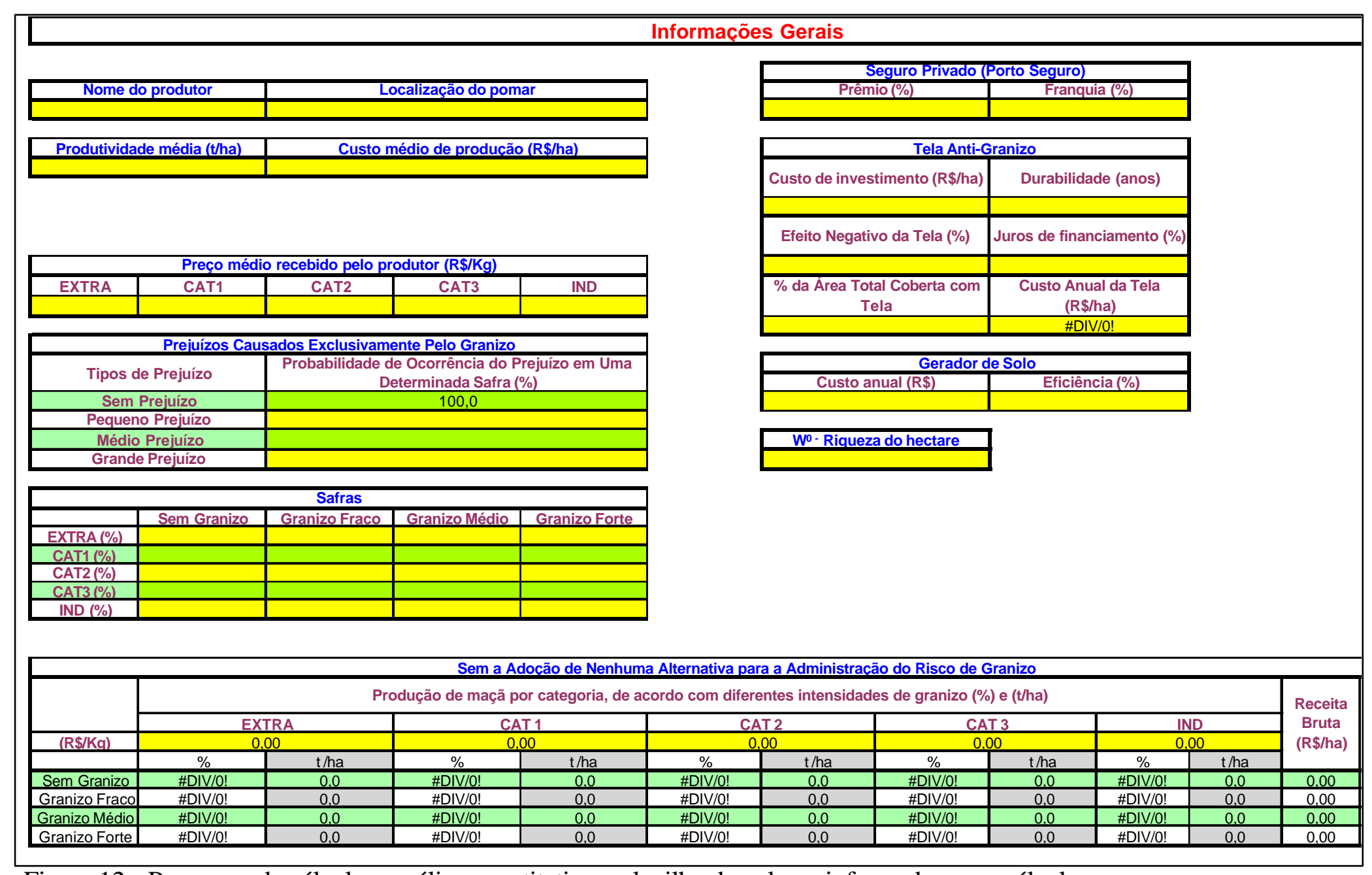

Figura 12 - Programa de cálculo e análise quantitativa - planilha de valores informados para cálculo. 


\subsection{Análise dos dados coletados através de questionário}

Da mesma forma que os resultados obtidos, a experiência de aplicar os questionários (ANEXOS A, B e C) também foi muito enriquecedora para o desenvolvimento do trabalho. Com esse exercício, verificoutse que a clara explicação da questão por parte do entrevistador é de máxima importância para que a compreensão das perguntas por parte do entrevistado seja exata, independente do seu nível intelectual ou cargo que ocupa dentro da empresa e, dessa forma, a respostas não apresentem desvios ou incoerências. No presente trabalho, particularmente, a maior dificuldade estava no fato de que alguns entrevistados de origem japonesa não compreendiam claramente a língua portuguesa.

\subsubsection{Questionário aplicado à cooperativa}

O questionário aplicado à cooperativa (ANEXO A) visou basicamente captar como a SANJO - Cooperativa Agrícola de São Joaquim enxerga e também, como enfrenta o problema das chuvas de granizo. Os representantes da cooperativa entrevistados foram Sr. Paulo Iida, Presidente da Cooperativa e Sr. Joatã de Oliveira Grazziotin, Gerente do Departamento Administrativo.

No final de 1993, com a liquidação da Cooperativa Agrícola de Cotia (CAC), 34 fruticultores ex-cooperados, fundaram a SANJO - Comércio e Transporte de Frutas São Joaquim Ltda. que em 29/11/1996 tornourse SANJO - Cooperativa Agrícola de São Joaquim, como alternativa para continuidade das atividades de produção, classificação e comercialização de suas maçãs de forma conjunta.

A evolução do volume de produção, do número de cooperados e da área de pomares ligados à SANJO nas últimas safras é apresentada no Quadro 6. 


\begin{tabular}{|c|c|c|c|}
\hline Safra & $\begin{array}{c}\text { Produção } \\
(\mathbf{t})\end{array}$ & $\begin{array}{c}\text { Número de } \\
\text { cooperados }\end{array}$ & Área plantada* (ha) \\
\hline $1998 / 1999$ & 25.000 & 45 & 768,58 \\
\hline $1999 / 2000$ & 30.000 & 47 & 768,58 \\
\hline $2000 / 2001$ & 26.000 & 52 & 790,00 \\
\hline $2001 / 2002$ & 28.000 & 63 & 800,00 \\
\hline
\end{tabular}

Quadro 4 - Evolução do volume de produção, do número de cooperados e da área de pomares ligados à SANJO no período entre as safras 1998/1999 2001/2002.

Fonte: Dados da pesquisa.

*Inclui áreas que ainda não entraram em produção. A área em produção varia muito de ano para ano devido ao processo de renovação dos pomares.

A qualidade de seus produtos, a parceria com seus clientes e a adesão ao programa de PIF - Produção Integrada de Frutas são os diferenciais estratégicos da cooperativa.

A capacidade de estocagem de suas câmaras frias que em 1994 era de 6.000t, atualmente é de 27.000 t e seus principais mercados são, no exterior, o continente europeu e a Malásia, e internamente, os estados de SP, MG, DF, RJ e AM.

Essas informações anteriores foram obtidas através das questões 1 a 8 do questionário.

A questão 9 do questionário (Como a cooperativa vê o problema do granizo?) levantou que, para a cooperativa, as conseqüências do granizo são:

a) Comprometimento do plano de comercialização, principalmente fornecimento de maçãs para clientes de $1^{\mathrm{a}}$ linha e para exportação - possibilidade de quebra da cadeia de fidelidade entre cliente e cooperativa (uma das principais preocupações da cooperativa);

b) Elevação dos custos fixos relativos - armazenagem a frio, embalagens, funcionários e máquinas têm custos que independem da qualidade das maçãs com que estão trabalhando; 
c) Diminui a rentabilidade de seus cooperados.

No propósito de amenizar os potenciais problemas financeiros que o granizo pode causar a seus cooperados, existe na cooperativa, desde a safra 1998/1999, um programa de seguro mútuo denominado Fundo de Apoio Agrícola. Esse programa foi desenvolvido para suprir, na época, a carência dos produtores de maçã com relação a um seguro que garantisse, ao menos, parte de sua receita e dessa forma não comprometesse o pagamento do financiamento bancário e por conseqüência permitisse a sua permanência na atividade. As questões 10 a 26 do questionário abordaram esse assunto.

Antes da implementação do Fundo de Apoio Agrícola, existia também, para os fruticultores, a opção do Programa de Garantia da Atividade Agropecuária (PROAGRO) do Governo Federal, porém acompanhada de desconfianças quanto a políticas governamentais que pudessem influenciar no ressarcimento do produtor e, também, na demora nas indenizações.

As normas do Fundo de Apoio Agrícola (laudos, valores para adesão, indenizações etc) são formuladas pelos próprios cooperados e vêm sendo adequadas e evoluindo a cada safra. O funcionamento do programa se dá basicamente da seguinte forma:

a) Em reunião entre os cooperados da SANJO, estima-se o valor do custo médio de produção das maçãs $(\mathrm{R} \$ / \mathrm{kg})$ e, também, o valor que cada interessado em participar do programa necessita depositar no fundo; esse valor é baseado no volume de maçãs produzido na sua safra anterior. O custo médio de produção $(\mathrm{R} \$ / \mathrm{kg})$ estimado serve como base de cálculo para as indenizações daqueles produtores que futuramente venham a precisar de auxílio do programa;

b) Caso ocorram chuvas de granizo, o produtor atingido deve avisar imediatamente a cooperativa e também enviar um aviso por escrito da ocorrência do evento. $\mathrm{O}$ agrônomo responsável vai até o pomar para verificar a gravidade dos danos;

c) Aqueles fruticultores atingidos pelo granizo dão continuidade normal à condução de seus pomares e enviam suas colheitas à cooperativa. A SANJO, após vender suas 
safras, verifica se a média de preço conseguida por esses produtores foi superior ou inferior ao custo médio de produção $(\mathrm{R} \$ / \mathrm{kg})$ estimado em reunião. Caso tenha sido inferior, esses cooperados tem direito a receber auxílio do Fundo de Apoio Agrícola no valor da diferença entre o custo médio de produção estimado e o valor médio de comercialização de suas maçãs;

d) As indenizações do Fundo de Apoio Agrícola têm como limite o seu valor acumulado, e em caso de muitos produtores necessitarem de auxílio, as indenizações são feitas de forma proporcional;

e) Não havendo chuvas de granizo, com o encerramento da venda da safra, o valor acumulado no fundo é devolvido aos participantes;

f) Durante o ano, enquanto não é necessária a realização de indenizações aos produtores, o valor acumulado no Fundo de Apoio Agrícola serve como capital de giro da cooperativa. Isso reduz significativamente a necessidade de captação de dinheiro junto aos bancos (diminui o custo do capital para a cooperativa).

Na primeira safra de existência do Fundo de Apoio Agrícola (1998/1999), nenhum produtor foi atingido pelo granizo de forma grave e, assim, não houve necessidade de auxílio do programa.

$\mathrm{Na}$ safra 1999/2000, devido a uma grande incidência de granizo, muitos cooperados necessitaram do auxílio do Fundo de Apoio Agrícola. Nesse ano o valor acumulado no fundo esgotou e quase não foi suficiente para as indenizações. Por essa razão e também devido a uma interessante proposta oferecida pela Porto Seguro Cia. de Seguros Gerais, na safra 2000/2001, todos os cooperados optaram por aderir ao seguro privado comercial e o Fundo de Apoio Agrícola foi desativado. Na safra 2001/2002, com o aumento dos valores de prêmio e franquia do seguro privado, o Fundo de Apoio Agrícola foi novamente reativado e precisou auxiliar apenas 1 participante com o valor de $\mathrm{R} \$ 4.334,02$.

Existe na cooperativa uma regra que obriga o produtor de maçãs a aderir pelo menos a um sistema de proteção contra as chuvas de granizo, seja esse sistema de mitigação ou de transferência do risco. Os produtores podem optar pelo PROAGRO, 
pelo seguro privado comercial ou pela tela anti-granizo. Optando por uma dessas alternativas, o cooperado está isento da obrigação de participação no Fundo de Apoio Agrícola. No caso da tela anti-granizo, a cobertura de $30 \%$ da área do pomar em produção isenta totalmente o produtor de participar do programa de seguro mútuo, a cobertura de $15 \%$ da área produtiva obriga o cooperado a participar do fundo apenas com a metade da sua produção. Na safra 2002/2003, 80\% dos cooperados aderiram ao Fundo de Apoio Agrícola. Esse programa é considerado uma experiência muito interessante para o grupo de produtores por ser um trabalho de ajuda mútua que fortalece o espírito cooperativista.

Existiram, nos primeiros anos de implantação do programa de seguro mútuo na SANJO, conversas entre a cooperativa e empresas de seguro privado na tentativa de se desenvolver algum tipo de resseguro para o Fundo de Apoio Agrícola. Na safra 2002/2003, com a saída da Porto Seguro Cia. de Seguros Gerais do ramo de seguro contra granizo em pomares de maçã em São Joaquim e, com a vinda da Agro Brasil Seguros, os contatos precisaram ser reiniciados.

A partir da questão 27 do questionário, outras alternativas para a administração do risco de granizo passaram a ser discutidas.

Sobre as telas antigranizo, a SANJO considera importante os seguintes pontos:

a) Muito interessante por garantir maçãs de qualidade para a comercialização;

b) Diminui problemas na relação custo fixo/qualidade do produto (alguns custos independem da qualidade da maçã com que se esta trabalhando, otimização do processo de armazenamento e classificação - economicamente inviável armazenar e classificar maçãs de baixa qualidade);

c) É um sistema caro para o produtor;

d) Causa problemas na coloração dos frutos e para algumas variedades problemas com maior incidência de doenças; 
e) Em S. Joaquim, problemas com solo raso (muitas pedras dificultam a instalação dos postes de sustentação das telas).

Pelos estudos desenvolvidos até o momento e pela eficiência apresentada, a cooperativa tem preferência pelo sistema de telas anti-granizo, que apresenta maiores vantagens para o produtor (garantia da renda) e também porque garante o seu produto comercial (maçãs de qualidade).

A cooperativa, apesar de saber do uso do sistema de geradores de solo em pomares de Fraiburgo, não vê muitas vantagens em sua utilização. Sobre essa alternativa, os pontos levantados foram:

a) Envolve outros produtores não cooperados, o que complica a instalação do sistema pela cooperativa;

b) Não conhecimento da real eficiência do sistema;

c) Necessidade de meio de comunicação bastante eficiente (telefone, rádio, estradas).

Quanto ao seguro privado comercial, a cooperativa considera essa alternativa muito interessante, mesmo assim, enxerga que ainda existem aspectos que precisam evoluir. Alguns cooperados estão optando por esse sistema. Os pontos levantados sobre essa alternativa foram:

a) Alternativa muito cara (valores de prêmio e franquia muito altos);

b) Apesar de garantir a renda do produtor, não garante a produção (a cooperativa precisa de maçã de qualidade para seus clientes);

c) Evasão de capital dos cooperados e, indiretamente, da cooperativa;

d) Nenhum apoio de instituições governamentais;

e) Devido a desistência da Porto Seguro Cia. de Seguros Gerais, surgiram, entre os produtores, dúvidas quanto a continuidade do produto (seguro contra granizo em pomares de maçã); 
f) De safra para safra, muitas mudanças nas regras do programa dificultam a elaboração de estratégias de longo prazo pelos produtores.

Também foi citada a alternativa dos foguetes anti granizo, porém consideram esse sistema muito caro, de eficiência duvidosa e perigoso.

\subsubsection{Questionário aplicado à empresa prestadora de serviços em meteorologia agrícola}

O questionário aplicado à CLIMATERRA Assessoria Planejamento Agronomia Ltda. (empresa prestadora de serviços em meteorologia agrícola) é apresentado no ANEXO B deste trabalho. As questões foram respondidas pelo Eng. Agrônomo Ronaldo Coutinho do Prado, diretor da empresa.

Os trabalhos da CLIMATERRA tiveram início em junho de 1995 na cidade de Florianópolis, SC. Inicialmente atendia estações de rádios que forneciam a previsão do tempo em sua programação. Em 1998 a empresa instalourse em São Joaquim e, atualmente, atende cooperativas do município, algumas empresas de terraplanagem do oeste de SC, agricultores nos municípios de Lages, Curitibanos, Fraiburgo e Água Doce, e também 16 estações de rádio, além de fornecer informações em http://www.climaterra.com.br.

Com relação ao granizo em S. Joaquim e em Fraiburgo, o entrevistado levantou os seguintes pontos:

a) As chuvas de granizo se formam basicamente a partir de nuvens convectivas $(\mathrm{Cb})$ e ocorrem geralmente na saída do inverno. Em S. Joaquim, particularmente, elas predominam de novembro a março;

b) O município de S. Joaquim, devido à sua altitude, apresenta uma camada de ar com temperatura positiva menor que ao nível do mar. São Joaquim está mais próximo das 
camadas frias da atmosfera onde se forma o granizo (linha de $0^{\circ} \mathrm{C}$ está mais próxima da superfície). Essa altitude é a principal responsável pela alta freqüência do granizo no município;

c) Distância do mar também favorece a ocorrência do granizo. A salinidade do ar de regiões litorâneas dificulta a formação das pedras de gelo nas nuvens;

d) Em um relevo acidentado, os vales servem como fonte de calor e umidade para atmosfera. $\mathrm{O}$ ar quente e úmido tende a subir e ao se encontrar com as frentes frias, formam o granizo. Esse granizo, antes de cair, desloca-se por alguns quilômetros na atmosfera, juntamente com a frente fria;

e) Nos anos em que temos o fenômeno do "El Niño" (verão chuvoso no sul do Brasil), a frequiência do granizo é maior, porém a sua intensidade média é menor. Ao contrário dos anos em que temos a "La niña" (verão com poucas chuvas no sul do Brasil), quando a frequiência do granizo é menor mas a sua intensidade média é maior.

$\mathrm{Na}$ visão particular do entrevistado, podem existir regiões em São Joaquim onde o granizo seja menos freqüente, onde o granizo não ocorra por anos seguidos, porém existem também muitos lugares onde a probabilidade da queda de granizo todos os anos é altíssima em função de características específicas.

Abordando o sistema de geradores de solo, o entrevistado forneceu as seguintes informações:

a) O sistema tem eficiência de 70 a $80 \%$ na proteção do patrimônio do agricultor (casa, árvores do pomar, bens da propriedade);

b) O sistema tem eficiência de aproximadamente $30 \%$ na diminuição da intensidade (energia, quantidade de pedras, duração) do granizo. Dessa forma, apresenta de 30 50\% de eficiência na proteção da safra;

c) Existem casos raros em que a nuvem "vem de costas" e, ao contrario do que normalmente ocorre, primeiro temos a chuva e em seguida o granizo. A chuva, que 
vem antes, diminui a concentração do reagente (Iodeto de Prata) lançado pelos geradores de solo na atmosfera e dessa forma o combate ao granizo tem sua eficiência reduzida significativamente;

d) Alguns fatores importantes para a maximização da eficiência do sistema são a existência de uma boa previsão do tempo (horário da ocorrência do granizo), as boas condições dos aparelhos de geradores de solo e também a garantia de que as pessoas responsáveis realmente irão acionar os aparelhos;

e) O relevo e a altitude da região onde serão instalados os geradores de solo não influenciam na eficiência do sistema, somente interferem na infra-estrutura de distribuição desses aparelhos;

f) É importante que nos locais onde os geradores de solo são instalados haja um mínimo de estrutura de comunicação (rádio amador, telefone, estrada) e, obviamente, uma pessoa responsável;

g) No ano 2000, foi desenvolvido um projeto piloto de instalação do sistema de geradores de solo em São Joaquim. Nesse projeto estariam envolvidos 150 produtores de maçã e o monitoramento seria feito pelo radar instalado em Fraiburgo. No primeiro ano do projeto (instalação do sistema), o custo para cada produtor estaria entre $\mathrm{R} \$ 400,00$ e $\mathrm{R} \$ 500,00$ por mês, a partir do segundo ano, quando existiriam somente os custos de manutenção do sistema, esse custo baixaria para $\mathrm{R} \$ 200,00$ a $\mathrm{R} \$ 300,00$ por mês por produtor. O custo para instalação de um sistema de geradores de solo completo que cobrisse todo o município de São Joaquim seria de aproximadamente US\$ 300.000,00, sem considerar o custo de aquisição de um radar meteorológico;

h) Caso os fruticultores de São Joaquim adotem o sistema de geradores de solo, a AGF - Anti-Granizo Fraiburgo, empresa que administra o sistema de geradores de solo em Fraiburgo poderia, também, administrar o sistema em São Joaquim. A CLIMATERRA auxiliaria o projeto realizando a previsão do tempo e definindo o melhor momento para o acionamento dos geradores de solo. 
Sobre os sistemas de telas anti-granizo, geradores de solo, seguro privado comercial e, seguro mútuo o entrevistado também fez os seguinte comentários:

Telas anti-granizo:

a) É o sistema mais eficiente;

b) Existe a necessidade de mais estudos sobre o efeito "sombreamento" das telas nas frutas e também sobre a possibilidade da maior incidência de doenças em pomares protegidos por esse sistema;

c) O custo de instalação das telas é alto;

d) Em São Joaquim, a ocorrência de neve obriga o fruticultor a recolher as telas no inverno.

Geradores de solo:

a) A desunião existente entre todos os produtores de maçã em São Joaquim é o problema limitante na instalação do sistema no município;

b) Custo do sistema, para cada produtor participante da sociedade, não é alto.

Seguro privado comercial:

a) Conhecendo o comportamento da ocorrência das chuvas de granizo, considera que o seguro pode vir a se tornar inviável economicamente;

b) A combinação entre seguro e geradores de solo, ou telas anti-granizo, poderia ser ideal.

Seguro mútuo (Fundo de Apoio Agrícola - SANJO):

a) Eficiente. Só funciona em grupos muito organizados.

O entrevistado citou ainda a diversificação espacial (apesar de aumentar os custos administrativos para o fruticultor), a diversificação de culturas (trabalhar com outras culturas agrícolas) e a diversificação de atividades (turismo) como formas de 
tentar diminuir os prejuízos causados pelo granizo e, assim garantir a renda do agricultor.

Quanto às probabilidades de ocorrência do granizo, o entrevistado informou que a percepção que as pessoas têm da realidade é, muitas vezes, distorcida, e que existe uma grande necessidade do desenvolvimento de um banco de dados sobre o granizo em São Joaquim. Esses dados já vêm sendo coletados pelo entrevistado em diferentes regiões do município. A comparação entre a probabilidade de ocorrência do granizo com os geradores de solo e sem esses aparelhos não pode ser feita, justamente por não existirem dados para análises estatísticas.

Sobre os prejuízos causados pelo granizo nas diferentes fases fenológicas da cultura da maçã, por não ser um produtor, o entrevistado preferiu não responder as questões referentes a esse tema.

\subsubsection{Questionário aplicado aos produtores de maçã}

O questionário aplicado junto aos produtores de maçã é apresentado no ANEXO $\mathrm{C}$ deste trabalho. Foram entrevistados 19 fruticultores, todos cooperados da SANJO Cooperativa Agrícola de São Joaquim, o que corresponde a $30 \%$ do seu quadro de cooperados. Foram selecionadas desde pessoas que estão na atividade há mais de 25 anos até pessoas que começaram na atividade há apenas 4 anos e, dos mais diversos níveis de produção. O nome dos cooperados e o tempo com que trabalham com a cultura da maçã são apresentados no Quadro 7. 


\begin{tabular}{|l|c|}
\hline \multicolumn{1}{|c|}{ Nome do cooperado entrevistado } & Tempo de trabalho com a maçã (anos) \\
\hline Augusto Tetsuya Ryu (Yasushi Ryu) & 4 \\
\hline Edson Jiro Hosoi & 5 \\
\hline Elisandro Pires Bertollo & 5 \\
\hline Fábio Satoru Hosoi & 10 \\
\hline Fábio Takahiko Kawano & 9 \\
\hline Henrique Makoto Hamano & 7 \\
\hline José Itamar Boneti & 20 \\
\hline Makoto Umemiya & 14 \\
\hline Marcelino Kiyoshi Furinata & 17 \\
\hline Marcos Haruo Fukus hima & 17 \\
\hline Masao Shimizu & 27 \\
\hline Mauricio Iomi Kobayashi (Kimiko Kobayashi) & 17 \\
\hline Miguel Angelo de Rocco & 19 \\
\hline Nelson Hitoshi lida & 25 \\
\hline Nobuyoshi Shimizu & 20 \\
\hline Paulo Minoru Yamaguchi & 15 \\
\hline Shigueru Umemiya & 26 \\
\hline Shoichi Yuri & 27 \\
\hline Yoshinori Katsurayama & 10 \\
\hline
\end{tabular}

Quadro 5 - Cooperados SANJO entrevistados e seus respectivos tempos de trabalho com a cultura da maçã.

Fonte: Dados da pesquisa.

A partir da análise das respostas obtidas, levantou-se os seguintes pontos:

a) As respostas obtidas para as dez primeiras perguntas do questionário, mostram que a grande maioria dos entrevistados se instalaram, ou são filhos daqueles que se instalaram em São Joaquim em projetos desenvolvidos pela extinta CAC Cooperativa Agrícola de Cotia, entre 1974 e 1976. São originários das mais diversas regiões do Brasil ou do mundo, alguns têm curso universitário (Agronomia, Economia) ou estágios com fruticultura no exterior (Japão, EUA) e muitos têm experiências no plantio de outras culturas e também com a criação de animais;

b) Inicialmente os pomares dos projetos da CAC foram implantados, em São Joaquim, nas localidades do Coruja e do Boava. Com o desenvolvimento e crescimento da atividade de plantio de maçãs, novas áreas passaram a ser exploradas e hoje podemos encontrar pomares de fruticultores ligados à SANJO em todo o município;

c) Nas últimas três safras, a produtividade média de um pomar em fase adulta ficou em torno de 43 t/ha e o custo médio de produção esteve em torno de $\mathrm{R} \$ 7.500,00 /$ ha. Já 
com relação à questão 13 (Qual o valor médio que recebe por suas maçãs $(R \$ / \mathrm{kg})$ de acordo com as categorias de classificação das frutas?), a cooperativa preferiu que esses valores não fossem divulgados e os produtores optaram por não fornecer essas informações;

d) Verificou-se que todos os produtores entrevistados já tiveram pelo menos uma safra com prejuízos causados pelo granizo e, também, que a aversão de cada fruticultor ao risco do granizo e a sua percepção com relação aos potenciais danos causados por esse evento climático dependem, em parte, se seu pomar já foi ou não atingido pelo granizo, da intensidade do granizo mais significativo que já atingiu sua área produtiva e também da freqüência com que ele afeta a sua produção;

e) As respostas obtidas para a questão 18 (Com relação ao seguro privado e ao seguro mútuo, tem interesse no uso dessas alternativas para a administração do risco de prejuízos causados pelas chuvas de granizo? No seu ponto de vista, quais as vantagens, desvantagens e a confiabilidade dessas alternativas?) mostraram que o interesse pelo seguro agrícola existe, porém é maior para a modalidade de seguro mútuo (Fundo de Apoio Agrícola - SANJO). As principais vantagens e desvantagens do seguro agrícola, citadas nas respostas dos questionários, são apresentadas no Quadro 8. 


\begin{tabular}{|c|c|c|}
\hline & Vantagens & Desvantagens \\
\hline $\begin{array}{l}\text { Seguro Privado } \\
\text { Comercial }\end{array}$ & $\begin{array}{l}\text { - Segura a renda do produtor; } \\
\text { - Cobre a receita esperada; } \\
\text { - Cobre o lucro; } \\
\text { - A indenização é imediata; } \\
\text { - O produtor é quem determina o } \\
\text { valor da produção; } \\
\text { - Produtor se sente mais protegido p/ } \\
\text { dar continuidade à atividade. }\end{array}$ & $\begin{array}{l}\text { - Muito caro; } \\
\text { - Regras mudaram todo ano; } \\
\text { - Desconfiança do produtor devido à } \\
\text { desistência da Porto Seguro Cia. } \\
\text { de Seguros; } \\
\text { - Mesmo que não caia granizo, valor } \\
\text { pago pelo prêmio não retorna; } \\
\text { - Valor da franquia é inadequado } \\
\text { (desproporcional à realidade). }\end{array}$ \\
\hline $\begin{array}{l}\text { Seguro Mútuo } \\
\text { (Fundo de Apoio } \\
\text { Agrícola) }\end{array}$ & $\begin{array}{l}\text { - Baixo custo; } \\
\text { - Garantia da cobertura do custo de } \\
\text { produção; } \\
\text { - Pode ser considerado como uma } \\
\text { poupança forçada; } \\
\text { - Se não houver indenizações, o } \\
\text { saldo permanece no fundo; } \\
\text { - O capital do fundo serve como } \\
\text { capital de giro da cooperativa, o } \\
\text { que indiretamente beneficia o } \\
\text { cooperado; } \\
\text { - O controle financeiro é feito pela } \\
\text { própria cooperativa e produtor tem } \\
\text { acesso a essa contabilidade; } \\
\text { - Por não visar lucro, é mais barato } \\
\text { que seguro privado; } \\
\text { - Seguro em grupo (o produtor não } \\
\text { está sozinho); } \\
\text { - Os próprios produtores determinam } \\
\text { os valores de também as regras; } \\
\text { - Preço acessível. }\end{array}$ & $\begin{array}{l}\text { - Em caso de granizo generalizado } \\
\text { (a grande maioria dos cooperados } \\
\text { for atingida), o fundo não teria } \\
\text { capital suficiente para as } \\
\text { indenizações; } \\
\text { - Demora nas indenizações (precisa } \\
\text { avaliar toda a maçã que está } \\
\text { armazenada na câmara); } \\
\text { - As indenizações vão somente até o } \\
\text { limite do fundo. As indenizações } \\
\text { podem não ser integrais; } \\
\text { - Cobre somente custo de produção } \\
\text { estimado. }\end{array}$ \\
\hline
\end{tabular}

Quadro 6 - Vantagens e desvantagens observadas, pelos fruticultores, m seguro privado comercial e no seguro mútuo.

Fonte: Dados da pesquisa.

Na mesma questão foi levantada ainda a confiabilidade dos entrevistados nessas duas modalidades de seguro agrícola. Verificou-se que a confiabilidade no sistema de seguro mútuo é maior. Os principais pontos negativos que afetam a confiabilidade do seguro privado comercial, citados pelos entrevistados, são as constantes mudanças nos valores de prêmio e franquia aplicados ano a ano e, a desistência da Porto Seguro Cia de Seguros Gerais em atuar no ramo. A única preocupação dos produtores com relação ao Fundo de Apoio Agrícola é o fato de que em caso de granizo generalizado, o capital acumulado no fundo pode não ser suficiente para as indenizações. 
f) A adesão ao seguro privado comercial foi significativa na safra 2000/2001 quando todos os cooperados da SANJO, sem exceção, decidiram optar por essa alternativa. No entanto, nas safras 1999/2000, 2000/2001 e 2002/2003, a adesão ao Fundo de Apoio Agrícola foi predominante. Na safra 1999/2000, devido a um granizo generalizado, os cooperados enfrentaram graves problemas com o Fundo de Apoio Agrícola que não possuía capital suficiente para as indenizações. Nessa mesma safra, houve ainda o agravante de uma produção recorde de maçãs no país e, devido ao excesso de oferta, ocorreu uma queda significativa do preço dessa fruta. A falta de qualidade das maçãs, causada pelo granizo, também contribuiu para diminuir ainda mais a recita do fruticultor.

Na safra 2000/2001, quando todos os cooperados ligados à SANJO aderiram ao seguro privado comercial, ocorreram diversos granizos e muitos produtores precisaram ser indenizados. Na opinião de vários entrevistados, as indenizações foram importantes para que os fruticultores não se descapitalizassem e dessa forma os investimentos necessários para a safra seguinte não ficassem comprometidos.

g) Da questão 21 à questão 26, o questionário tratou do sistema de telas anti-granizo. Verificou-se que o interesse na adoção desse sistema é grande entre os entrevistados, que muitos têm planos de cobrir suas áreas produtivas nos próximos anos e que atualmente já existem fruticultores que estão fazendo a instalação desse sistema em seus pomares com auxílio de financiamento disponibilizado pelo BNDES (Banco Nacional de Desenvolvimento Econômico e Social) através do BRDE (Banco Regional de Desenvolvimento do Extremo Sul). Esse financiamento apresenta valor limite de $\mathrm{R} \$ 150.000,00$ dependendo das garantias apresentadas, juros anuais de $8,75 \%$ e um total de 8 anos para pagamento, sendo os 3 primeiros anos de carência e os outros 5 para a amortização da dívida.

Os produtores estimam que o custo total para a instalação do sistema gire em torno de $\mathrm{R} \$ 14.000,00 / \mathrm{ha}$, a durabilidade das telas esteja próxima de 13 anos e que a 
diminuição na sua receita bruta devido ao efeito "sombreamento" das telas seja em média de $8,5 \%$.

Os principais benefícios e problemas apresentados por esse sistema, citados pelos entrevistados, são listados no Quadro 9.

\begin{tabular}{|c|c|}
\hline Benefícios & Problemas \\
\hline 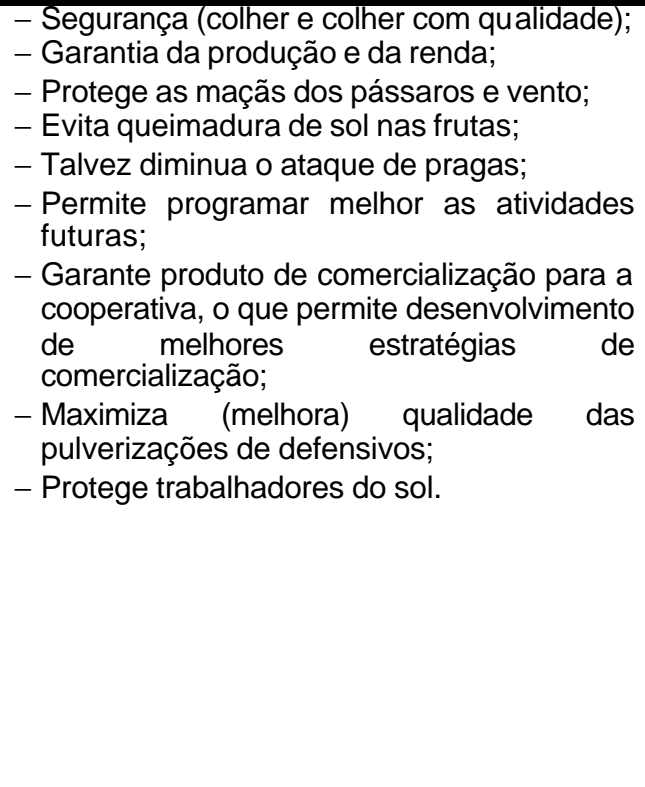 & $\begin{array}{l}\text { - Diminui a coloração dos frutos; } \\
\text { - Custos altos de implantação e manutenção; } \\
\text { - Implantação do s istema é complicado; } \\
\text { - Topografia da região de São Joaquim não } \\
\text { permite que o sistema seja instalado em } \\
\text { todo lugar; } \\
\text { - Solo de São Joaquim com muitas pedras } \\
\text { dificulta a instalação dos postes de } \\
\text { sustentação das telas; } \\
\text { - Necessidade de mão-de-obra para } \\
\text { manutenção (estender e recolher tela); } \\
\text { - Neve pode derrubar a tela; } \\
\text { - Ventos fortes podem arrancar a tela; } \\
\text { - Faltam estudos sobre o sistema nas } \\
\text { condições de S. Joaquim; } \\
\text { - Problemas na polinização das flores (tela } \\
\text { prejudica o trabalho das abelhas); } \\
\text { - Ligeiro aumento da temperatura sob a tela } \\
\text { (microclima pode contribuir para aumento } \\
\text { na incidência de doenças, principalmente } \\
\text { fúngicas); } \\
\text { - Talvez maior incidência de ácaros. }\end{array}$ \\
\hline
\end{tabular}

Quadro 7 - Principais benefícios e problemas do sistema de telas antigranizo, citados pelos entrevistados.

Fonte: Informações obtidas na pesquisa.

h) Da questão 27 à 31, o assunto abordado foi o sistema de geradores de solo. Pelas opiniões coletadas observoutse que o conhecimento sobre esse sistema é pequeno e que não existe interesse na adoção dessa alternativa nos pomares de São Joaquim. Quase a totalidade dos entrevistados não respondeu as questões que tratavam do custo do sistema, de sua eficiência e dos benefícios e problemas que os geradores de solo apresentam. Para os que responderam porém, os valores do custo anual para cada produtor beneficiado variou de $\mathrm{R} \$ 2.500,00$ a $\mathrm{R} \$ 25.000,00$ e os valores para a eficiência do sistema variaram de $0 \%$ a $80 \%$. Para responder essas questões, os entrevistados se basearam em palestras, programas de televisão, conversas com 
especialistas ou produtores estrangeiros que já usaram o sistema e, viagens internacionais. Os possíveis benefícios e problemas citados estão apresentados no Quadro 10.

\begin{tabular}{|l|l|}
\hline \multicolumn{1}{|c|}{ Benefícios } & \multicolumn{1}{c|}{ Problemas } \\
\hline - Diminui a intensidade do granizo; & - Necessidade de associação de produtores \\
- É mais eficiente que sistema de foguetes; & (dificuldade de organizar produtores); \\
- Minimiza a ocorrência de granizos fortes. & - Necessidade de pessoas encarregadas; \\
& - Custo de instalação e manutenção do \\
& sistema é alto; \\
& - Dúvida se o produto (Agl) realmente atinge \\
& as nuvens; \\
& - Eficiência duvidosa; \\
& - Não tem 100\% de garantia - não é 100\% \\
& confiável; \\
& - Possibilidade de falha operacional; \\
& - Não funciona p/ áreas pequenas; \\
& - Difícil para pequenos produtores, pomares \\
& muito dispersos; \\
& - Incerteza se realmente deve ou não ligar os \\
& geradores em caso de formação de nuvens \\
& (observação de nuvens). \\
\hline
\end{tabular}

Quadro 8 - Principais benefícios e problemas do sistema de geradores de solo, citados pelos entrevistados.

Fonte: Informações obtidas na pesquisa.

Existiram reuniões entre fruticultores das regiões brasileiras produtoras de maçã para discutir a possibilidade da implantação do sistema de geradores de solo, porém, com base em depoimentos de produtores europeus que também participaram desses debates e já tinham experiência com os geradores de solo, pelo menos em São Joaquim, essa idéia foi descartada.

i) Sobre outras estratégias para a administração do problema do granizo, os produtores citaram as seguintes alternativas:

- Próprio produtor acumular seu fundo de reserva para eventuais prejuízos devido ao granizo;

- Diversificação das atividades (partir para a pecuária);

- Trabalhar com estatísticas (coleta de dados) e procurar regiões em que o granizo é menos freqüente. 
j) A partir da análise das respostas dadas para a questão 33 do questionário (Como produtor de maçãs, considerando os conhecimentos existentes até o momento, qual a sua preferência com relação às alternativas para a administração do risco de granizo? Por quê? ), verificourse que a preocupação com a qualidade das maçãs faz com que a maioria dos fruticultores entrevistados dêem preferência ao sistema de cobertura de telas anti-granizo. Conforme dados da pesquisa, esse seria o único sistema com total eficiência na proteção das frutas contra o granizo.

k) Na questão 34, na qual era aberto um espaço para comentários diversos sobre o presente trabalho ou algumas das alternativas para minimizar os problemas do granizo, alguns pontos foram levantados:

- O presente trabalho pode vir a despertar interesse de empresas especializadas em instalar telas;

- O presente trabalho pode despertar interesse de órgãos governamentais que incentivem financeiramente (facilidade de financiamento) a adoção de alguma alternativa $\mathrm{p} /$ administração desse risco, tendo em vista a importância econômica e social (empregos) que a atividade representa para os municípios produtores (se a maçã vai diretamente $\mathrm{p} /$ a indústria, diminuem as vagas de emprego no processo de classificação e embalagem das maçãs);

- As alternativas para a administração do iisco do granizo devem ter como principal objetivo a garantia de renda do produtor e por conseqüência sua sobrevivência na atividade;

- O custo das alternativas existentes ainda é muito alto.

- O Brasil precisa pensar no subsídio ao seguro. Seguros mais acessíveis, para manter os agricultores na atividade (concorrência dos países desenvolvidos);

- O fruticultor não pode ficar sem algum tipo de proteção. A região de S. Joaquim é uma região de muito granizo; 
- É importante pensar na cooperativa. E a tela pode garantir maçãs de qualidade para comercialização;

- As comparações (econômicas, facilidade de implantação e manutenção) entre as alternativas, para cada categoria de produtor (pequeno, médio ou grande), são importantes para que se possa ter uma melhor visão de qual a alternativa mais viável em cada caso.

1) No processo de aplicação dos questionários, verificourse que existe uma preocupação por parte dos fruticultores com relação ao Fundo de Apoio Agrícola. Essa preocupação está relacionada ao fato de que caso a grande maioria dos pomares dos cooperados sofra danos consideráveis devido ao granizo, o Fundo de Apoio Agrícola pode não ter capital acumulado suficiente para a indenização de todos os que tiverem direito. Baseando-se nessa preocupação e nos valores reais do Programa do Fundo de Apoio Agrícola, safra 2002/2003, obtidos no questionário, pode-se realizar o seguinte cálculo:

Produção total da cooperativa safra 2002/2003 = 30.000 t

Preço médio pago pela maçã “indústria” safra 2002/2003 = R \$ 0,08/kg

Custo médio de produção estimado safra 2002/2003 = R \$ 0,20/kg

Supondo que todos os cooperados participem do Fundo de Apoio Agrícola, e um caso extremo em que ocorra um granizo generalizado e a totalidade da produção da cooperativa necessite ser destinada para a indústria, a receita da cooperativa seria de:

Produção total $x$ Preço médio $=30.000$ t x R $\$ 0,08 / \mathrm{kg}=\mathrm{R} \$ 2.400 .000,00$

Sendo que o custo médio de produção estimado foi de $\mathrm{R} \$ 0,20 / \mathrm{kg}$, e a produção total da cooperativa foi de $30.000 t$, o custo total estimado de produção seria de:

$30.000 \mathrm{t} \times \mathrm{R} \$ 0,20 / \mathrm{kg}=\mathrm{R} \$ 6.000 .000,00$ 
Como cada produtor teria direito a receber do Fundo de Apoio Agrícola a diferença entre o valor do custo médio de produção estimado e o valor de indústria recebido pelas suas maçãs, o valor total das indenizações seria de:

Custo de produção - Receita $=\mathrm{R} \$ 6.000 .000,00-\mathrm{R} \$ 2.400 .000,00=\mathrm{R} \$ 3.600 .000,00$

No questionário aplicado à cooperativa, levantou-se que as indenizações são feitas somente até o limite do Fundo de Apoio Agrícola que, na safra em questão, acumulou $\mathrm{R} \$ 511.000,00$.

A partir dos valores calculados podemos concluir que, ocorrendo um granizo extremamente severo, o Fundo de Apoio Agrícola tem capital suficiente para indenizar seus participantes em, aproximadamente, 14,2\% do prejuízo máximo possível.

Capital do fundo de apoio / Indenizações $=\mathrm{R} \$ 511 \mathrm{mil} / \mathrm{R} \$ 3.600 \mathrm{mil}=0,1419$

Que corresponde a aproximadamente $=14,2 \%$ 


\subsection{Aplicação, em planilha de cálculo, dos dados coletados no questionário}

Para avaliar qual alternativa seria mais viável economicamente e, ter uma melhor visualização dos méritos de cada sistema estudado, os valores médios coletados através do questionário (percepção dos entrevistados) foram aplicados no "GranizoMGMT".

Os valores médios coletados, foram:

- Nome do produtor: "Fruticultor"

- Localização do pomar: São Joaquim

- Produtividade média do pomar (t/ha): 43,25t/ha

- Custo médio de produção do pomar sem considerar custos de seguro, telas antigranizo e geradores de solo ( $\mathrm{R} \$ / \mathrm{ha})$ : $\mathrm{R} \$ 7.784,00 / \mathrm{ha}$

- $\quad$ Preço $^{8}$ médio pago aos produtores por cada uma das categorias de classificação das maçãs $(\mathrm{R} \$ / \mathrm{kg})$ :

Extra: $\mathrm{R} \$ 1,05 / \mathrm{kg}$

CAT1: $\mathrm{R} \$ 0,85 / \mathrm{kg}$

CAT2: $\mathrm{R} \$ 0,50 / \mathrm{kg}$

CAT3: $\mathrm{R} \$ 0,30 / \mathrm{kg}$

IND: R\$ 0,08/kg

\footnotetext{
${ }^{8}$ Valores hipotéticos próximos à realidade, por razões estratégicas, contudo, a cooperativa SANJO preferiu não revelar os valores reais.
} 
- Probabilidade de ocorrência dos diferentes tipos de prejuízo em uma determinada safra $(\%)$ devido ao granizo:

Pequeno prejuízo: $41,0 \%$

Médio prejuízo: $28,0 \%$

Grande prejuízo: $15,0 \%$

- \% colhida de cada categoria de maçã em safras de anos "Sem Granizo":

EXTRA: $11,0 \%$

CAT1: $39,0 \%$

CAT2: $28,0 \%$

CAT3: $15,5 \%$

IND: $6,5 \%$

- \% colhida de cada categoria de maçã em safras de anos com "Granizo Fraco":

EXTRA: $5,1 \%$

CAT1: $30,0 \%$

CAT2: $31,2 \%$

CAT3: $21,7 \%$

IND: $12,0 \%$

- \% colhida de cada categoria de maçã em safras de anos com "Granizo Médio":

EXTRA: $1,2 \%$

CAT1: $18,2 \%$

CAT2: $29,3 \%$

CAT3: $31,0 \%$

IND: $20,3 \%$ 
- \% colhida de cada categoria de maçã em safras de anos com "Granizo Forte":

EXTRA: $0 \%$

CAT1: $4,5 \%$

CAT2: $10,0 \%$

CAT3: $20,4 \%$

IND: $65,1 \%$

- $\quad$ Valores ${ }^{9}$ de prêmio e franquia do seguro privado comercial (\%):

Prêmio: $12,63 \%$

Franquia: $20,00 \%$

- Custo de implantação de telas anti-granizo (R $\$ / h a)$ e sua durabilidade (anos):

Custo: $\mathrm{R} \$ 13.750,00 / \mathrm{ha}$

Durabilidade: 13 anos

- Provável diminuição na receita do produtor (\%) devido ao "efeito sombreamento" das telas anti-granizo (Efeito negativo das Telas Anti-Granizo): 8,6\%

- Porção do pomar já coberta com telas anti-granizo ou que o produtor pretende cobrir (\%): $30 \%$

- Juros cobrados no financiamento da instalação de telas anti granizo (\%): 8,75\%

- Custo anual dos geradores de solo para cada produtor (R\$/área protegida): $\mathrm{R} \$ 5.000,00 / a ́ r e a$ protegida

- Provável eficiência dos geradores de solo (\%): $26 \%$

\footnotetext{
${ }^{9}$ Valores para a safra 2002/2003 - Agro Brasil Seguros.
} 
Resultados obtidos:

Aplicando-se os valores médios coletados através dos questionários, no “GranizoMGMT", obtivemos os seguintes resultados, apresentados no Quadro 11. 


\begin{tabular}{|c|c|c|c|c|c|c|c|c|}
\hline Seguro & Gerador de Solo & $\begin{array}{l}\text { Tela Anti- } \\
\text { Granizo }\end{array}$ & Prejuizo & $\begin{array}{l}\text { Probabilidade do } \\
\text { Prejuizo (\%) }\end{array}$ & $\begin{array}{l}\text { Possivel } \\
\text { Receita } \\
\text { Líquida } \\
\text { (R\$/ha) }\end{array}$ & $\begin{array}{l}\text { Receita Líquida Média } \\
\text { e Desvio Padrão da } \\
\text { Receita Líquida } \\
\text { (R\$/ha) }\end{array}$ & $\mid \begin{array}{c}\text { Receita Liquida (R\$/ha) } \\
\text { em Função da Aversão } \\
\text { ao Risco }\end{array}$ & $\begin{array}{l}\text { R Coeficiente de } \\
\text { aversão ao risco }\end{array}$ \\
\hline Sem Seguro & Sem Gerador de Solo & Sem Tela & Sem Prejuizo & 16,0 & 19839,78 & 1262849 & \multirow{4}{*}{$10.950,16$} & 4 \\
\hline Sem Seguro & Sem Gerador de Solo & Sem Tela & Pequeno Prejuízo & 41,0 & 15538,56 & $12.0<0,40$ & & Média \\
\hline Sem Seguro & Sem Gerador de Solo & Sem Tela & Médio Prejuízo & 28,0 & 10512,48 & \multirow{2}{*}{$5.793,69$} & & \\
\hline Sem Seguro & Sem Gerador de Solo & Sem Tela & Grande Prejuizo & 15,0 & 932,17 & & & \\
\hline Sem Seguro & Sem Gerador de Solo & Com Tela & Sem Prejuízo & 16,0 & 18646,75 & \multirow{2}{*}{$13.598,86$} & \multirow{4}{*}{$12.776,47$} & \\
\hline Sem Seguro & Sem Gerador de Solo & Com Tela & Pequeno Prejuízo & 41,0 & 15635,90 & & & \\
\hline Sem Seguro & Sem Gerador de Solo & Com Tela & Médio Prejuizo & 28,0 & 12117,65 & \multirow{2}{*}{$4.055,58$} & & \\
\hline Sem Seguro & Sem Gerador de Solo & Com Tela & Grande Prejuizo & 15,0 & 5411,43 & & & \\
\hline Sem Seguro & Com Gerador de Solo & Sem Tela & Sem Prejuízo & 16,0 & 14839,78 & \multirow{2}{*}{$9.503,43$} & \multirow{4}{*}{$8.584,37$} & \\
\hline Sem Seguro & Com Gerador de Solo & Sem Tela & Pequeno Prejuizo & 41,0 & 11656,88 & & & \\
\hline Sem Seguro & Com Gerador de Solo & Sem Tela & Médio Prejuizo & 28,0 & 7937,58 & \multirow{2}{*}{$4.287,33$} & & \\
\hline Sem Seguro & Com Gerador de Solo & Sem Tela & Grande Prejuizo & 15,0 & 848,15 & & & \\
\hline Sem Seguro & Com Gerador de Solo & Com Tela & Sem Prejuizo & 16,0 & 13646,75 & \multirow{2}{*}{$8.566,44$} & \multirow{4}{*}{$7.736,04$} & \\
\hline Sem Seguro & Com Gerador de Solo & Com Tela & Pequeno Prejuizo & 41,0 & 11418,72 & & & \\
\hline Sem Seguro & Com Gerador de Solo & Com Tela & Médio Prejuizo & 28,0 & 3880,95 & \multirow{2}{*}{$4.075,29$} & & \\
\hline Sem Seguro & Com Gerador de Solo & Com Tela & Grande Prejuizo & 15,0 & 4097,42 & & & \\
\hline Com Seguro & Sem Gerador de Solo & Sem Tela & Sem Prejuizo & 16,0 & 16350,89 & \multirow{2}{*}{$12.211,75$} & \multirow{4}{*}{$12.032,87$} & \\
\hline Com Seguro & Sem Gerador de Solo & Sem Tela & Pequeno Prejuízo & 41,0 & 12049,68 & & & \\
\hline Com Seguro & Sem Gerador de Solo & Sem Tela & Médio Prejuízo & 28,0 & 10826,14 & \multirow{2}{*}{$1.891,44$} & & \\
\hline Com Seguro & Sem Gerador de Solo & Sem Tela & Grande Prejuizo & 15,0 & 10826,14 & & & \\
\hline Com Seguro & Sem Gerador de Solo & Com Tela & Sem Prejuízo & 16,0 & 16204,53 & \multirow{2}{*}{$12.900,90$} & \multirow{4}{*}{$12.762,91$} & \\
\hline Com Seguro & Sem Gerador de Solo & Com Tela & Pequeno Prejuizo & 41,0 & 13193,69 & & & \\
\hline Com Seguro & Sem Gerador de Solo & Com Tela & Médio Prejuízo & 28,0 & 11392,47 & \multirow{2}{*}{$1.661,26$} & & \\
\hline Com Seguro & Sem Gerador de Solo & Com Tela & Grande Prejuizo & 15,0 & 11392,47 & & & \\
\hline Com Seguro & Com Gerador de Solo & Sem Tela & Sem Prejuízo & 16,0 & 11350,89 & \multirow{2}{*}{$7.670,26$} & \multirow{4}{*}{$7.483,69$} & \\
\hline Com Seguro & Com Gerador de Solo & Sem Tela & Pequeno Prejuízo & 41,0 & 8167,99 & & & \\
\hline Com Seguro & Com Gerador de Solo & Sem Tela & Médio Prejuízo & 28,0 & 5826,14 & \multirow{2}{*}{$1.931,69$} & & \\
\hline Com Seguro & Com Gerador de Solo & Sem Tela & Grande Prejuizo & 15,0 & 5826,14 & & & \\
\hline Com Seguro & Com Gerador de Solo & Com Tela & Sem Prejuízo & 16,0 & 11204,53 & \multirow{2}{*}{$8.224,34$} & \multirow{4}{*}{$8.069,99$} & \\
\hline Com Seguro & Com Gerador de Solo & Com Tela & Pequeno Prejuízo & 41,0 & 8976,51 & & & \\
\hline Com Seguro & Com Gerador de Solo & Com Tela & Médio Prejuízo & 28,0 & 6401,33 & \multirow{2}{*}{$1.756,96$} & & \\
\hline Com Seguro & Com Gerador de Solo & Com Tela & Grande Prejuízo & 15,0 & 6392,47 & & & \\
\hline
\end{tabular}

Quadro 9 - Resultados obtidos através do GranizoMGMT, aplicando-se valores médios coletados em questionário.

Fonte: Resultado da pesquisa. 
Nesses resultados (Quadro 11), a análise da viabilidade e eficiência das possíveis estratégias para a administração do risco das chuvas de granizo pode ser feita através da comparação entre os seus valores de "Receita Líquida Média (R $\$$ ha)" e "Desvio Padrão da Receita Líquida (R\$/ha)" (sétima coluna a partir da esquerda). A Receita Líquida Média ( $\mathrm{R} \$ / \mathrm{ha}$ ) é a média dos valores de "Possível Receita Líquida ( $\mathrm{R} / \mathrm{ha})$ " (sexta coluna a partir da esquerda) ponderada pelos valores de "Probabilidade do Prejuízo (\%)" (quinta coluna a partir da esquerda). O “Desvio Padrão da Receita Líquida (R $\$ / h a)$ ) é o desvio padrão calculado dos valores de "Possível Receita Líquida (R \$/ha)" (sexta coluna a partir da esquerda).

Utilizando para análise os valores médios coletados nos questionários obtivemos os seguintes resultados:

- As estratégias que apresentaram os maiores valores de "Receita Líquida Média (R\$/ha)", em ordem decrescente foram:

1. Sem Seguro - Sem Gerador de Solo - Com Tela

2. Com Seguro - Sem Gerador de Solo - Com Tela

3. Sem Seguro - Sem Gerador de Solo - Sem Tela

4. Com Seguro - Sem Gerador de Solo - Sem Tela

5. Sem Seguro - Com Gerador de Solo - Sem Tela

6. Sem Seguro - Com Gerador de Solo - Com Tela

7. Com Seguro - Com Gerador de Solo - Com Tela

8. Com Seguro - Com Gerador de Solo - Sem Tela

É interessante para os produtores de maçã que a estratégia adotada lhes ofereça uma alta "Receita Líquida Média (R\$/ha)", porém, em um processo de tomada de decisão, a minimização do risco através da diminuição da incerteza é fundamental. $O$ valor do "Desvio Padrão da Receita Líquida (R \$ha)" nos dá uma noção da dimensão dessa incerteza. 
- As estratégias que apresentaram os menores valores de "Desvio Padrão da Receita Líquida (R\$/ha)", em ordem crescente foram:

1. Com Seguro - Sem Gerador de Solo - Com Tela

2. Com Seguro - Com Gerador de Solo - Com Tela

3. Com Seguro - Sem Gerador de Solo - Sem Tela

4. Com Seguro - Com Gerador de Solo - Sem Tela

5. Sem Seguro - Sem Gerador de Solo - Com Tela

6. Sem Seguro - Com Gerador de Solo - Com Tela

7. Sem Seguro - Com Gerador de Solo - Sem Tela

8. Sem Seguro - Sem Gerador de Solo - Sem Tela

Pelos resultados obtidos, apresentados no Quadro 11, verifica-se que a opção pelo seguro agrícola, combinado ou não com outra alternativa de proteção faz com que se tenham os menores valores de "Desvio Padrão da Receita Líquida (R $\$ / h a) "$. Ao contrário do que ocorre ao adotar-se a estratégia de não fazer uso de nenhum sistema de proteção. Sendo que, quanto menor o valor do "Desvio Padrão da Receita Líquida (R\$/ha)", menor a variação da receita líquida do agricultor em relação à média das possíveis receitas líquidas, o seguro agrícola representa uma alternativa interessante para a estabilidade da receita líquida do produtor de maçãs ano a ano.

Nesse caso em particular, em que foram utilizados para cálculo os valores médios coletados através de questionário, a estratégia ideal seria aderir ao seguro agrícola, não fazer uso dos geradores de solo e cobrir parte (30\%) da área do pomar com telas antigranizo (lembrando que está sendo considerada "área segurada" somente a área não coberta com telas). Essa estratégia resultou em uma Receita Líquida Media de R \$12.900,90/ha e um Desvio Padrão da Receita Líquida de R\$1.661,26/ha. 


\section{CONCLUSÕES}

O gerenciamento do risco de chuvas de granizo em pomares de maçã exige conhecimentos multidisciplinares sobre a cultura da maçã. Esses conhecimentos são provenientes de áreas como agronomia, agrometeorologia, estatística, economia e administração, integrados neste trabalho através de técnicas de análise de decisões. $\mathrm{Na}$ atualidade, para os produtores de maçã de São Joaquim e Fraiburgo, em Santa Catarina, especificamente, as chuvas de granizo constituem o problema com maior dificuldade de administração e controle.

$\mathrm{Na}$ metodologia adotada para o desenvolvimento deste trabalho, a aplicação de questionários teve grande importância para o entendimento mais aprofundado do problema das chuvas de granizo em pomares de maçã, assim como para a coleta de dados primários. Dados secundários podem apresentar distorções indesejáveis para um determinado tipo de análise. A coleta de informações com aquelas pessoas que enfrentam e convivem com o problema em estudo, de certa forma evitou que tivéssemos esse tipo de influência em nossa pesquisa.

Neste trabalho pudemos comprovar também que o diagrama de decisão é uma ferramenta útil para enxergarmos as relações qualitativas existentes entre as diversas variáveis envolvidas na administração de um problema, desde as alternativas existentes para o seu gerenciamento, as suas influências sobre o problema, até as possíveis conseqüências da escolha de uma determinada alternativa.

As alternativas para o gerenciamento do risco de chuvas de granizo levantadas neste trabalho através das revisões bibliográficas, pesquisas na internet e pesquisas de campo, apresentam impactos diferenciados sobre o evento climático em questão, 
mitigando ou transferindo esse risco para outros agentes do mercado. Entre essas alternativas, independentemente de apresentarem relações custo/benefício diferentes, todas elas (telas anti-granizo, geradores de solo, foguetes anti granizo, pulverização de nuvens com utilização de aviões, ondas de choque ionizadas, seguro agrícola e diversificação espacial) apresentam alguma efetividade na minimização dos prejuízos causados pelas chuvas de granizo. No estudo realizado, verificou-se que essas alternativas podem ser adotadas de maneira isolada ou combinadas, individualmente ou em grupo, o que dá aos fruticultores um maior número de opções no momento da elaboração de suas estratégias para a administração desse risco. A adoção de um determinado sistema para proteção do pomar e, conseqüentemente de sua receita, depende, basicamente, da aversão do produtor de maçãs ao risco e, da sua disponibilidade de capital para investimento.

Existe, entre os fruticultores, além da preocupação com a sua receita na safra, também a preocupação com a garantia de maçãs de qualidade para comercialização e consequiente fidelidade de clientes. Verificamos no trabalho que esse fato faz com que alternativas que se baseiam na mitigação do risco do granizo, como as telas anti granizo e os geradores de solo, tenham, maior preferência sobre o seguro agrícola (alternativa baseada na transferência do risco) que, apesar de garantir a receita do produtor, não garante frutas de qualidade no final da safra.

No Brasil, as alternativas que já foram utilizadas ou que vêm sendo adotadas para a administração do risco das chuvas de granizo em pomares de maçã são: coberturas de telas anti-granizo, os geradores de solo e os foguetes anti-granizo baseados na utilização do iodeto de prata, seguro agrícola e, diversificação espacial. Não existem, no Brasil, relatos da utilização de aviões para a pulverização de iodeto de prata nas nuvens potencialmente causadoras de granizo nem da utilização de sistemas baseados na emissão de ondas de choque ionizadas.

$\mathrm{Na}$ análise realizada, a cobertura de telas anti-granizo constitui a possibilidade da oferta de frutos de qualidade ao final da safra, porém, a custos elevados, e com efeitos de longo prazo (sombreamento) sobre as macieiras não totalmente conhecidos. Tanto em São Joaquim quanto em Fraiburgo alguns produtores vêm adotando esta alternativa por 
considerá- la a mais efetiva na garantia da receita na safra.

O sistema de geradores de solo tem considerável efetividade na redução da freqüência e intensidade do granizo, porém, apresenta custo elevado para implantação e manutenção, assim como dificuldades para seu gerenciamento, que demanda um esforço cooperativo dos produtores. O modelo mais apropriado para a gestão dessa alternativa não é claro para pequenos e médios produtores. Em Fraiburgo, onde predominam as grandes empresas produtoras, os geradores de solo vêm sendo utilizados desde 1996. Em São Joaquim, o predomínio de pequenos e médios produtores dificulta a organização de grupos e, por esse motivo, essa alternativa, até o momento, não foi adotada.

As experiências realizadas no passado, nas regiões produtoras de maçã de SC, na tentativa de minimizar os prejuízos causados pelas chuvas de granizo através do lançamento de foguetes anti-granizo não apresentaram resultados satisfatórios por problemas técnicos e devido ao alto custo dos equipamentos. Atualmente, com as novas gerações de foguetes anti-granizo e aprimoramento desta tecnologia, a realização de novos testes com o sistema pode ser interessante para os fruticultores dessas regiões.

Quanto ao seguro agrícola, mesmo sendo atrativo por garantir parte da receita do agricultor na safra, não reduz as consequiências físicas do fenômeno sobre a qualidade e quantidade das frutas, o que pode influenciar negativamente no cumprimento de contratos comerciais pelas cooperativas, empresas ou produtores individuais. Além disso, o seguro atualmente disponível não protege o produtor contra os prejuízos de longo prazo.

O seguro agrícola, apesar de ser uma alternativa que dá ao produtor de maçãs, ano a ano, grande estabilidade em sua receita líquida, é uma alternativa considerada cara pelos produtores. Os seus valores de prêmio e franquia são considerados, pelos agricultores, muito altos frente a rentabilidade da cultura da maçã, e os benefícios oferecidos pelos seguros disponibilizados. Sendo que a pomicultura constitui importante fonte de renda para muitos pequenos produtores e, também, base da economia de muitos municípios dos Estados de SC e RS, verificourse, neste trabalho, um forte interesse por parte dos produtores de maior apoio governamental (políticas agrícolas, incentivos financeiros) no desenvolvimento de um seguro agrícola mais acessível. 
Uma alternativa importante na região estudada, levantada nas pesquisas de campo, não mencionada na literatura, é a diversificação espacial da produção, que é entendida pelos produtores como uma prática relativamente efetiva e bastante utilizada, tendo em vista as características espaciais da ocorrência do granizo. Apesar do gerenciamento de áreas não contíguas gerar um aumento no custo administrativo, dificilmente uma chuva de granizo atinge todas as áreas de um mesmo produtor.

O desenvolvimento de estratégias para a administração do risco de chuvas de granizo em pomares de maçã através do uso combinado de sistemas de proteção (geradores de solo e seguro agrícola; telas anti-granizo e diversificação espacial; entre outras combinações) não é simples e depende, além da probabilidade de ocorrência das chuvas de granizo naquele local, da eficiência de cada alternativa adotada, do capital que se pretende investir, da aversão ao risco do produtor de maçãs e de outros fatores particulares de cada uma das alternativas. O software GranizoMGMT (ANEXO D), desenvolvido com base no diagrama de decisão e nas pesquisas realizadas, possibilita a análise quantitativa das possíveis estratégias de gerenciamento do risco em estudo, seja essa estratégia baseada em um ou mais sistemas combinados.

Finalmente, a similaridade do problema do risco de granizo analisado no contexto de pomares de maçã com o risco que afeta outras culturas como uva, pêssego, nêspera, ameixa e pêra, sugere que modelo desenvolvido, assim como o software produzido, possam ser adaptados para utilização dentro do gerenciamento do granizo nessas culturas, com relativa facilidade. 
ANEXOS 
ANEXO A - Questionário: cooperativa de produtores de maçãs.

\author{
Universidade de São Paulo \\ Escola Superior de Agricultura "Luiz de Queiroz" \\ Departamento de Economia, Administração e Sociologia \\ Programa de Pós-Graduação em Economia Aplicada
}

Gestão do Risco de Granizo Através do Seguro Agrícola e Outras Alternativas: Modelo e Estudo de Caso para Pomares de Maçã em São Joaquim e Fraiburgo, SC.

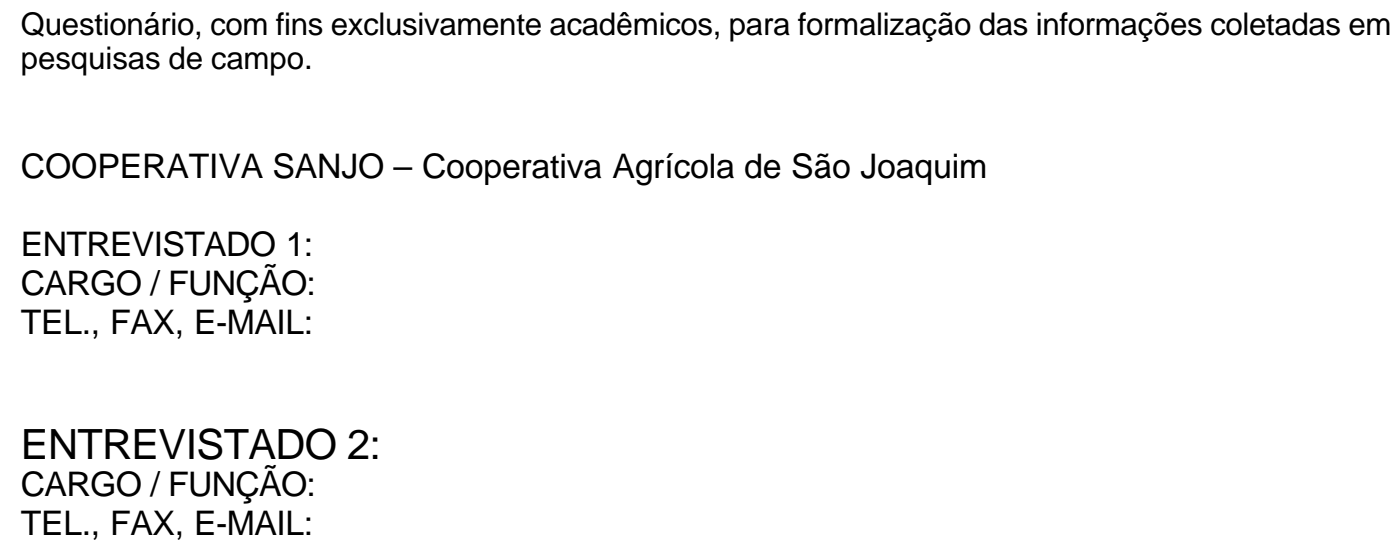

ALUNO: Henrique Massaru Yuri NÍVEL: Mestrado 
1. TELEFONE, FAX, E-MAIL E ENDEREÇO DA COOPERATIVA:

\begin{tabular}{|c|l|}
\hline TELEFONE & \\
\hline FAX & \\
\hline E-MAIL & \\
\hline HOME PAGE & \\
\hline & \\
ENDERECO & \\
& \\
\hline
\end{tabular}

2. HISTÓRIA DA COOPERATIVA: 
3. COMO FOI A EVOLUÇÃO DO NÚMERO DE COOPERADOS?

\begin{tabular}{|c|c|}
\hline SAFRA & NÚMERO DE COOPERADOS \\
\hline $1995 / 1996$ & \\
\hline $1996 / 1997$ & \\
\hline $1997 / 1998$ & \\
\hline $1998 / 1999$ & \\
\hline $1999 / 2000$ & \\
\hline $2000 / 2001$ & \\
\hline $2001 / 2002$ & \\
\hline $2002 / 2003$ (perpectivas) & \\
\hline
\end{tabular}

4. QUAL A ÁREA PLANTADA E EM PRODUÇÃO (ha) DOS COOPERADOS (passado e perspectivas, localização)?

\begin{tabular}{|c|c|c|c|}
\hline SAFRA & $\begin{array}{c}\text { ÁREA PLANTADA } \\
\text { (ha) }\end{array}$ & $\begin{array}{c}\text { ÁREA EM PRODUÇÃO } \\
\text { (ha) }\end{array}$ & $\begin{array}{c}\text { LOCALIZAÇÃO } \\
\text { PREDOMINANTE }\end{array}$ \\
\hline $1995 / 1996$ & & & \\
\hline $1996 / 1997$ & & & \\
\hline $1997 / 1998$ & & & \\
\hline $1998 / 1999$ & & & \\
\hline $1999 / 2000$ & & & \\
\hline $2000 / 2001$ & & & \\
\hline $2001 / 2002$ & & & \\
\hline $2002 / 2003$ & & & \\
\hline $2003 / 2004$ & & & \\
(perspectivas) & & & \\
\hline
\end{tabular}

5. QUAL O VOLUME TOTAL DA PRODUÇÃO (t e \%) DA COOPERATIVA (passado e perspectivas)?

\begin{tabular}{|c|c|c|c|c|c|c|c|c|c|c|}
\hline \multirow{4}{*}{ SAFRA } & \multicolumn{10}{|c|}{ VOLUME DA PRODUÇÃO DA COOPERATIVA ( $\mathrm{e}$ e \%) } \\
\hline & \multicolumn{2}{|c|}{ EXIRA } & \multicolumn{2}{|c|}{ CAI 1} & \multicolumn{2}{|c|}{ CAT2 } & \multicolumn{2}{|c|}{ CAI3 } & \multicolumn{2}{|c|}{ CAI 4} \\
\hline & $\mathrm{R} \$$ & & $\mathrm{R} \$$ & & $\mathrm{R} \$$ & & $\mathrm{R} \$$ & & $\mathrm{R} \$$ & \\
\hline & $\mathrm{t}$ & $\%$ & $\mathrm{t}$ & $\%$ & $\mathrm{t}$ & $\%$ & $\mathrm{t}$ & $\%$ & $\mathrm{t}$ & $\%$ \\
\hline 1995/1996 & & & & & & & & & & \\
\hline 1996/1997 & & & & & & & & & & \\
\hline $1997 / 1998$ & & & & & & & & & & \\
\hline 1998/1999 & & & & & & & & & & \\
\hline $1999 / 2000$ & & & & & & & & & & \\
\hline $2000 / 2001$ & & & & & & & & & & \\
\hline $2001 / 2002$ & & & & & & & & & & \\
\hline $2002 / 2003$ & & & & & & & & & & \\
\hline $\begin{array}{c}2003 / 2004 \\
\text { (perspectivas }\end{array}$ & & & & & & & & & & \\
\hline
\end{tabular}


6. QUAL A CAPACIDADE ATUAL DE ESTOCAGEM A FRIO DA COPERATIVA (novos projetos?)?

7. QUAIS OS PRINCIPAIS MERCADOS DA COOPERATIVA (interno e externo)? 
8. QUAL O DIFERENCIAL ESTRATÉGICO DA COOPERATIVA? 
9. COMO A COOPERATIVA VÊ O PROBLEMA DO GRANIZO? 
10. BREVE DESCRIÇÃO DO PROGRAMA DE FUNDO MÚTUO:

11. QUEM TROUXE A IDÉIA PARA A COOPERATIVA? ESSA PESSOA BASEOU-SE EM EXPERIÊNCIAS DE OUTRAS ASSOCIAÇÕES / COOPERATIVAS? 
12. COMO FOI O HISTÓRICO DO FUNDO MÚTUO NA COOPERATIVA?

BALANÇO DO FUNDO

\begin{tabular}{|c|c|c|c|c|c|}
\hline \multicolumn{6}{|c|}{ BALANÇO DO FUNDO } \\
\hline SAFRA & INICIAL & $\begin{array}{c}\text { PREMIOS } \\
\text { RECEBIDOS }\end{array}$ & INDENIZAÇÕES & $\begin{array}{l}\text { RECEITAS DE } \\
\text { APLICAÇÕES }\end{array}$ & $\begin{array}{l}\text { SALDO } \\
\text { FINAL }\end{array}$ \\
\hline & & & & & \\
\hline & & & & & \\
\hline & & & & & \\
\hline & & & & & \\
\hline & & & & & \\
\hline & & & & & \\
\hline & & & & & \\
\hline & & & & & \\
\hline & & & & & \\
\hline & & & & & \\
\hline & & & & & \\
\hline
\end{tabular}


13. SABENDO-SE QUE EXISTIRAM SAFRAS EM QUE O PROGRAMA DE FUNDO MÚTUO FOI DESATIVADO, POR QUE HOUVE ESSA DESATIVAÇÃO?

14. POR QUE O PROGRAMA DE FUNDO MÚTUO FOI REATIVADO? 
15. TODOS OS COOPERADOS PARTICIPAM DO PROGRAMA DE FUNDO MÚTUO? SE NÃO, POR QUÊ? QUANTOS PARTICIPAM? 
16. QUAIS OS VALORES PAGOS, AO LONGO DO TEMPO, COMO PRÊMIO PARA TER DIREITO DE PARTICIPAÇÃO NO PROGRAMA DE FUNDO MÚTUO?

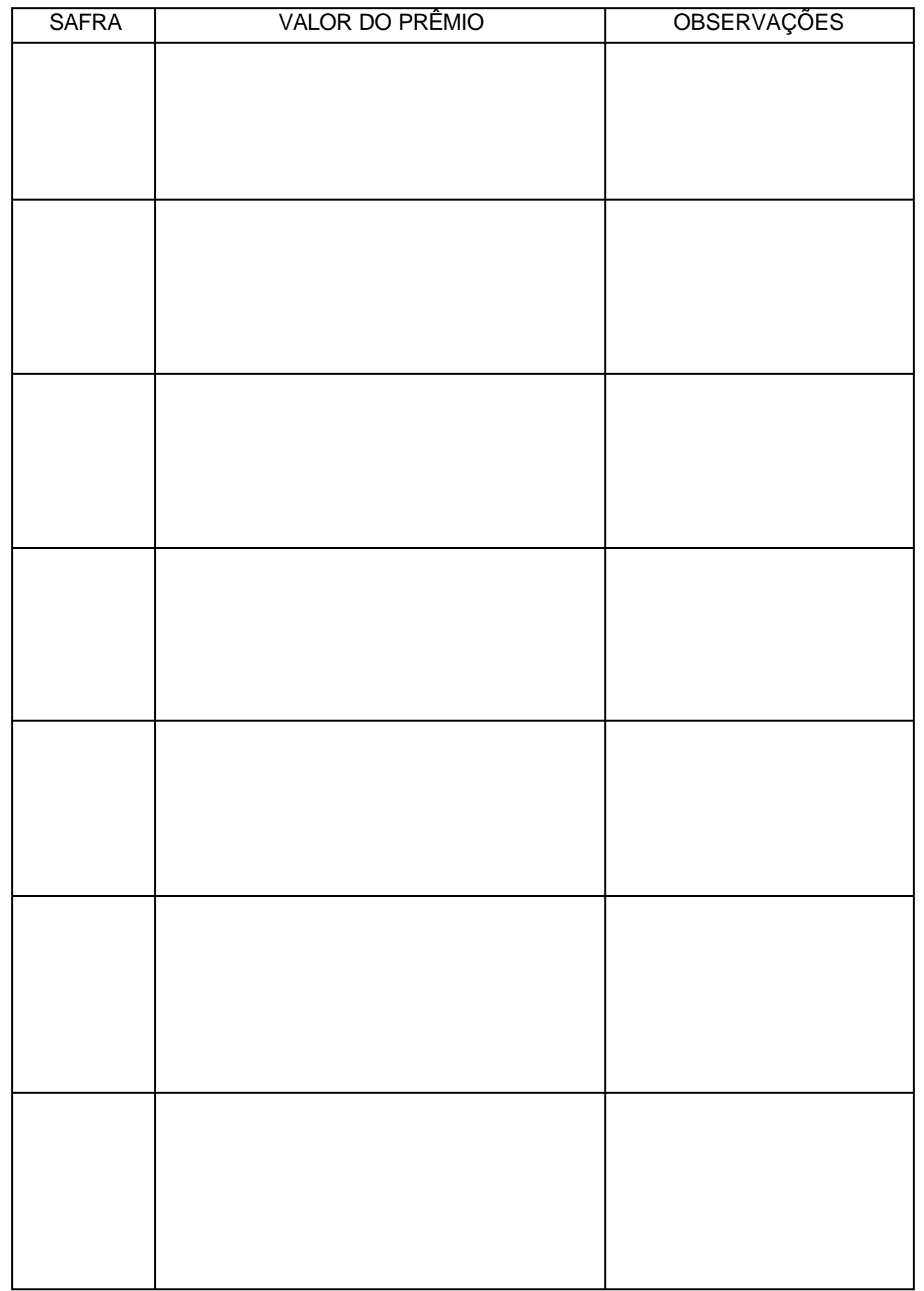


78

17. EM CASO DE SINISTRO, COMO E POR QUEM (FORAM) SÃO REALIZADOS OS LAUDOS / VISTORIAS PARA A AVALIAÇÃO DOS PREJUÍZOS?

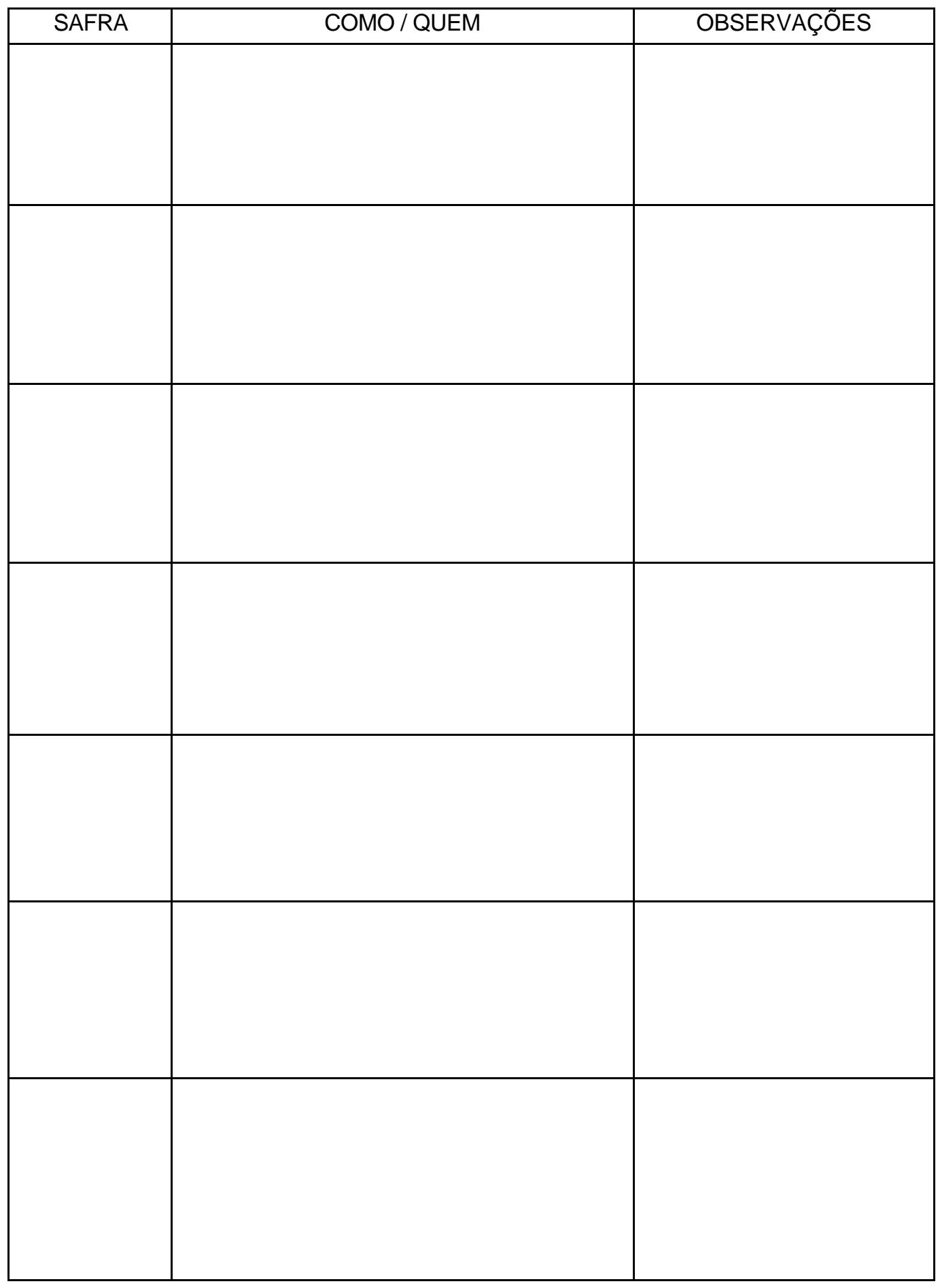


18. COMO (FORAM) SÃO CALCULADAS AS INDENIZAÇÕES? EXISTIU OU EXISTE FRANQUIA A SER DESCONTADA?

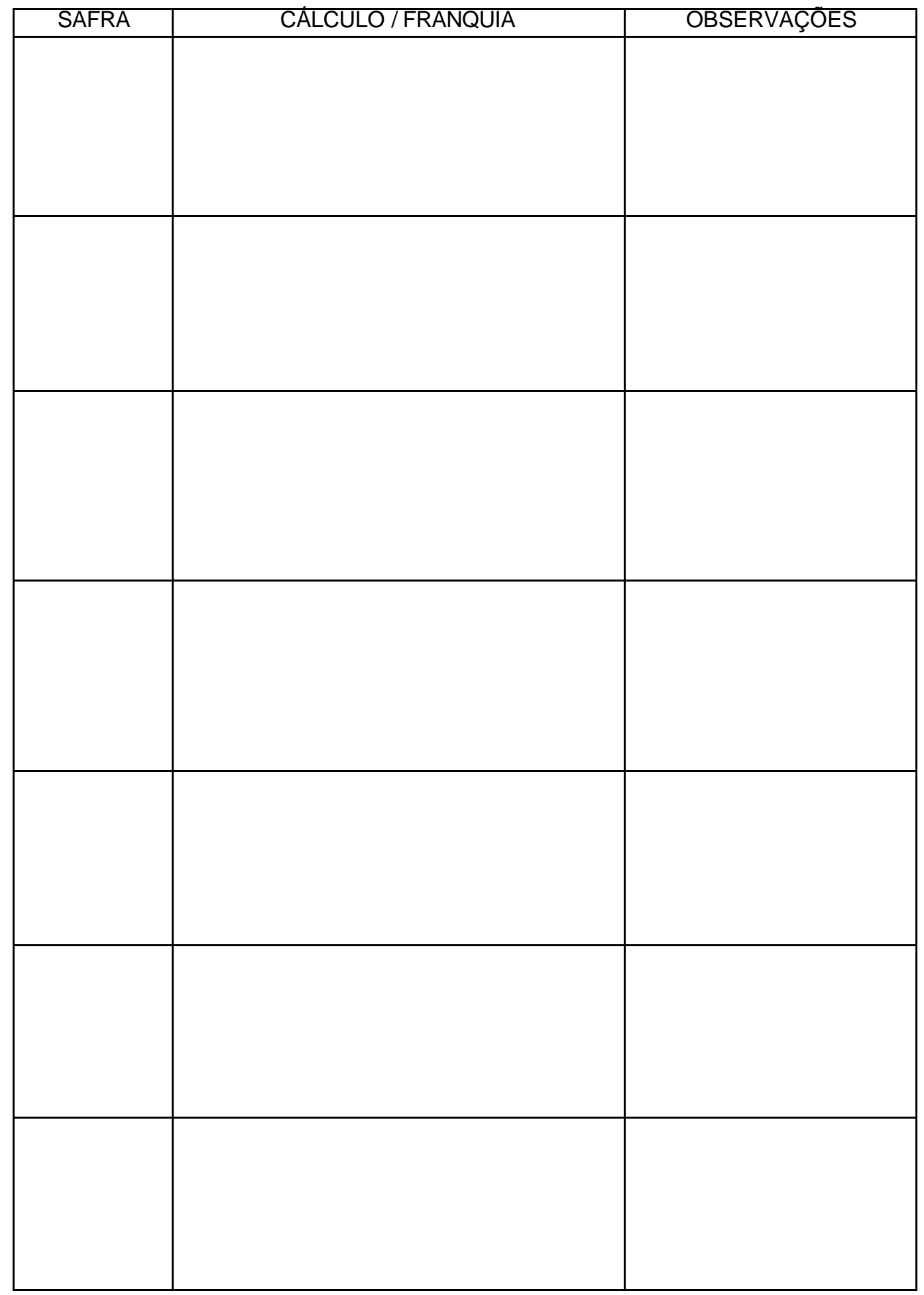


19. COMO FOI, PARA A COOPERATIVA, O HISTÓRICO DOS PREJUÍZOS CAUSADOS PELO GRANIZO? (Todos os cooperados participavam do Fundo Mútuo?)

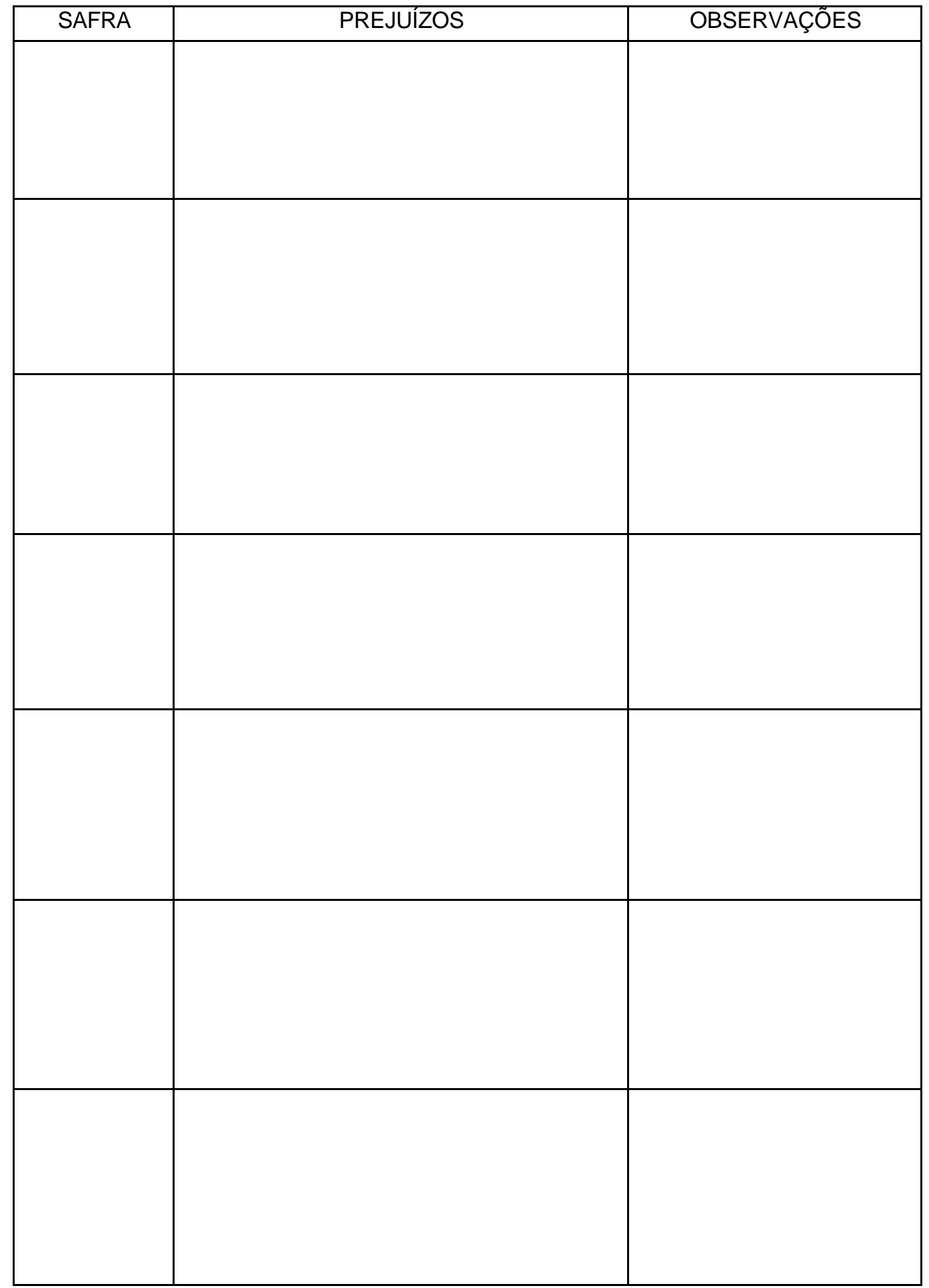


20. COMO FOI O HISTÓ RICO DAS INDENIZAÇÕES PAGAS PELO FUNDO MÚTUO?

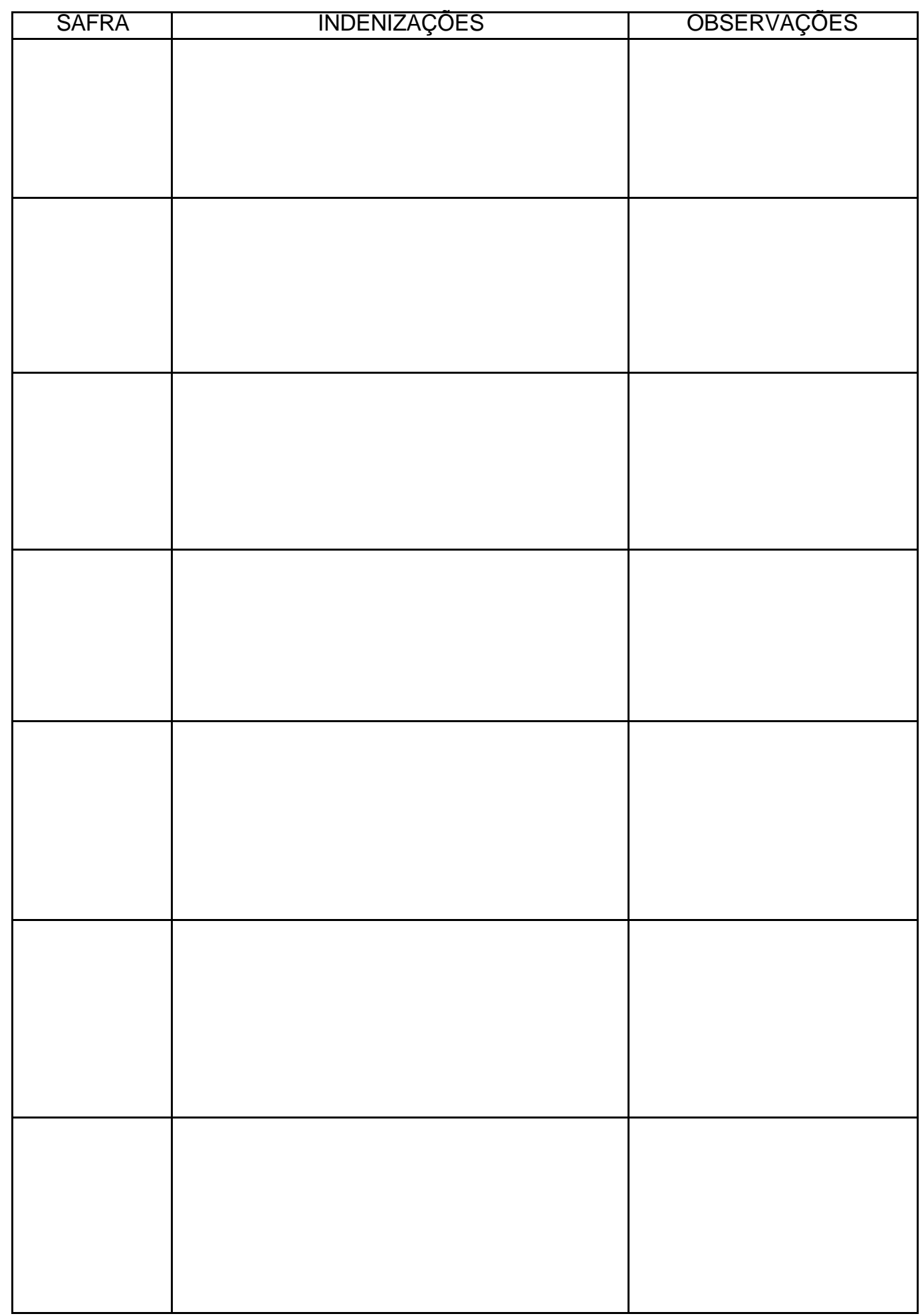


21. EM QUE SAFRA OCORRERAM OS MAIORES PREJUÍZOS CAUSADOS PELO GRANIZO? NESSA SAFRA EXISTIA O FUNDO MÚTUO?

22. COM RELAÇÃO Á PERGUNTA ANTERIOR, DE QUANTO FOI O PREJUÍZO (\%) PARA A COOPERATIVA COM RELAÇÃO AO VOLUME PRODUZIDO OU COM RELAÇÃO À SUA RECEITA?

\begin{tabular}{|l|l|l|}
\hline SAFRA & PREJUÍZO (volume produzido) & PREJUÍZO (receita da cooperativa) \\
\hline & & \\
\hline & & \\
\hline & & \\
\hline & & \\
\hline
\end{tabular}

23. NA SAFRA EM QUE OCORRERAM OS MAIORES PREJUÍZOS CAUSADOS PELO GRANIZO, O CAPITAL QUE EXISTIA NO FUNDO MÚTUO FOI SUFICIENTE PARA A INDENIZAÇÃO DE TODOS OS PARTICIPANTES CUJAS ÁREAS DE PRODUÇÃO FORAM ATINGIDAS E O NÍVEL DE PREJUIIZO FOI SIGNIFICATIVO? 
24. CASO VENHAM A OCORRER NOVAMENTE GRANDES PREJUÍZOS (COMO O DA SAFRA CITADA ANTERIORMENTE), O FUNDO MÚTUO, ATUALMENTE, TERIA CAPITAL SUFICIENTE PARA AS INDENIZAÇÕES?

25. CASO VENHA A OCORRER UM GRANIZO GENERALIZADO, QUE ATINJA GRANDE PARTE DOS COOPERADOS, E O CAPITAL EXISTENTE NO FUNDO MÚTUO NÃO SEJA SUFICIENTE PARA A TOTALIDADE DAS INDENIZAÇÕES, EXISTE ALGUM TIPO DE RESSEGURO? 
26. ALÉM DO FUNDO MÚTUO, DENTRO DA COOPERATIVA EXISTE ALGUM OUTRO PROGRAMA QUE VISA O AUXÍLIO DE SEUS COOPERADOS EM CASO DE PREJUÍZOS CAUSADOS PELO GRANIZO? 
27. COMO A COOPERATIVA ENXERGA AS SEGUINTES ALTERNATIVAS?

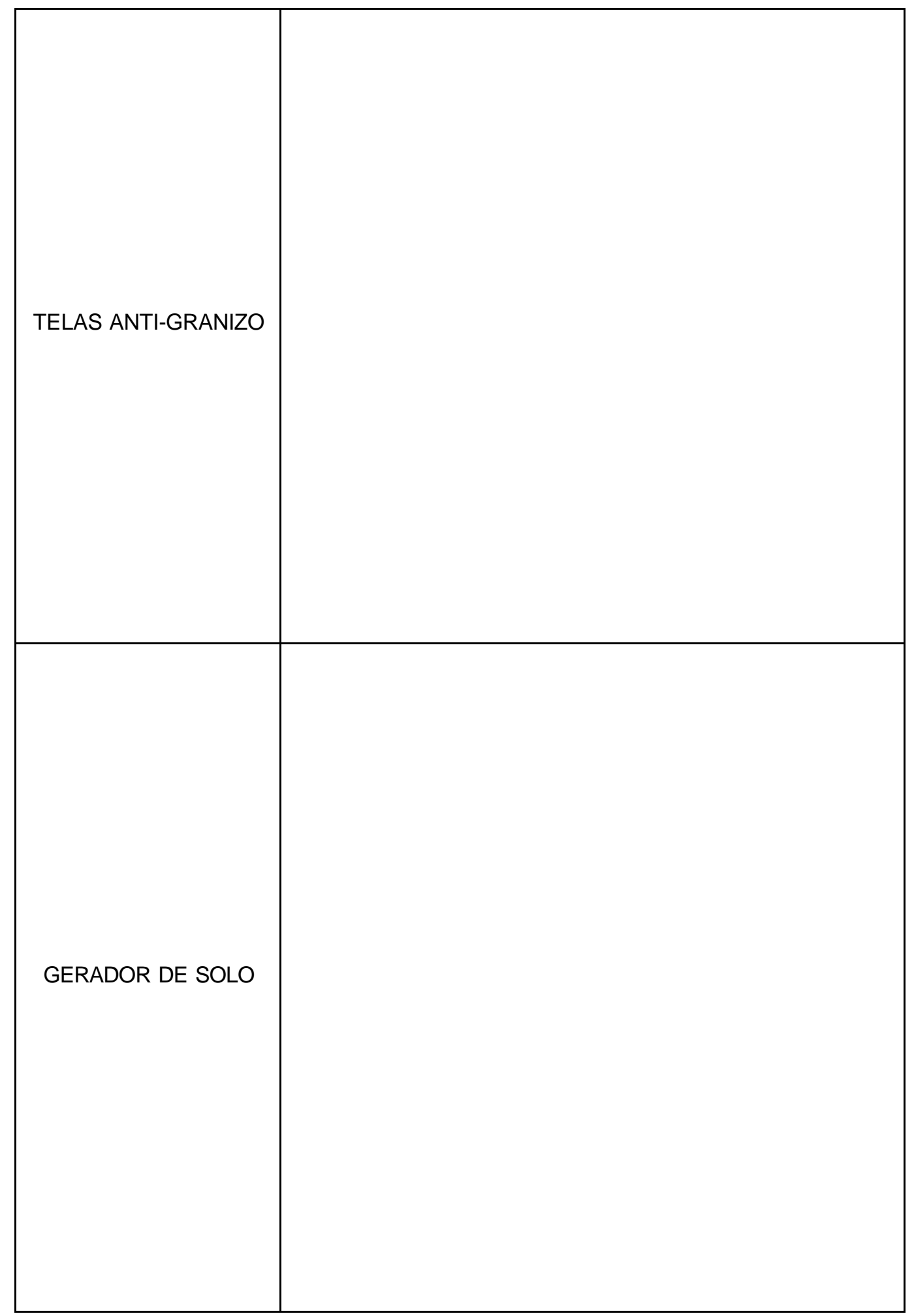




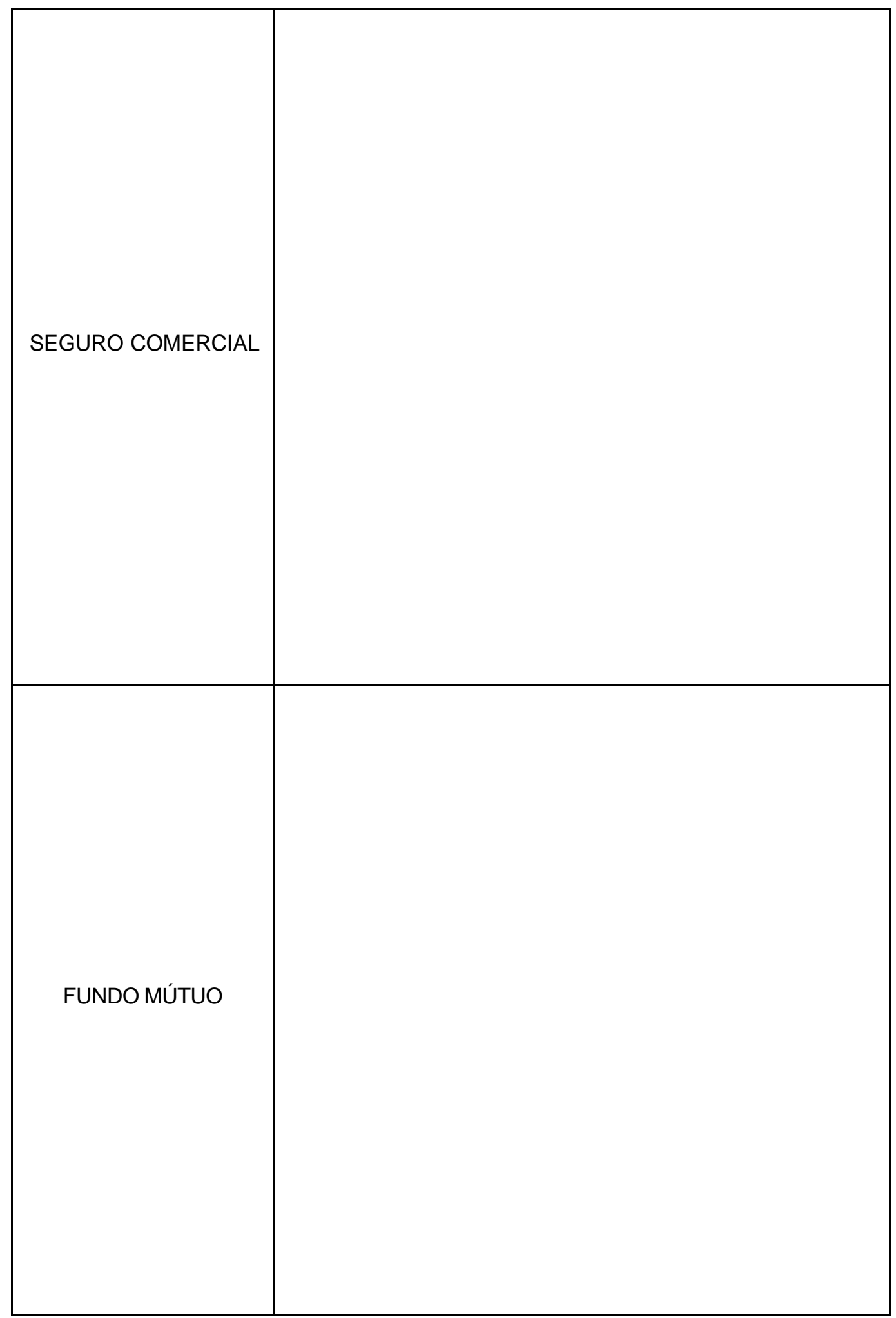




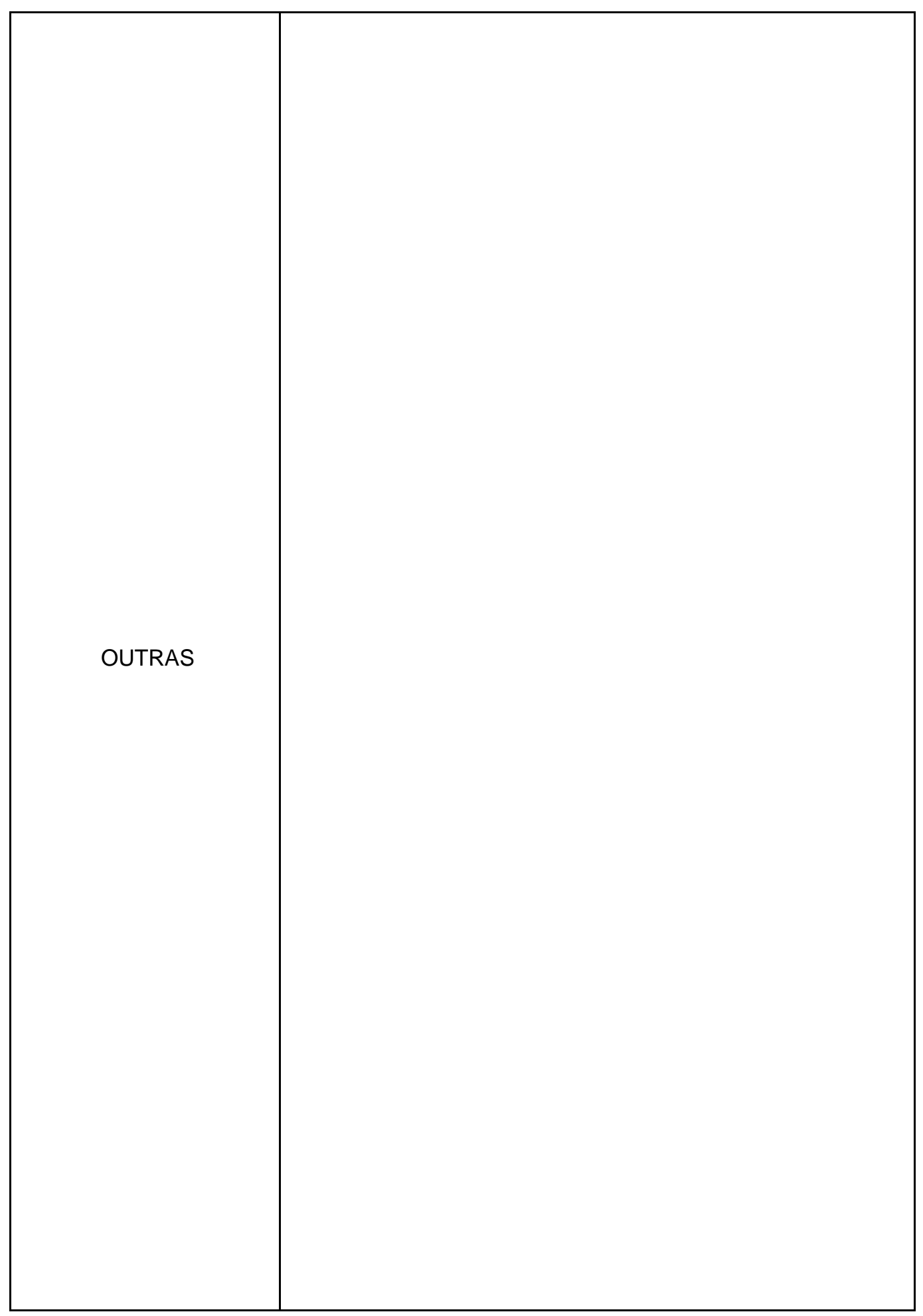


28. PARA A COOPERATIVA, EXISTE UMA ALTERNATIVA PREFERENCIAL PARA A ADMINISTRAÇÃO DOS RISCOS DE GRANIZO? CADA COOPERADO INDIVIDUALMENTE PODE ADOTAR A ALTERNATIVA QUE MELHOR LHE CONVIER? 
29. COMO A COOPERATIVA VÊ O PROBLEMA DA FALTA DE MAÇÃS PARA O CUMPRIMENTO DE CONTRATOS EM SAFRAS EM QUE OCORREM GRANIZOS?

30. A COOPERATIVA CONHECE ALGUMA OUTRA ALTERNATIVA PARA A ADMINISTRAÇÃO (MITIGAÇÃO OU TRANSFERÊNCIA) DO RISCO DAS CHUVAS DE GRANIZO ALÊM DAS QUAIS JÁ ESTÃO SENDO ABORDADAS NESTE TRABALHO? 
31. OUTROS COMENTÁRIOS QUE CONSIDERE RELEVANTES PARA O TRABALHO: 
ANEXO B - Questionário: empresa prestadora de serviços em meteorologia agrícola.

\author{
Universidade de São Paulo \\ Escola Superior de Agricultura "Luiz de Queiroz" \\ Departamento de Economia, Administração e Sociologia \\ Programa de Pós-Graduação em Economia Aplicada
}

$\underline{\text { Gestão do Risco de Granizo Através do Seguro Agrícola e }}$ Outras Alternativas: Modelo e Estudo de Caso para Pomares de Maçã em São Joaquim e Fraiburgo, SC.

Questionário, com fins exclusivamente acadêmicos, para formalização das informações coletadas em pesquisas de campo.

ENTREVISTADO:

CARGO / FUNÇÃO:

DATA DA ENTREVISTA:

ALUNO: Henrique Massaru Yuri

NÍVEL: Mestrado

Piracicaba - SP

Outubro/2002 
1. NOME COMPLETO DO ENTREVISTADO:

2. PAÍS, ESTADO OU CIDADE DE ORIGEM:

3. PROFISSÃO:

4. FORMAÇÃO UNIVERSITÁRIA:

5. TEMPO NA ATIVIDADE AGRÍCOLA:

6. TEMPO DE TRABALHO COM A CULTURA DA MAÇÃ:

7. OUTRAS CULTURAS COM A QUAL JÁ TRABALHOU:

8. NOME DA EMPRESA:

9. TELEFONE, FAX E E-MAIL PARA CONTATO:

\begin{tabular}{|c|l|}
\hline TELEFONE & \\
\hline FAX & \\
\hline E-MAlL & \\
\hline
\end{tabular}

10. LOCALIZAÇÃO DA EMPRESA (sede, filiais):

\begin{tabular}{|c|c|c|c|}
\hline & ENDEREÇO & LATITUDE & LONGITUDE \\
\hline SEDE & & & \\
\hline FILIAL 1 & & & \\
\hline FILIAL 2 & & & \\
\hline
\end{tabular}


11. HISTÓRIA DA EMPRESA: 
12. COM RELAÇÃO AO FENÔMENO METEOROLÓGICO "GRANIZO”:

a. DE QUANTAS MANEIRAS PODEM OCORRER A FORMACX̃O DO GRANIZO NA ATMOSFERA? O RELEVO E A ALTITUDE DA REGIÃO PODEM INFLUENCIAR NESSES PROCESSOS?

b. EM SÃO JOAQUIM E FRAIBURGO, A FORMAÇÃO DO GRANIZO SE DÁ DA MESMA MANEIRA? SERIA POSSÍVEL IDENTIFICAR QUAIS OS PROCESSOS DE FORMAÇÃO DO GRANIZO QUE PRODOMINAM EM CADA UM DESSES MUNICÍPIOS? 
c. O GRANIZO SOFRE INFLUENCIA DO FENÔMENO EL NIÑO?

13. QUAL A SUA PERCEPÇÃO COM RELAÇÀO À PROBABILIDADE DE OCORRÊNCIA EM UMA SAFRA, DAS DIFERENTES INTENSIDADES DE PREJUÍZOS CAUSADOS PELO GRANIZO (em \%)?

\begin{tabular}{|c|c|c|c|}
\hline $\begin{array}{c}\text { PEQUENO } \\
\text { PREJUÍZO } \\
\text { (Granizo Fraco) }\end{array}$ & $\begin{array}{c}\text { PREJUÍZO MÉDIO } \\
\text { (Granizo Médio) }\end{array}$ & $\begin{array}{c}\text { GRANDE } \\
\text { PREJUÍZO } \\
\text { (Granizo Forte) }\end{array}$ & $\begin{array}{c}\text { SEM PREJUÍZO } \\
\text { (Sem Granizo) }\end{array}$ \\
\hline & & & \\
\hline
\end{tabular}

14. COM RELAÇÃO AO SISTEMA DE GERADORES DE SOLO:

a. QUAIS OS REAIS BENEFÍCIOS DOS GERADORES DE SOLO? 
b. EM QUANTO, EM MÉDIA, VOCÊ ACREDITA QUE O SISTEMA DE GERADORES DE SOLO PODE DIMINUIR A OCORRENNCIA E INTENSIDADE DO GRANIZO EM POR CONSEQÜÊNCIA OS PREJUIIZOS DOS AGRICULTORES?

c. A EFICIÊNCIA DO SISTEMA DE GERADORES DE SOLO DEPENDE DO PROCESSO FORMADOR DO GRANIZO NA ATMOSFERA? 
d. O RELEVO E A ALTITUDE DA REGIÃO ONDE SÃO INSTALADOS OS GERADORES DE SOLO INFLUENCIAM NA EFICIÊNCIA DO SISTEMA?

e. COMO É O RELEVO NAS OUTRAS REGIÕES DO MUNDO ONDE O SISTEMA DE GERADORES DE SOLO É UTILIZADO NA ADMINISTRAÇÃO DOS RISCOS DE GRANIZO?

f. O RELEVO DE SÃO JOAQUIM PERMITE A INSTALAÇÃO E TRABALHO COM O SISTEMA DE GERADORES DE SOLO? 
g. PARA SÃO JOAQUIM, QUAL SERIA O CUSTO APROXIMADO DE IMPLANTAÇÃO DO SISTEMA DE GERADORES DE SOLO?

h. PARA SÃO JOAQUIM, QUAL SERIAO CUSTO DE MANUTENÇÃO DO SISTEMA DE GERADORES DE SOLO? 
i. EM SÃO JOAQUIM, QUEM PODERIA ADMINISTRAR O SISTEMA DE GERADORES DE SOLO? QUANTAS PESSOAS SERIAM NECESSÁRIAS?

j. EM SÃO JOAQUIM, COMO SERIA ADMINISTRADO ESSE SISTEMA (divisão dos custos, operadores dos equipamentos, manutenção, fornecimento de materiais...)? 
15. COMO VOCÊ, PESSOALMENTE, ENXERGA AS SEGUINTES ALTERNATIVAS?

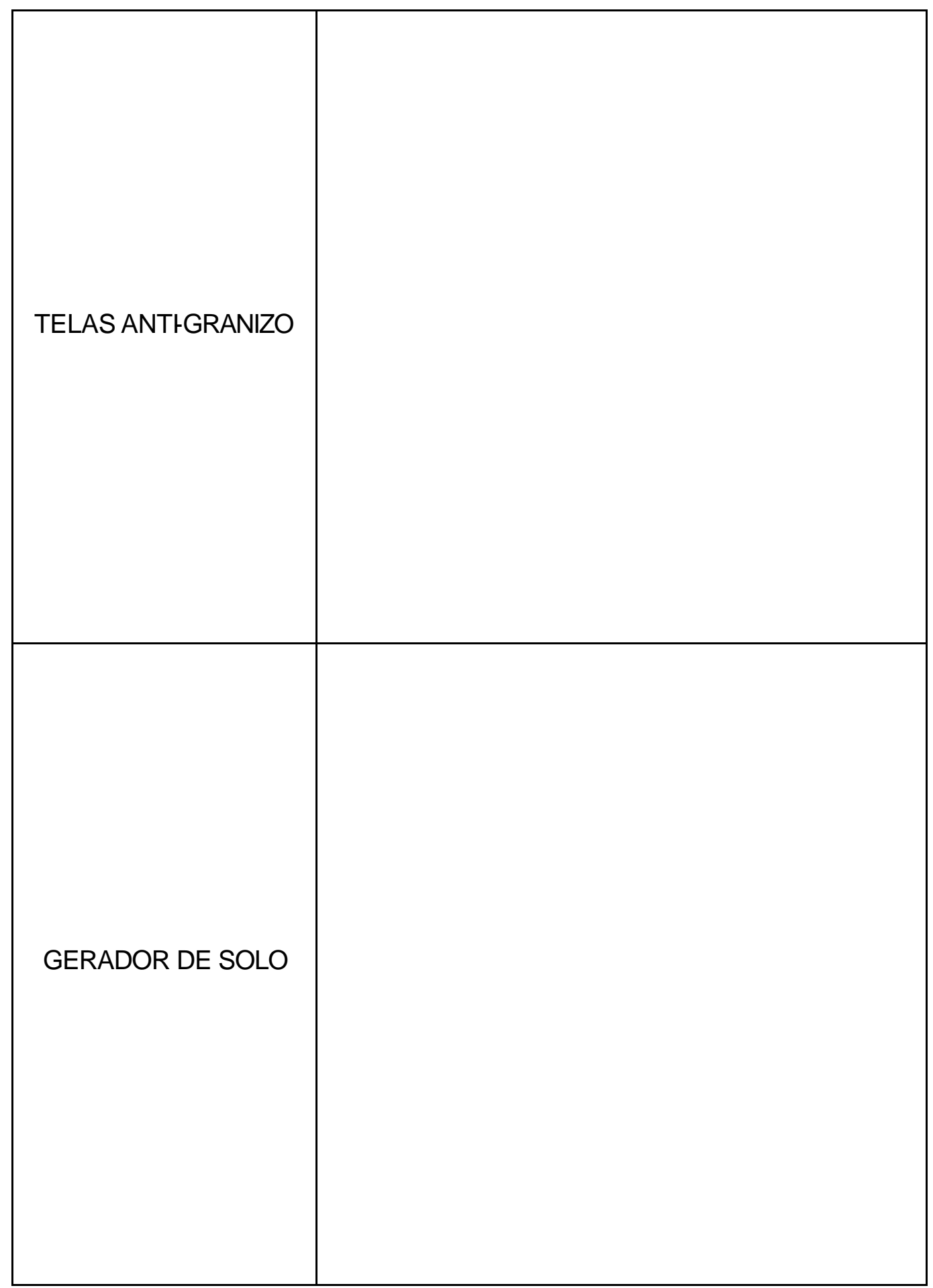




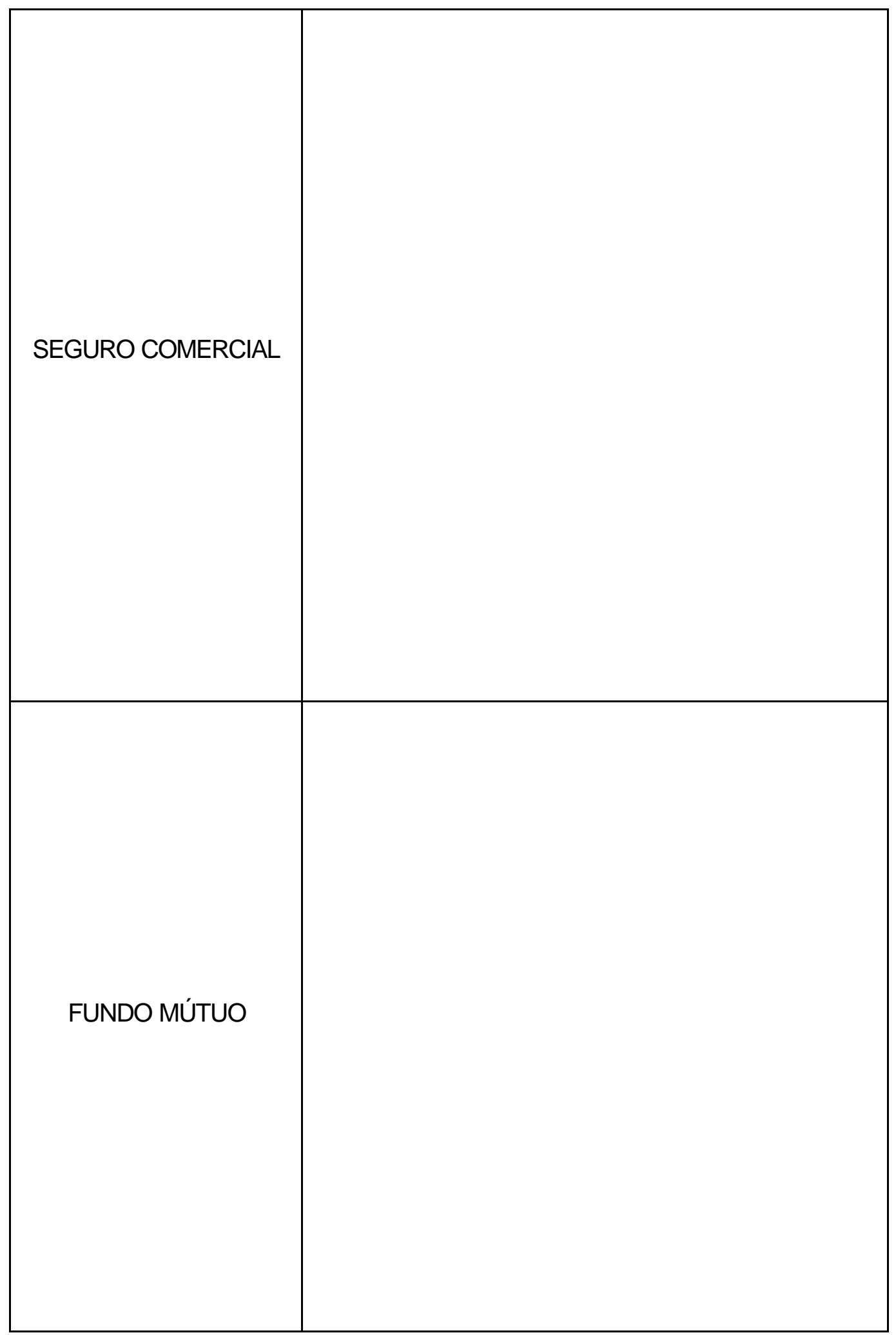




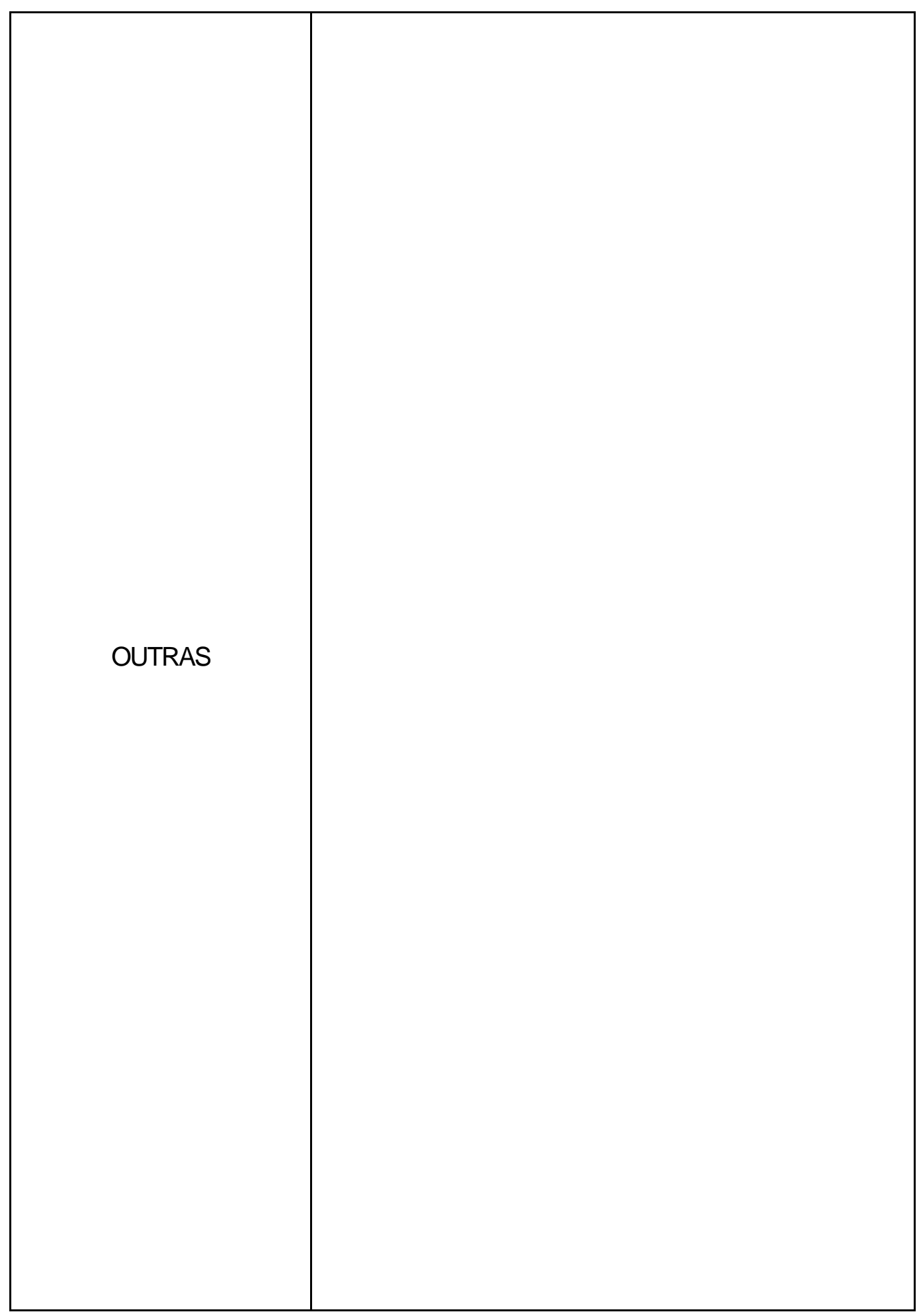


16. CONHECE ALGUMA OUTRA ALTERNATIVA PARA A ADMINISTRAÇÃO (MITIGAÇÃO OU TRANSFERÊNCIA) DO RISCO DAS CHUVAS DE GRANIZO ALÉM DAS QUAIS JÁ ESTÃO SENDO ABORDADAS NESTE TRABALHO? 
17. DO SEU PONTO DE VISTA PARTICULAR, EM QUANTO ACREDITA QUE SEJA A PROBABILIDADE DE OCORRÊNCIA DO GRANIZO E A FAIXA DE PREJUÍZO POR ELE CAUSADO, DE ACORDO COM A FASE DE DESENVOLVIMENTO DAS MAÇÃS?

SÃO JOAQUIM - SEM GERADOR DE SOLO

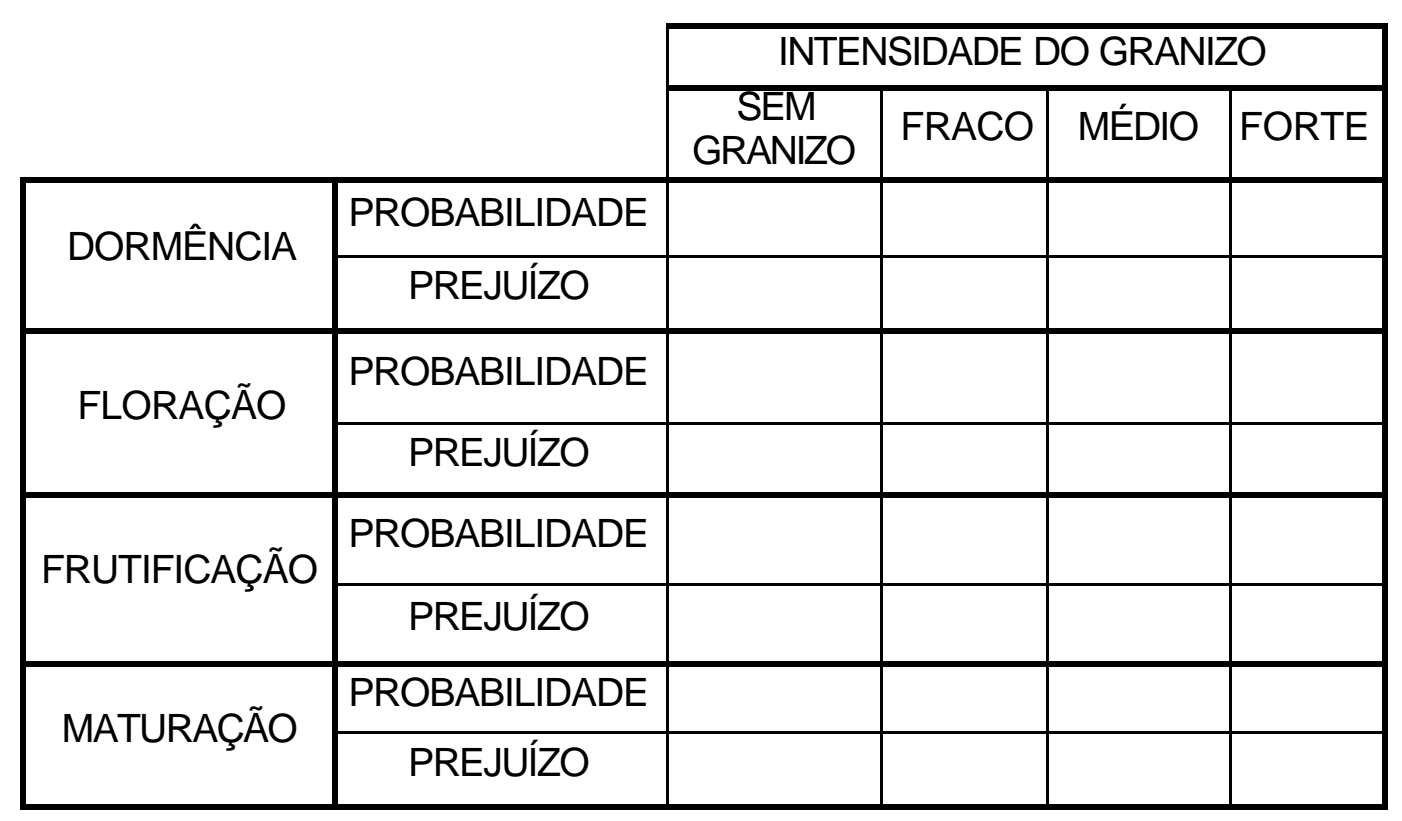

SÃO JOAQUIM - COM GERADOR DE SOLO

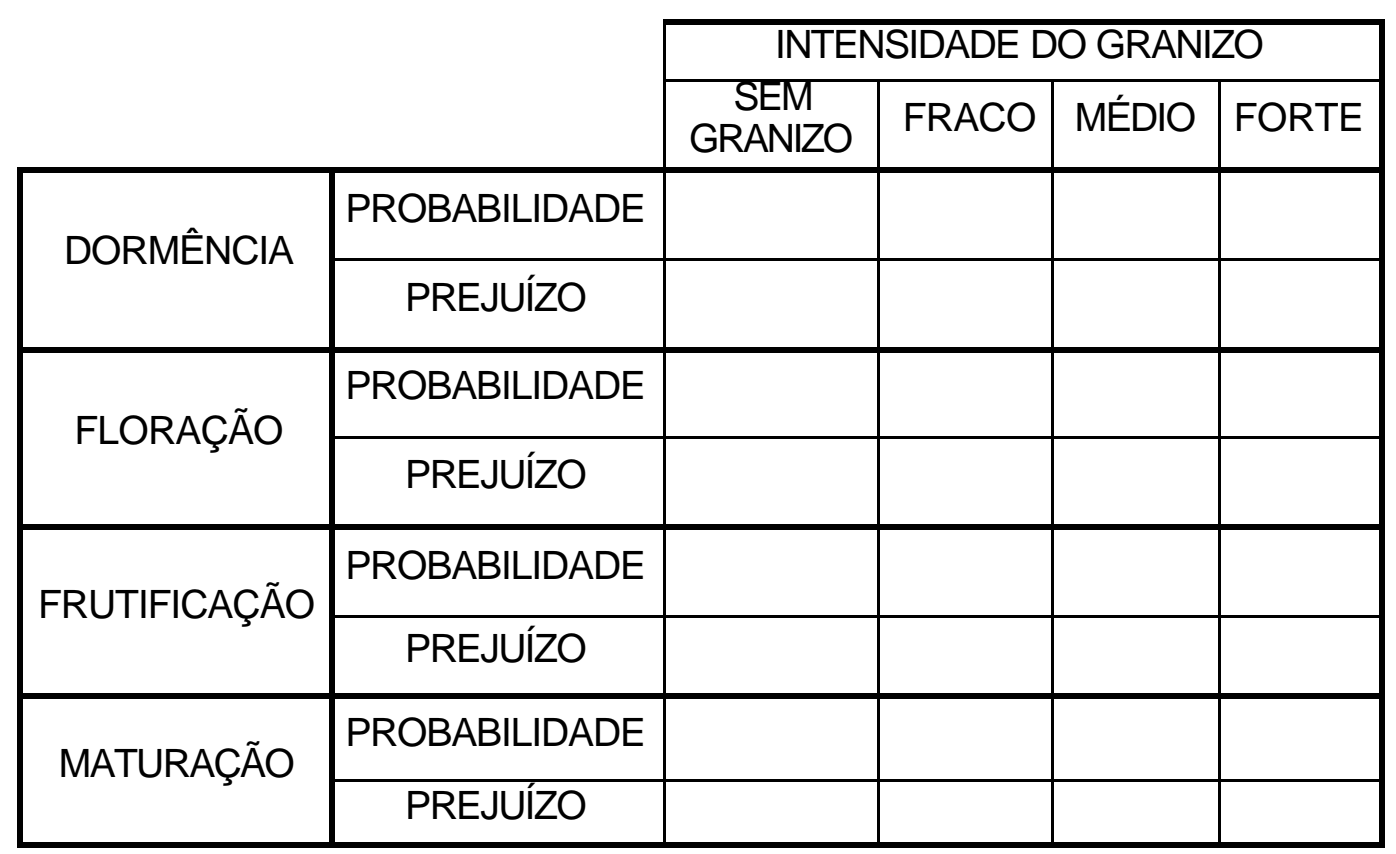


FRAIBURGO - SEM GERADOR DE SOLO

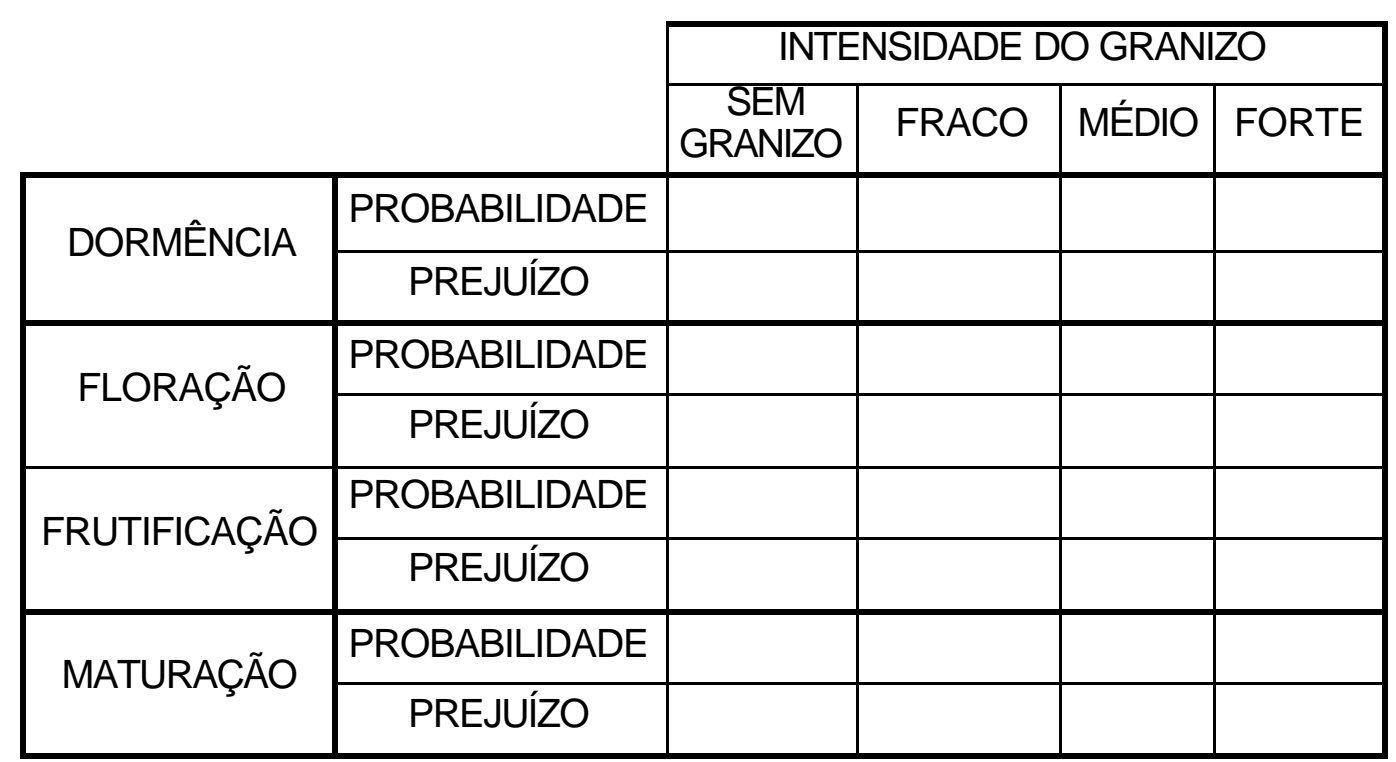

FRAIBURGO - COM GERADOR DE SOLO

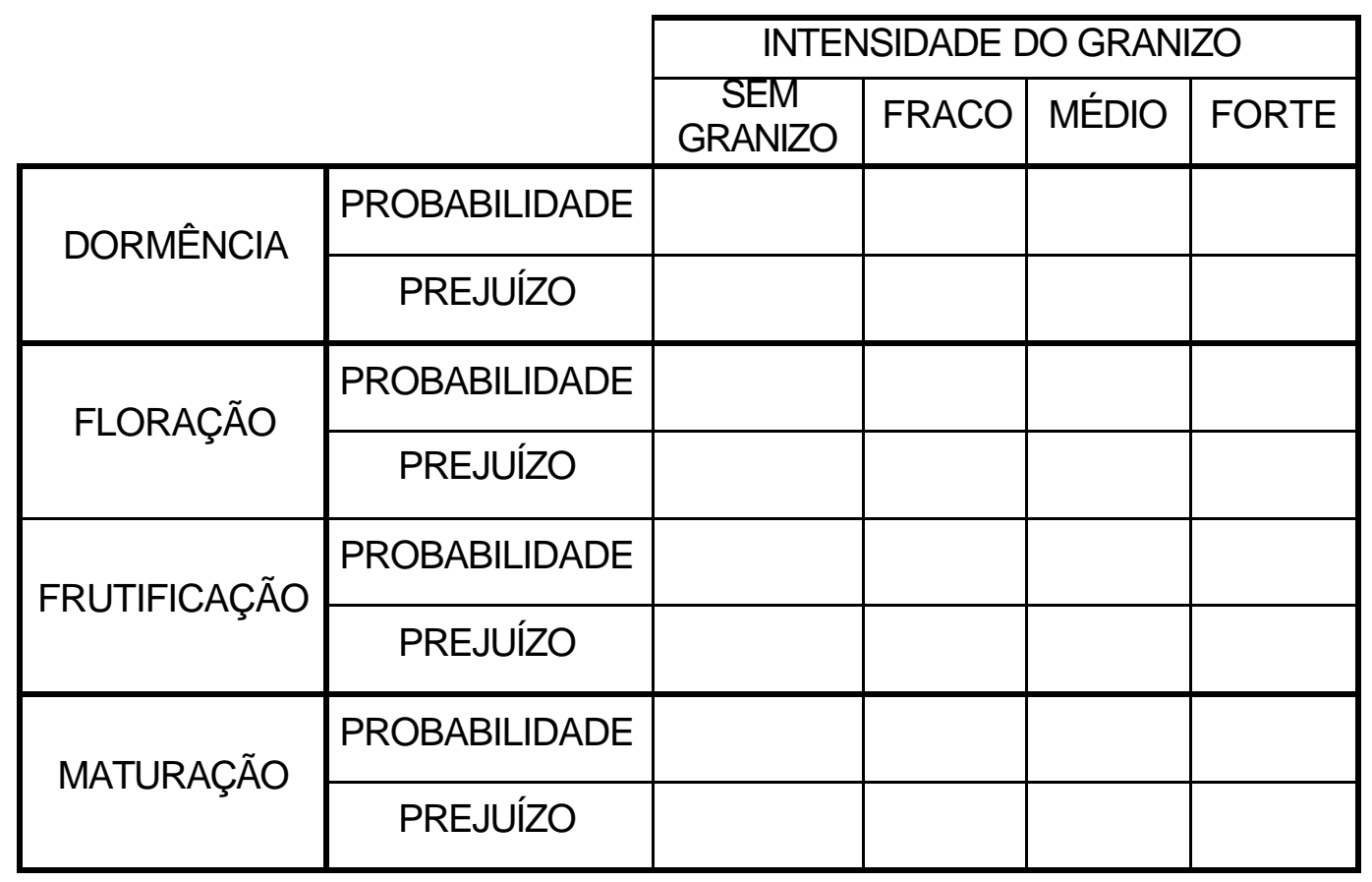


18. OUTROS COMENTÁRIOS QUE CONSIDERE RELEVANTES PARA O TRABALHO: 
ANEXO C - Questionário: produtor de maçãs.

\author{
Universidade de São Paulo \\ Escola Superior de Agricultura "Luiz de Queiroz" \\ Departamento de Economia, Administração e Sociologia \\ Programa de Pós-Graduação em Economia Aplicada
}

\title{
Gestão do Risco de Granizo Através do Seguro Agrícola e Outras Alternativas: Modelo e Estudo de Caso para Pomares de Maçã em São Joaquim e Fraiburgo, SC.
} Questionário, com fins exclusivamente acadêmicos, para formalização das informações coletadas em
pesquisas de campo.

ENTREVISTADO:

DATA DA ENTREVISTA:

ALUNO: Henrique Massaru Yuri NÍVEL: Mestrado 
1. NOME COMPLETO DO ENTREVISTADO:

2. TELEFONE, FAX E E-MAIL PARA CONTATO:

\begin{tabular}{|c|l|}
\hline TELEFONE & \\
\hline FAX & \\
\hline E-MAIL & \\
\hline ENDEREÇO & \\
\hline
\end{tabular}

3. PAÍS, ESTADO OU CIDADE DE ORIGEM:

4. PROFISSÃO:

5. FORMAÇÃO UNIVERSITÁRIA:

6. TEMPO NA ATIVIDADE AGRÍCOLA:

7. TEMPO DE TRABALHO COM A CULTURA DA MAÇÃ:

8. OUTRAS CULTURAS COM A QUAL JÁ TRABALHOU:

9. LOCALIZAÇÃO DOS POMARES:

\begin{tabular}{|c|l|l|l|l|}
\hline & ENDEREÇO & $\begin{array}{c}\text { ÁREA/N } \\
\text { ÁRVORES }\end{array}$ & LATITUDE & LONGITUDE \\
\hline POMAR 1 & & & & \\
\hline POMAR 2 & & & & \\
\hline POMAR 3 & & & & \\
\hline POMAR 4 & & & & \\
\hline
\end{tabular}


10. SUA HISTÓRIA NA PRODUÇÃO DE MAÇÃS: 
11. QUAL A PRODUTIVIDADE MÉDIA DE SEU POMAR (tha)?

\begin{tabular}{|c|c|c|c|c|}
\hline \multirow{2}{*}{ SAFRA } & \multicolumn{3}{|c|}{ PRODUTIVIDADE MÉDIA (t/ha) } \\
\cline { 2 - 5 } & POMAR 1 & POMAR 2 & POMAR 3 & POMAR 4 \\
\hline SAFRA 2000/2001 & & & & \\
\hline SAFRA 2001/2002 & & & & \\
\hline $\begin{array}{c}\text { SAFRA 2002/2003 } \\
\text { (previsão) }\end{array}$ & & & & \\
\hline
\end{tabular}

12. QUAL O CUSTO MÉDIO DE PRODUÇÃO DE SEU POMAR (R\$/ha), SEM CONSIDERAR GASTOS COM MÉTODOS PARA ADMINISTRAÇÃO DOS POTENCIAIS PREJUIIZOS CAUSADOS PELO GRANIZO?

\begin{tabular}{|c|l|l|l|l|}
\hline \multirow{2}{*}{ SAFRA } & \multicolumn{4}{|c|}{ CUSTO MÉDIO (R\$/ha) } \\
\cline { 2 - 5 } & POMAR 1 & POMAR 2 & POMAR 3 & POMAR 4 \\
\hline SAFRA 2000/2001 & & & & \\
\hline SAFRA 2001/2002 & & & & \\
\hline $\begin{array}{c}\text { SAFRA 2002/2003 } \\
\text { (previsão) }\end{array}$ & & & & \\
\hline
\end{tabular}

13. QUAL O VALOR MÉDIO QUE RECEBE POR SUAS MAÇÃS (R\$/kg) DE ACORDO COM AS CATEGORIAS DE CLASSIFICAÇÃO DAS FRUTAS?

\begin{tabular}{|c|l|l|l|l|l|}
\hline SAFRA & EXTRA & CAT 1 & CAT 2 & CAT 3 & IND \\
\hline SAFRA 2000/2001 & & & & & \\
\hline SAFRA 2001/2002 & & & & & \\
\hline $\begin{array}{c}\text { SAFRA 2002/2003 } \\
\text { (previsão) }\end{array}$ & & & & & \\
\hline
\end{tabular}


14. COMENTE COMO FORAM OS PREJUÍZOS JÁ SOFRIDOS DEVIDO AO GRANIZO EM SAFRAS PASSADAS (maior prejuízo já sofrido, dificuldades para a cobertura de financiamento, reflexo nas safras seguintes...): 
15. QUAL A SUA PERCEPÇÃO COM RELAÇÀO À PROBABILIDADE DE OCORRÊNCIA, EM UMA SAFRA, DAS DIFERENTES INTENSIDADES DE PREJUÍZOS CAUSADOS PELO GRANIZO (em \%)?

\begin{tabular}{|c|c|c|c|}
$\begin{array}{c}\text { PEQUENO } \\
\text { PREJUÍZO } \\
\text { (Granizo Fraco) }\end{array}$ & $\begin{array}{c}\text { PREJUÍZO MÉDIO } \\
\text { (Granizo Médio) }\end{array}$ & $\begin{array}{c}\text { GRANDE } \\
\text { PREJUÍZO } \\
\text { (Granizo Forte) }\end{array}$ & $\begin{array}{c}\text { SEM PREJUÍZO } \\
\text { (Sem Granizo) }\end{array}$ \\
\hline & & & \\
\hline
\end{tabular}

31. DO SEU PONTO DE VISTA PARTICULAR, EM QUANTO ACREDITA QUE SEJA A PROBABILIDADE DE OCORRÊNCIA DO GRANIZO E A FAIXA DE PREJUÍZO POR ELE CAUSADO, DE ACORDO COM A FASE DE DESENVOLVIMENTO DAS MAÇÃS?

\begin{tabular}{|c|c|c|c|c|c|}
\hline & & \multicolumn{4}{|c|}{ INTENSIDADE DO GRANIZO } \\
\hline & & $\begin{array}{c}\text { SEM } \\
\text { GRANIZO }\end{array}$ & FRACO & MÉDIO & FORTE \\
\hline \multirow{2}{*}{ DORMÊNCIA } & PROBABILIDADE & & & & \\
\hline & PREJUÍZO & & & & \\
\hline \multirow{2}{*}{ FLORAÇÃO } & PROBABILIDADE & & & & \\
\hline & PREJUÍZOO & & & & \\
\hline \multirow{2}{*}{ FRUTIFICAÇÃO } & PROBABILIDADE & & & & \\
\hline & PREJUÍZO & & & & \\
\hline \multirow{2}{*}{ MATURAÇÃO } & PROBABILIDADE & & & & \\
\hline & PREJUÍZOO & & & & \\
\hline
\end{tabular}


17. NAS SAFRAS, QUAL A PORCENTAGEM (\%) COLHIDA DE CADA CATEGORIA DE CLASSIFICAÇÃO DE MAÇÃS, DE ACORDO COM A INTENSIDADE DO GRANIZO?

\begin{tabular}{|c|c|c|c|c|c|}
\hline \multicolumn{1}{|c|}{ SEM GRANIZO-SEM PREJUÍZO CAUSADO PELO GRANIZO } \\
\hline $\begin{array}{c}\text { \% DERDA DA } \\
\text { PRODUÇÃO }\end{array}$ & EXTRA & CAT 1 & CAT 2 & CAT 3 & IND \\
\hline & & & & &
\end{tabular}

\begin{tabular}{|c|c|c|c|c|c|}
\hline \multicolumn{6}{|c|}{ GRANIZO FRACO - PEQUENO PREJUÍZO CAUSADO PELO GRANIZO } \\
\hline $\begin{array}{c}\text { \%DE DERDA DA } \\
\text { PRODUÇÃO }\end{array}$ & EXTRA & CAT 1 & CAT 2 & CAT 3 & IND \\
\hline & & & & & \\
\hline
\end{tabular}

\begin{tabular}{|c|c|c|c|c|c|}
\hline \multicolumn{6}{|c|}{ GRANIZO MÉDIO - MÉDIO PREJUÍZO CAUSADO PELO GRANIZO } \\
\hline $\begin{array}{c}\text { \% DE } \\
\text { PERDA DA } \\
\text { PRODUÇÂO }\end{array}$ & EXTRA & CAT 1 & CAT 2 & CAT 3 & IND \\
\hline & & & & & \\
\hline
\end{tabular}

\begin{tabular}{|c|c|c|c|c|c|}
\hline \multicolumn{6}{|c|}{ GRANIZO FORTE - GRANDE PREJUÍZO CAUSADO PELO GRANIZO } \\
\hline $\begin{array}{c}\text { \%DE } \\
\text { PERDADA } \\
\text { PRODUÇÃO }\end{array}$ & EXTRA & CAT 1 & CAT 2 & CAT 3 & IND \\
\hline & & & & & \\
\hline
\end{tabular}


18. COM RELAÇÃO AO SEGURO PRIVADO E AO SEGURO MÚTUO, TEM INTERESSE NO USO DESSAS ALTERNATIVAS PARA A ADMINISTRAÇÃO DO RISCO DE PREJUÍZOS CAUSADOS PELAS CHUVAS DE GRANIZO? NO SEU PONTO DE VISTA, QUAIS AS VANTAGENS, DESVANTAGENS E A CONFIABILIDADE DESSAS ALTERNATIVAS? 
19. QUAL A ÁREA (ha) OU O VALOR SEGURADO (R\$) NAS SEGUINTES SAFRAS E OS VALORES DE PRÊMIO E FRANQUIA COBRADOS PELO SEGURO PRIVADO E PELO FUNDO MÚTUO (\% do valor segurado)?

\begin{tabular}{|c|c|c|c|c|c|c|}
\hline \multirow[b]{2}{*}{ SAFRA } & \multicolumn{3}{|c|}{ SEGURO PRIVADO } & \multicolumn{3}{|c|}{ FUNDO MÚTUO } \\
\hline & PRÊMIO & FRANQUIA & $\begin{array}{l}\text { AREAOU } \\
\text { VALOR } \\
\text { SEGURADO }\end{array}$ & PRÊMIO & FRANQUIA & $\begin{array}{c}\text { AREAOU } \\
\text { VALOR } \\
\text { SEGURADO }\end{array}$ \\
\hline 1996/1997 & & & & & & \\
\hline $1997 / 1998$ & & & & & & \\
\hline 1998/1999 & & & & & & \\
\hline $1999 / 2000$ & & & & & & \\
\hline $2000 / 2001$ & & & & & & \\
\hline $2001 / 2002$ & & & & & & \\
\hline $2002 / 2003$ & & & & & & \\
\hline
\end{tabular}

20. COMO É O SEU HISTÓRICO DE ÁREA ATINGIDA, NÍVEL DE DANOS, E INDENIZAÇÕES RECEBIDAS?

\begin{tabular}{|c|c|c|c|c|c|c|}
\hline \multirow[b]{2}{*}{ SAFRA } & \multicolumn{3}{|c|}{ SEGURO PRIVADO } & \multicolumn{3}{|c|}{ FUNDO MUTUO } \\
\hline & $\begin{array}{c}\text { ÁREA } \\
\text { ATINGIDA } \\
\text { (ha) }\end{array}$ & $\begin{array}{c}\text { NIVEL } \\
\text { DE } \\
\text { DANOS } \\
(\%)\end{array}$ & $\begin{array}{c}\text { INDENIZAÇÃO } \\
(\mathrm{R} \$)\end{array}$ & $\begin{array}{c}\text { ÁREA } \\
\text { ATINGIDA } \\
\text { (ha) }\end{array}$ & $\begin{array}{c}\text { NIVEL } \\
\text { DE } \\
\text { DANOS } \\
(\%)\end{array}$ & $\begin{array}{c}\text { INDENIZAÇÃO } \\
(\mathrm{R} \$)\end{array}$ \\
\hline 1996/1997 & & & & & & \\
\hline $\begin{array}{l}1997 / 1998 \\
1998 / 1999\end{array}$ & & & & & & \\
\hline $1999 / 2000$ & & & & & & \\
\hline $2000 / 2001$ & & & & & & \\
\hline 2001/2002 & & & & & & \\
\hline $2002 / 2003$ & & & & & & \\
\hline
\end{tabular}


21. TEM ALGUM INTERESSE NA UTILIZAÇÃO DO SISTEMA DE TELAS ANTT GRANIZO?

22. QUAIS PODERIAM SER OS PRINCIPAIS BENEFÍCIOS E OS PRINCIPAIS PROBLEMAS DA UTILIZAÇÃO DAS TELAS ANTIGRANIZO? 
23. QUAL O CUSTO PARA A INSTALAÇÃO DO SISTEMA DE TELAS ANTT GRANIZO (R\$/ha) E QUAL A SUA DURABILIDADE (anos)?

\begin{tabular}{|l|l|}
\hline CUSTO PARA INSTALAÇÃO (R\$/ha) & DURABILIDADE (anos) \\
\hline & \\
\hline
\end{tabular}

24. QUAL A PROVÁVEL DIMINUIÇÃO EM SUA RECEITA BRUTA (em \%) DEVIDO AO SOMBREAMENTO CAUSADO PELAS TELAS ANTIGRANIZO?

DIMINUIÇÃO DA RECEITA BRUTA DEVIDO AO EFEITO "SOMBREAMENTO" (\%)

25. QUAL A PORCENTAGEM (\%) DE SEU POMAR QUE PRETENDE COBRIR OU JÁ ESTÁ COBERTA COM TELAS ANTIGRANIZO?

\% DA ÁREA DO POMAR JÁ COBERTA OU QUE PRETENDE COBRIR COM TELAS ANTI-GRANIZO 
26. EXISTE A DISPONIBILIDADE DE FINANCIAMENTO PARA INSTALAÇÃO DO SISTEMA DE TELAS ANTIGRANIZO?

QUAL AS FONTES?

QUAL OS VALORES?

QUAIS OS JUROS?

QUAIS AS CONDIÇÕES?

OS PRODUTORES ESTÃO FAZENDO USO DESSE FINANCIAMENTO?

EXISTEM OUTRAS FONTES DE

FINANCIAMENTO? 
27. TEM ALGUM INTERESSE NA UTILIZAÇÃO DO SISTEMA DE GERADORES DE SOLO?

28. QUAIS PODERIAM SER OS PRINCIPAIS BENEFÍCIOS E OS PRINCIPAIS PROBLEMAS DA UTILIZAÇÃO DOS GERADORES DE SOLO? 
29. PARA CADA AGRICULTOR INDIVIDUALMENTE, QUAL SERIA O PROVÁVEL CUSTO ANUAL DO SISTEMA DE GERADORES DE SOLO (R\$/ano)?

PROVÁVEL CUSTO ANUAL DO SISTEMA DE GERADORES DE SOLO (R\$/ano)

30. EM QUE PORCENTAGEM (\%) ACREDITA QUE O SISTEMA DE GERADORES DE SOLO SEJA CAPAZ DE DIMINUIR OS PREJUÍZOS CAUSADOS PELO GRANIZO EM UMA SAFRA?

GERADORES DE SOLO - PROVÁVEL CONTRIBUIÇÃO NA REDUÇÃO DOS PREJUÍZOS (\%)

31. COM RELAÇÃO A PERGUNTA ANTERIOR, EM QUE INFORMAÇÕES BASEOU-SE PARA RESPONDER A QUESTÃO? ACREDITA QUE O RELEVO DA REGIÃO DE SÃO JOAQUIM E O TIPO DE GRANIZO (intensidade e modo de formação) INFLUENCIAM NA EFICIÊNCIA DO SISTEMA DE GERADORES DE SOLO? 
32. TEM CONHECIMENTO DE OUTRAS ESTRATÉGIAS ADOTADAS EM OUTRAS REGIÕES DO BRASIL OU DO MUNDO PARA A ADMINISTRAÇÃO DO RISCO DE GRANIZO E MINIMIZAÇÃO DOS PREJUÍZOS CAUSADOS POR ESSE FENÔMENO CLIMÁTICO? COMO AVALIA ESSES TRABALHOS?

33. COMO PRODUTOR DE MAÇÃS, CONSIDERANDO OS CONHECIMENTOS EXISTENTES ATÉ O MOMENTO, QUAL A SUA PREFERÊNCIA COM RELAÇÃO ÀS ALTERNATIVAS PARA A ADMINISTRAÇÃO DO RISCO DE GRANIZO? POR QUÊ? 
34. OUTROS COMENTÁRIOS QUE CONSIDERE RELEVANTES PARA O TRABALHO: 
ANEXO D - Programa computacional de cálculo "GranizoMGMT" (em CD-rom). 


\section{REFERÊNCIAS BIBLIOGRÁFICAS}

ASSOCIAÇÃO BRASILEIRA DE PRODUTORES DE MAÇÃ - ABPM. Associação Brasileira de Produtores de Maçã - ABPM. http://www.abpm.org.br (15 abr. 2001)

ANDERSON, J.L.; FRISBY, J.W.; GATHERUM, D.M.; SEELEY, S.D. 'Delicious' apple (Malus) responses to rowcover microclimate. Acta Horticulturae, n.451, p.749-754, 1997.

ANTUNES, F.Z. Adverse phenomena in agriculture. Informe Agropecuario, v.12, n.138, p.23-24, 1986.

ARRUDA, H.V.; ASSIS, F.N.; PEREIRA, A.R. Aplicações da estatística à climatologia: teoria e prática. Pelotas: Ed. da UFPel, 1996. 161p.

AZEVEDO-FILHO, A. Seguro agrícola no Brasil: certezas e limitações com aplicações à cultura da soja. In: CÂMARA, G. Soja: tecnologia da produção II. Piracicaba: ESALQ/USP, 2000. p.49-80.

BATTAGLIA, M.; TASSARA, M.A. Ensayo de una red plastica antigranizo en manzanos en el Alto Valle de Rio Negro. Rivista de Agricoltura Subtropicale e Tropicale, v.86, n.2, p.375-384, 1992.

BERLATO, A.M.; FONTANA, D.C.; MELO, R.W. Risco de ocorrência de granizo no Estado do Rio Grande do Sul. Revista Brasileira de Agrometeorologia, v.8, n.2, p.121-132, 2000.

BOE, B.A.; JOHNSON, L.R.; MIELKE JUNIOR, P.W.; PRIEGNITZ, D.L.; SMITH, P.L. An exploratory analysis of crop hail insurance data for evidence of cloud seeding effects in North Dakota. Journal of Applied Meteorology, v.36, n.5, p.463-473, May 1997. 
BONETI, J.I.S.; KATSURAYAMA, Y. Doenças da macieira (Malus domestica Bork.). In: BONETI, J.I.S.; KATSURAYAMA, Y.; RIBEIRO, L.G. Manual de identificação de doenças e pragas da macieira. Florianópolis: EPAGRI, 1999. p.13-95.

CHANGNON, S.A. Hailfall characteristics related to crop damage. Journal of Applied Meteorology, n.10, p.270-274, 1971.

CHANGNON JUNIOR, S.A. Temporal and spatial variations in hail in the Upper Great Plains and Midwest. Journal of Climate and Applied Meteorology, v.23, n.11, p.1531-1541, 1984.

CLIMATERRA. Climaterra: São Joaquim/SC. http://www.climaterra.com.br (05 abr. 2002)

CONTI, J.B. A ocorrência de granizo no Estado de São Paulo. Botucatu: Universidade Estadual Paulista, Instituto de Biociênc ias, Letras e Ciências Exatas, 1981. 151p.

COSTA, A.; NEVES, M.F.; VOLPE, C.A. Granizo: prejuízos e viabilidade econômica de método preventivo para a região de São Sebastião do Paraíso - MG. In: SIMPÓSIO INTERNACIONAL DE INICIAÇÃO CIENTÍFICA DA UNIVERSIDADE DE SÃO PAULO, 8., Piracicaba, 2000. Resumos. Piracicaba: ESALQ/USP, 2000, p.368.

CYBERAMBIENTAL. Encuentre todo lo relacionado al medioambiente y sus normativas en España. http://www.cyberambiental.com (27 mar. 2002)

DALE, R.F. Statistical climatology. Indiana: Purdue University, 1976. 191p.

DESSENS, J. Hail in southwestern France I: hailfall characteristics and hailstorm environment. Journal of Climate and Applied Meteorology, v.25, n.1, p.35-47, 1986a.

DESSENS, J. Hail in southwestern France II: results of a 30 year hail prevention project whit silver iodide seeding from the ground. Journal of Climate and Applied Meteorology, v.25, n.1, p.48-58, 1986b.

DESSENS, J. A physical evaluation of a hail suppression project whit silver iodide ground burners in southwestern France. Journal of Applied Meteorology, v.12, n.37, p.1588-1599, 1998.

ETKIN, D.; WHITE, R. Climate change, extreme events and the canadian insurance industry. Natural Hazards, n.16, p.135-163, 1997. 
HAIFFA, H.; HAMMOND, J.S.; KEENEY, R. L. Smart choices: a practical guide to making better decision. Boston: Harvard Business Scholl Press, 1998a. 272p.

HAIFFA, H.; HAMMOND, J.S.; KEENEY, R.L. The hidden traps in decision making Harvard Business Review, n.76, Sept./Oct. 1998b.

HAIL STOP EQUIPMENTS. Équipements hailstop equipments. http://www.hailstop.qc.ca (25 Sept. 2002)

HARAGAN, D.R. Precipitation argumentation: problems and progress. Water Resources, n.10, p.547-554, 1974.

HOWARD, R.A.; MATHERSON, J.E. Influence diagrams. In: HOWARD, R.A.; MATHERSON, J.E. (Ed.). The principle and application of decision analisys. Menlo Park: The Strategic Decision Group, 1984. v.2. cap.37, p.719-763.

HOWARD, R. A. From influence to relevance to knowledge. In: OLIVER, R.; SMITH, J. (Ed.) Influence diagrams, belief nets and decision analysis. Chichester: John Wiley \& Sons, 1990. p.3-23.

INSTITUTO BRASILEIRO DE GEOGRAFIA E ESTATÍSTICA - IBGE. Sistema IBGE de Recuperação Automática - SIDRA. http://www.sidra.ibge.gov.br (19 nov. 2000)

IUCHI, T.; IUCHI, V.L.; NAVA, G. Distúrbios fisiológicos e desequilíbrios nutricionais em macieira. Florianópolis: EPAGRI/JICA, 2001. cap.2, p.50-52: Russeting.

LEITE, G.B.; MONDARDO, M.; PETRI, J.L. Influências climáticas e culturais em pomares com cobertura de tela anti-granizo. Caçador: ABPM/EPAGRI, 2000. p.69-80. (Relatório técnico do convênio Associação Brasileira de Produtores de Maçã / Empresa de Pesquisa Agropecuária e Extensão Rural de Santa Catarina S.A)

SAPOI S.A. SAPOI S.A.: sistema antigranizo. http://www.sapoi-sa.com (05 abr. 2002)

SHACHTER, R.D. Evaluating influence diagrams. Operations Research, v.34, n.6, p.871-882, 1986.

SHACHTER, R.D. Probabilistic inference and influence diagrams. Operations Research, v.35, n.6, p.589-604, 1987.

SONKA, S.T.; SWANSON, E.R.; TAYLOR, C.R.; VAN BLOKLAND, P.J. An economic analysis of hail suppression. Journal of Applied Meteorology, v.17, n.10, p.1432-1440, 1978. 
THOM, H.C.S. Some methods of climatological analysis. Geneva: Secretariat of the World Meteorological Organization, 1966. 33p.

YURI, H.M.; AZEVEDO-FILHO, A. Administração do risco de chuvas de granizo em pomares de maçã (compact disc). In: SIMPÓSIO DE INICIAÇÃO CIENTÍFICA DA UNIVERSIDADE DE SÃO PAULO, 7., Piracicaba, 1999. Resumos. Piracicaba: ESALQ/USP, 1999. p.437. 


\section{BIBLIOGRAFIA RECOMENDADA}

ABBASPOUR, K.C.; HALL, J.W.; MOON, D.E. A yield model for use in determining crop insurance premiums. Agricultural and Forest Meteorology, v.60, n.1-2, p.33$51,1992$.

ACOSTA, A.H.M. Loss esteem manual caused by hail in apple (Malus pumilla Mill). México: s.ed., 1995. 55p.

ACTIVE protection: economic and moral profit: protection against hail. Puglia Agricola, v.6, n.5-6, p.16-18, 1978.

AKAI, T.; NAKAJIMA, M.; KAGAWA, M. Hail injury of the japanese pear fruit [Pyrus serotina]. Bulletin of the Tokushima Horticultural Experiment Station, n.9, p.16, 1980.

APPLES from overseas: rich supply despite of heavy damage caused by hail in New Zealand. Obst und Gemuese, v.21, n.3, p.152-159, 1994.

ASBRAND, A. Hail insurance: have you already sent in your cultivation records? Landwirtschaftliches Wochenblatt Westfalen Lippe, v.149, n.19, p.18-19, 1992.

ASSOCIATION NATIONALE D`ETUDE ET DE LUTTE CONTRE LES FLEAUX ATMOSPHERIQUES. Program of hail prevention by the National Association for the Study and Control of Atmospheric Calamities: 1981 campaign (France). Toulouse: ANELFA, 1982. 32p.

ASSOCIATION NATIONALE D`ETUDE ET DE LUTTE CONTRE LES FLEAUX ATMOSPHERIQUES. Hail prevention program of the National Association for the Study and Control of Atmospheric Calamities: 1982 season. Toulouse: ANELFA, 1983. 67p. 
ASSOCIATION NATIONALE D`ETUDE ET DE LUTTE CONTRE LES FLEAUX ATMOSPHERIQUES. Hail prevention program of the National Association for the Study and Control of Atmospheric Catastrophe: 1985 season. Toulouse: ANELFA, 1986. 50p.

ASSOCIATION NATIONALE D'ETUDE ET DE LUTTE CONTRE LES FLEAUX ATMOSPHERIQUES. Program of prevention against hail by the National Association for the Study and the Control of Atmospheric Hazards: campaign 1988. Toulouse: ANELFA, 1989. 27p.

ASSOCIATION NATIONALE D’ETUDE ET DE LUTTE CONTRE LES FLEAUX ATMOSPHERIQUES. Report of the 1989 campaign, climatology of hail in the departments of the ANELFA network (1957-1987): discussion on hail control in France. Toulouse: ANELFA, 1990. 47p.

ASSOCIATION NATIONALE D’ETUDE ET DE LUTTE CONTRE LES FLEAUX ATMOSPHERIQUES. Report of the 1990 campaign, climatology of hail in the departments of the ANELFA network (1957-1987). Toulouse: ANELFA, 1991. 40p.

ASSOCIATION NATIONALE D’ETUDE ET DE LUTTE CONTRE LES FLEAUX ATMOSPHERIQUES. Report of the 1991 anti-hail campaign Toulouse: ANELFA, 1992. 63p.

ASSOCIATION NATIONALE D’ETUDE ET DE LUTTE CONTRE LES FLEAUX ATMOSPHERIQUES. Equipments, technology and results of hail control in the ex-USSR. Toulouse: ANELFA, 1994. 79p.

ASSOCIATION NATIONALE D’ETUDE ET DE LUTTE CONTRE LES FLEAUX ATMOSPHERIQUES. Report of the campaign 1994 against hail : problem of hail control as considered by Helmut Weickmann. Toulouse: ANELFA, 1995. 39p.

ASSOCIATION NATIONALE D'ETUDE ET DE LUTTE CONTRE LES FLEAUX ATMOSPHERIQUES. Summarized climatology of hail in the departments of the ANELFA network (1952-1995): ice nucleation characteristics of the new silver iodide solution used by ANELFA: towards a physical demonstration of hail prevention efficacy. Toulouse: ANELFA, 1996. 35p.

ASSOCIATION NATIONALE D'ETUDE ET DE LUTTE CONTRE LES FLEAUX ATMOSPHERIQUES. Report of the 1996 campaign against hail: reminder of some general notions on hail prevention by aerosol generators. Toulouse: ANELFA, 1997. 39p. 
AUGENIE, P. Installation of anti-hail nets. (L'installation de toiles antigrele). Fruit Belge, v.65, n.467, p.76-80, 1997.

AZEVEDO-FILHO, A. A primer on belief networks and influence diagrams. Stanford: Stanford University, Department of Engineering-Economic Systems, 1995. 37p. (Research Report)

BANC, P.; BOUCHER, L. Hail cost. Arboriculture Fruitiere, v.43, n.492, p.23-25, 1996.

BAUGHER, T.A.; HOGMIRE JUNIOR, H.W.; LIGHTNER, G.W. Determining apple packout losses and impact on profitability. Applied Agricultural Research v.5, n.4, p.343-349, 1990.

BELHOMME, R. Protection of harvests. In: INTERNATIONAL CONGRESS OF SOCIAL ECONOMY IN AGRICULTURE AND IN A RURAL ENVIRONMENT, Paris, 1984. Proceedings. Paris: CENECA, 1984. p.153-156.

BELTRAMELLI, T. Protection against hail in Veneto (Italy). Terra e Vita, v.21, n.12, p.66-67, 1980.

BIEDERMANN, H. A new control system against hail. Obst und Garten, v.99, n.8, p.353-354, 1980.

BIZER, E. Protective nets. Deutscher Gartenbau v.44, n.15, p.1002-1006, 1990.

BLANKE, M.; WEIDENFELD, H. Light transmission of nets for hail and bird protection. Erwerbsobstbau v.39, n.5, p.141-143, 1997.

BOBEV, S.; DECKERS, T.; MOMOL, M.T.; SAYGILI, H. Field susceptibility to fire blight of pome fruits in Bulgaria. Acta Horticulturae, n.489, p.221-224, 1999.

BOONE, L. Impacts of hail supression in Nebraska: economic appraisal. Agricultural Economics Research, v.29, n.3, p.113-114, July 1977.

BORDEAUX-MONTRIEUX, L. The adaptation of mutual farming insurance funds to new market conditions. Comptes Rendus de l'Academie d'Agriculture de France, v.78, n.1, p.61-70, 1992.

BORZINI, G. Anti-hail campaign and vine mildew control by anti-hail nets imbued with cupric salts or woven with copper wires. Informatore Agrario, v.38, n.28, p.21765-21766, 1982.

BOUBALS, D. How far have we got with the hail control problem? Progres Agricole et Viticole, v.103, n.13-14, p.332-334, 1986. 
BOUCHER, L. The management of hail risks. Infos Paris, n.125, p.16-19, 1996.

BRANDONE, G. Apple orchards active protection with nets against hail. Terra e Vita, v.38, n.26, p.40-41, 1997.

BRETH, D.I.; BENTLEY, A.; MOMOL, M.T.; SEEM, R.C.; ALDWINCKLE, H.S.; MOMOL, M.T.; SAYGILI, H. Fire blight on apple: effects of wind and rain in development of trauma blight. Acta Horticulturae, n.489, p.471-473, 1999.

BROCHET, P. Hail: analysis of the phenomenon and difficulties of rational control. Phytoma, n.323, p.43-49, 1980.

BROWN, R.J. Hail: meteorology, damage, prevention, and forecasting 1964-1975. Springfield: National Technical Information Service, 1979a. v.1. 3 microfilmes.

BROWN, R.J. Hail: meteorology, damage, prevention, and forecasting 1976-March 1979. Springfield: National Technical Information Service, 1979b. v.2. 1 microfilme.

BROWNING, K.A.; ATLAS, D. Some new approaches in hail suppression experiments. Journal of Applied Meteorology, v.16, n.4, p.327-332, 1977.

BUERGER, K.H. How necessary is an insurance against hail in rape? Raps, v.9, n.2, p.88-91, 1991.

BUNCH protection prevents hail damage. Landbouweekblad, n.956, p.44-45, 1996.

CAMPBELL, J.E. High density bed systems in Europe and hail protection in northern Italy including the 23rd International Horticultural Congress in Florence. Orange: New South Wales Agriculture and Fisheries, 1991. 7p.

CAPONIGRO, P.; CAPONIGRO, R.; VENTO, D. Use of meteorological satellites in the frame of trials for the anti-hail control. In: CONVEGNO INTERNAZIONALE SCIENTIFICO SULLO SPAZIO, 18., Rome, 1978. Conference paper. Rome: Ministero dell' Agricoltura e delle Foreste, Ufficio Centrale di Ecologia Agraria. 1978. 5p.

CASTAGNE, P. Hail protection nets: innovation and adaptation. Arboriculture Fruitiere, n.503, p.48-51, 1997.

CERVI-CIBOLDI, E. Emotivity and calculation in hail insurance (in Italy). Terra e Vita, v.1, n.20, p.28-29, 1980a.

CERVI-CIBOLDI, E. Pay attention to the hail damage survey. Terra e Vita, v.21, n.33, p.34-35, $1980 b$. 
CHALON, J.P. Hail climatology and forecasting: the control of atmospheric nuisances: the cases of hail fall. Comptes Rendus des Seances de l'Academie d'Agriculture de France, v.71, n.11, p.1291-1301, 1985.

CHANGNON, S.A. Hail suppression: impacts and issues. Urbana: Illinois State Water Survey, 1977. 427p.

CHANGNON, S.A.; MORGAN JUNIOR, G.M.; ACHTEMEIER, G.L.; TOWERY, N.G.; GROSH, R.C. Design of a hail suppression project for Illinois. Journal of Applied Meteorology, v.14, n.5, p.771-782, 1975.

CHANGNON JUNIOR, S.A. The scales of hail. Journal of Applied Meteorology, v.16, n.6, p.626-648, 1977.

CHENG, Z. The general natural calamity and control strategies of fruit trees. Bulletin of Agricultural Science and Technology, n.4, p.29, 1994.

CHIOZZI, L.F.; CANATO, A. Protection against hail: is it convenient the net or insurance? Informatore Agrario, v.36, n.22, p.10891-10895, 1980.

CORDIOLI, M. Protection against hail with level nets. Informatore Agrario, v.53, n.18, p.68-71, 1997.

CORRADI, C. To give antihail nets to the orchard. Terra e Vita, v.36, n.10, p.127-132, 1995.

COST of installing a hail control device over an apple-orchard. Marche International des Fruits et Legumes Frais, n.34, p.13, 1979.

DAURIACH, J. A roof over the orchard: windbreak net, parahail net, anti- frost system with motor-driver propeller. Arboriculture Fruitiere, n.394, p.49-54, 1987.

DE-BRETTEVILLE, A. The control of atmospheric nuisances: the cases of hailfall: the point of view of the hail insurers. Comptes Rendus des Seances de l'Academie d'Agriculture de France, v.71, n.11, p.1273-1290, 1985.

DE-BRETTEVILLE-A. It is possible to insure crops? Comptes Rendus de l'Academie d'Agriculture de France, v.76, n.3, p.3-15, 1990.

DE-JONG, D.; FLEMING, M.; IWIG, W.C.; PERRY, C.R. An assessment of the appropriate size measure for probability proportional to size path sampling of apple trees. s.l.: s.ed.,1995. 17p.

DELGADO, M.; KALUZNY-PINON, L. Choice of netting for hail protection. Arboriculture Fruitiere, n.497, p.17-22, 1996. 
DESSENS, J. Controlling hail: an objective comparison between different methods. France Agricole, v.36, n.1853, p.21, 1981.

DESSENS, J. Hail in southwestern France: 1. Hailfall characteristics ans hailstorm environment; 2. Results of a 30-year hail prevention project with silver iodide seeding from the ground. Toulouse: ANELFA, 1986c. 26p.

DESSENS, J. Application of hail measurements to management of hail control trials without sampling. Bulletin d'Association Nationale d'Etude et de Lutte contre les Fleaux Atmospheriques, n.39, p.51-55, 1991.

DESSENS, J. A physical evaluation of a hail suppression project whit silver iodide ground burners in southwestern France. Journal of Applied Meteorology, v.12, n.37, p.1588-1599, 1998.

DI-COCCO, E. An efficient control against hail. Terra e Vita, v.17, n.6, p.20-21, 1976.

DIEREND, W.; ALKER, R.; GOETTE, E. Nets for hail-protection in the french fruitgrowing. Erwerbsobstbau, v.39, n.6, p.171-173, 1997.

DODDS, K.A.; PENROSE, L.J.; BOWER, C.C.; NICOL, H. The importance of pest and disease damage as a cause of commercial downgrading of apple fruit. Australian Journal of Experimental Agriculture, v.34, n.3, p.431-434, 1994.

DOMOTO, P.A. The survival and performance of four cultivars on six dwarfing interstems. Compact Fruit Tree, v.15, p.19-24, 1982.

DUVAL, G. Protection of french farmers against climatic risks. Comptes Rendus de l'Academie d'Agriculture de France, v.82, n.7, p.145-156, 1996.

EGUMENOVSKI, P.; ILICH, P.S.; RISTEVSKI, P. Hail suppression over crops in Macedonia in 1981-90. Skopje: Godisen Zbornik na Zemjodelskiot Fakultet, Univerzitet St. Kiril i Metodij, 1995. p.157-164. (Research report, 40)

ENCOURAGEMENT to hail insurance plant. Vignes et Vins, n.283, p.31-32, 1979.

ESTEBAN-SANCHEZ, A. Hail control. Madrid: Ministerio de Agricultura, 1975a. 20p. (Publicaciones de extensión agraria)

ESTEBAN-SANCHEZ, A. Hail control methods. Revista del Instituto Agrícola Catalan de San Isidro, v.124, n.7-8, p.9-16, 1975 b.

FASSINO, G. Active control against hail. Informatore Agrario, v.36, n.39, p.1233112332, 1980. 
FERRARI, P.; ORSI, S. Prevention of hail in the Trento Province. Esperienze e Ricerche, v.4, p.221-251, 1973.

FIRST experiences with hail control device, a real effect or just a chance? Schweizerische Zeitschrift fuer Obst und Weinbau, v.117, n.17, p.494-497, 1981.

FIVE thousand years of anti hail campaign. Terra e Vita, v.22, n.43, p.48, 1981.

FRANCHINI, G. Techniques and prospects for antihail control: fruit and vegetables, in Italy. Frutticoltura, v.36, n.12, p.45-47, 1974.

FREMY, H. Hail damage as considered by the agricultural profession. Comptes Rendus des Seances de l'Academie d'Agriculture de France, v.71, n.11, p.12671272, 1985.

GARCIA-SANJUAN, J. Hails and hail-stones: diez temas sobre el clima. Madrid: Ministerio de Agricultura, 1978. p.131-149. (Publicaciones de extensión agraria)

GARDNER-RAW; FLETCHER, C.A. Hail protection systems for deciduous fruit trees. Deciduous Fruit Grower, v.40, n.6, p.206-212, 1990.

GARNAUD, J.C. Anti-hail nets in fruit orchards. Plasticulture, n.113, p.33-42, 1997.

GATHERUM, D.M.; ANDERSON, J.L.; SEELEY, S.D.; FRISBY, J.W.; BARRITT, B.H.; KAPPEL, F. 'Delicious' apple (Malus) responses to row cover microclimate. Acta Horticulturae, n.451, p.749-754, 1997.

GINOUVES, M.; JARRIER, M. Hail: formation and prevention. Chambres d'Agriculture, v.51, n.662-663, p.1-47, 1980.

GIULIVO, C.; PONCHIA, G. Up-to-date on the apple tree: anti-hail nets on high rate planting. Italia Agricola, v.115, n.3, p.63-68, 1978.

GOERGENS, M. Hail in orchards. Mitteilungen des Obstbauversuchsringes des Alten Landes, v.49, n.3, p.109-116, 1994.

GOIDANICH, G. Fungicidal and anti-hail nets. Terra e Vita, v.17, n.31, p.14-15, 1976.

GRAF, B.; HOPLI, H.; RAUSCHER, S.; HOHN, H. Hail nets influence the migratory behaviour of codling moth and leaf roller. Obst und Weinbau v.135, n.12, p.289292, 1999. 
GRONBACH, G. A courageous pilote copes with dangerous hail clouds: interim results of a vast experiment: good hail prognosis: smaller hailstones. Wuerttembergisches Wochenblatt fuer Landwirtschaft, v.154, n.9, p.22-24, 1987.

GULINO, F. Organization of anti-frost and anti-hail defence in Alto-Adige. Frutticoltura, v.43, n.12, p.47-53, 1981.

HAIL insurance: taking a risk is a risky business. Wheat Grower, v.4, n.6, p.18-19, 1981.

HAIL insurance: death or rebirth? Nets against hail: the illusion of panacea. Arboriculture Fruitiere, n.481, p.8-13, 1995.

HELLMANN, M. Monilia fruit rot on wounded apple fruits at summertime. Obstbau, v.22, n.4, p.191-192, 1997.

HENSMANS, F. Effect of meteorological factors on fruits: hail. Fruit Belge, v.51, n.404, p.313-314, 1983.

HERMINJARD, P. The orchard: hail, how to protect these crops today and tomorrow. Revue Horticole Suisse, v.71, n.1-2, p.4-7, 1998.

HOBOLTH, L.A. Diseases and pests on horticultural crops. Maanedsoversigt over Plantesygdomme, n.545, p.128-130, 1983.

HUTIN, C.; OSAER, A. Les filets paragrele: utilisation pour la protection des vergers. Infos Paris, n.125, p.22-25, 1996.

JANKOVIC, R. The effect of shading with a hail: production screen on the chloroplast contents in the leaves of nursery trees. Jugoslovensko Vocars tvo, v.19, n.70-74, p.453-458, 1985.

JANKOVIC, D.; TODOROVIC, R.; VUKOVIC, L.J. Investigation of sensitivity of apple fruits to hail. Nauka u Praksi, v.15, n.4, p.445-450, 1985.

JOHNSON, L.R.; SMITH, P.L.; MIELKE JUNIOR, P.W. Some evaluations of the North Dakota cloud modification project. American Society of Agricultural Engineers, n.942017, p.9-14, 1994.

JOVANOVIC, M. The first yugoslav consultation on protection against hail and other measures for artificial influence on weather. Republicki hidrometeoroloski zavod SR Srbije. Beograd: s.ed., 1985. 421p. 
KELLERHALS, M.; RIESEN, W.; WEIBEL, F. IPM and organic apple cultivation: choice of sites and cultivars. Obst und Weinbau, v.133, n.3, p.80-81, 1997.

KEMP, J.; DE-VILLIERS, M.; JACOBS, W. Hail on agricultural crops. OTKaner, v.39, n.6, p.10-11, 1995.

KIM, J.S. A study on the relation between mutual relief business and insurance business in the crop insurance scheme in Japan. Journal of Rural Problem v.4, n.1, p.1826, 1988.

KIM, J.S.; YOON, J.T.; CHO, D.H.; CHOI, B.S.; LEE, W.S.; OH, J.Y. Survey of hailstorm damage on apple trees in the Kyungbuk area in 1992. Journal of the Korean Society for Horticultural Science, v.35, n.4, p.345-350, 1994.

KNIGHT, C.A.; SQUIRES, P. Hailstorms of the central high plains. Boulder: Colorado Associated University Press, 1982. 2v.: v.1. The national hail research experiment. v.2. Case studies of the national hail research experiment.

KNIGHT, T.O.; LOVELL, A.C.; RISTER, M.E.; COBLE, K.H. An analysis of lenders influence on agricultural producers risk management decisions. Southern Journal of Agricultural Economics, v.21, n.2, p.21-33, 1989.

KOLLATZ, U. A dynamic planning model for fruit production. Berichte Ueber Landwirtschaft, v.73, n.4, p.624-641, 1995.

KON, H.; TAKAHASHI, Y.; YOSHITOMI, H.; HANYU, J.; NAKAYAMA, K. Influences of net covering on the meteorological environments inside (Pyrus) orchard. Journal of Agricultural Meteorology, v.45, n.1, p.13-18, 1989.

KOZMINSKI, C.; BORIN, M.; SATTIN, M. Climatic risk to crops in Poland. In: CONGRESS OF THE EUROPEAN SOCIETY FOR AGRONOMY, 3., Padova, 1994. Proceedings. Padova: Padova University, 1994. p.818 -819.

LACAUX, J.P.; WARBURTON, J.A. The disposition of silver released from Soviet Oblako rockets in precipitation during the hail suppression experiment Grossversuch IV: 1. measurements of background and a preliminary seeding test. Journal of Applied Meteorology, v.19, n.7, p.771-778, 1980.

LANGNER, R.; WOLFF, H. Hail insurance: increasing importance for the potato cultivation. Kartoffelbau v.48, n.3, p.100-101, 1997.

LAUR, A. Adaptation of the agricultural social security system. Comptes Rendus de l'Academie d'Agriculture de France, v.76, n.3, p.27-36, 1990. 
LEFRANC, J.N. Nets to protect fruit crops against hail are expensive but beneficial. France Agricole, v.35, n.1765, p.17-19, 1979.

LEGROS, N. Anti-hail nets: study of systems. Fruit Belge, v.65, n.467, p.69-73, 1997a.

LEGROS, N. Existing systems in France. Fruit Belge, v.65, n.467, p.74-75, 1997 b.

LEGROS, N. Hail control nets: synthesis. Fruit Belge, v.65, n.467, p.76-80, 1997c.

LE-LEU, R. Hail control: $71 \%$ efficiency during 4 years in Beaujolais. France Agricole, n.1554, p.41-44, 1975.

LEVADOUX, B. Research on economic feasability of an effective prevention of hail. Economie Rurale, n.149, p.51-53, 1982.

LHOMME, J.P.; ROJAS, O.E. The analysis of drought, frost, and hail risks in bolivian highland agriculture. Turrialba (IICA), v.36, n.2, p.219-224, 1986.

LOESCHE, M. Only the quality counts: the new onion insurance. Rheinische Monatsschrift fuer Gemuese, v.85, n.3, p.194-196, 1997.

LUCHKOV, P.G.; TAOV, I.M. Restoration of growth and fruiting of apples damaged by hail and low temperatures. Sadovodstvo i Vinogradarstvo, n.2, p.8-9, 1999.

MAAD, H. The costs of hail insurance in Austria. Top Agrar Oesterreich Journal, v.5, p.19-21, 1996.

MAEGATA, M.; HAMADA, E. The accomplishments of a fish culture mutual association and its future: a case study of Toishi town of the Nagasaki prefecture. Bulletin of the Faculty of Fisheries Nagasaki University, n.67, p.31-35, 1990.

MARENGONI, B. Anti-hail net: technical organizational and economic aspects. Informatore di Ortoflorofrutticoltura, v.20, n.8, p.9-13, 1979.

MARENGONI, D. There are also anti hail nets. Informatore Agrario, v.30, n.28, p.16424-16425, 1974.

MATHER, G.K. An analysis of a possible crop response to hail suppression seeding: the Nelspruit hail suppression project. Journal of Applied Meteorology, v.16, n.9, p.959-970, 1977.

MAURI, G. Antihail protection and control against the apple-tree scab by "copper" anti-hail net. Informatore Agrario, v.40, n.18, p.57-59, 1984. 
MAURO, V.; LUISA, M. Experiences of the control of the common cockchafer (Melolontha melolontha L.) in Trentino by means of plastic nets. Bulletin OILB SROP, v.19, n.2, p.83-88, 1996.

MAZZOTTI, L. Anti-hail rockets: the last attempt to stop irreparable damage. Terra e Vita, v.22, n.48, p.34, 1981.

MELI, T.; RIESEN, W.; HUSISTE, A.; KREBS, C.H. Insurance against damages caused by hail or protection through installation of covers? Schweizerische Zeitschrift fuer Obst und Weinbau, v.123, n.18, p.478-482, 1987.

MEZEIX, J.F. The french, the italians and the swiss are looking for an efficient way of hail control. Information Agricole, n.503, p.57-58, 1979.

MEZEIX, J.F. Recent research in hail suppression results of the french-italian-swiss experiment Grossversuch 4. Comptes Rendus des Seances de l'Academie d'Agriculture de France, v.71, n.11, p.1311-1322, 1985.

MEZEIX, J.F. Hail prevention, reality, failure or hope. Arboriculture Fruitiere, n.394, p.31-36, 1987a.

MEZEIX, J.F. Comments on "hail in southwestern France II: results of a 30-year hail prevention project with silver iodide seeding from the ground". Journal of Climate and Applied Meteorology, v.26, n.12, p.1775-1776, $1987 \mathrm{~b}$.

MEZEIX, J.F.; ADMIRAT, P.; CHASSANY, J. Validity of hail index related to meteorological situations in Languedoc area. Meteorologie, v.6, n.17, p.43-49, 1979.

MEZEIX, J.F.; WALDVOGEL, A.; VENTO, D. Hail. Recherche, v. 17, n.175, p.300$310,1986$.

MILOVANKIC, M. Bearing potential of some apple cultivars. Jugoslovensko Vocarstvo, v.19, n.71-72, p.79-84, 1985.

MORGAN JUNIOR, G.M.; TOWERY, N.G. Small-scale variability of hail and its significance for hail prevention experiments. Journal of Applied Meteorology, v.14, n.5, p.763-770, 1975.

MULLER, W. Project of hail control in the Stuttgart area, 1980-1989. Bulletin d'Association Nationale d'Etude et de Lutte contre les Fleaux Atmospheriques, n.37, p.28-31, 1989. 
MUNKNER, H.H. Panorama of cooperatives, mutuals and associations in Germany, which do not consider themselves as forming a sector of "Economie Sociale". Annals of Public and Cooperative Economics, v.65, n.2, p.301-331, 1994.

MURAOKA, K.; MIYASHI, T.; HOSIKAWA, S.; MATSUNAMI, T.; SATO, S. Hail damage of orchards and their aftercares. Gunma Journal of Agricultural Research, n.2, p.6-22, 1986.

MURGAI, R.; WINTERS, P.; SADOULET, E.; DE-JANVRY, A. Localized and incomplete mutual insurance. California: University of California, Department of Agricultural and Resource Economics, Division of Agriculture and Natural Resources, 1998. 28p. (Working paper)

MUSACCHI, S.; FARINA, M. Cultivation methods for apple in high density plantations. Informatore Agrario, v.54, n.22, p.65-69, 1998.

MUTTI, G. Seeding on clouds. Terra e Vita, v.19, n.49, p.26-27, 1978.

OH, J.Y.; KIM, J.S.; LIM, J.H. Studies on the damage of hailstone in the main crop. Research Reports of The Office of Rural Development, v.26, p.50-55, 1984.

OLIVELLI, V. Protection against wind and hail for olive-harvesting. Mondo Agricolo, v.31, n.35-36, p.13, 1980.

OLIVELLI, V. Active protection with nets and polycarbonate plates. Mondo Agricolo, v.33, n.40, p.7, 1982.

OLLIG, W. Hail protection with nets. Rheinische Monatsschrift fuer Gemuese, v.85, n.3, p.182-183, 1997.

OMOTO, Y. Hail problems in Japan. Journal of Agricultural Meteorology, v.40, n.2, p.163-172, 1984.

OPRA, L.J. Hail suppression data bank. In: The first yugoslav consultation on protection against hail and other measures for artificial influence on weather. Tara: Republicki hidrometeoroloski zavod SR Srbije, 1985. p.211-219.

ORTH, U.; KOLLATZ, U. Hail damage: accept, insure against or avoid? An economic comparison of three strategies for the management of hail risk in fruit growing. Erwerbsobstbau, v.37, n.1, p.19-22, 1995.

OSAER, A.; HUTIN, C.; BOUCHER, L. Hail protection nets. Paris: CTIFL, Nov. 1996. 182p. 
OSAER, A.; VAYSSE, P.; BERTHOUMIEU, J.F.; AUDUBERT, A.; TRILLOT, M. Spring frost, orchard protection. s.l.: s.ed., 1998. 151p.

PACINI, L. Anti- hail netting in Italy. Plasticulture, n.113, p.43-45, 1997.

PAPULI, G. La difesa attiva contro la grandine. Pesaro: Accademia Agraria di Pesaro, 1974. v.7, p.129-144. (Research report)

PENG, J.L. An investigation of mutual aid in agricultural insurance in the Heilongjiang Province Reclamation Area. Chinese Rural Economy, n.1, p.64-70, 1996.

PETERMAIR, J. Hail damage keeps itself within limits. Obstbau Weinbau, v.32, n.12, p.344-345, 1995.

PETERMAIR, J. Hail storms 1996. Obstbau Weinbau, v.33, n.12, p.329-330, 1996.

PLATTEAU, J.P. Mutual insurance as an elusive concept in traditional rural communities. Journal of Development Studies, v.33, n.6, p.764-796, 1997.

POPOVSKI, K.H. Hail damages on the vegetative and reproductive organs of the apple. Skopje: s.ed., 1984. 116p.

PRAKASH, S.; NAUTIYAL, M.C. Protect pome and stone fruit orchards from frost and hailstorm damages. Indian Horticulture, v.39, n.1, p.17-19, 1994.

PRESTAMBURGO, S. The insurance contract for hail damage: imperfect markets in agriculture. Genio Rurale, v.58, n.6, p.11-21, 1995.

RAGAZZINI, D. Anti-hail net or insurance: economic analysis in the apple-tree cultivation. Terra e Vita, v.25, n.43, p.1-11, 1984.

REID, P.; INNES, G. Fruit tree pollination under nets. Australasian Beekeeper, v.98, n.6, p.229-231, 1996.

RENARD, A.C. Environmental insurance for better risk management. Revue Laitiere Francaise, n.561, p.25-26, 1996.

RIESEN, W.; HUSISTEIN, A.; KREBS, C.H.; AFFOLTER, G. How to put up a protective net against hail? Schweizerische Zeitschrift fuer Obst und Weinbau, n.19, p.504-509, 1987.

RODRIGUEZ-RODRIGUEZ, R. Hail in agriculture. Semana Vitivinicola, n.1728, p.3489-3503, 1979. 
ROMERO, R.; BALASCH, S. Evaluation of the anti-hail camp aigns in Navarra: an application of the Box-Jenkins approach to time series analysis. Investigación Agraria. Producción y Protección Vegetales, v.1, n.3, p.359-377, 1986.

ROMERO, R.; TORRECILLAS, F.; SOLERA, I. Efficiency evaluation of hail protection measures in Levante area (Spain): first results. Boletin del Servicio de Defensa contra Plagas e Inspeccion Fitopatologica, v.8, n.2, p.169-177, 1982.

ROSSI, P. Experimental schedule for estimating hail damage in fruit crops. Informatore Agrario, v.54, n.10, p.73-78, 1998.

ROUSSEAUX, L. Controlling hail. France Agricole, v.36, n.1845, p.27-31, 1980.

RUBEN, R. Making cooperatives work, contract choice and resource management within land reform cooperatives in Honduras. s.l.: CEDLA Latin American Studies, 1999. 20p.

RUEGG, J. Do hail nets affect the scab situation in apples? Obst und Weinbau, v.133, n.4, p.88-91, 1997.

SACCOMANDI, V. Law no. 59/92 on cooperatives: first evaluation with special regard to the agricultural sector. Rivista di Economia Agraria, v.47, n.3, p.479-494, 1992.

SAIDI, H. About hail in Tunisia. Tunis: s.ed., Mar. 1976. 117p.

SCARTEZZINI, H. Southern Tyrol: a good harvest despite frost. Obstbau Weinbau, v.34, n.7-8, p.206-207, 1997.

SCOTT, B. The use of netting for hail protection: design and management considerations for pome fruit orchards. In: ROBINSON, J.B. Australian temperate fruits review conference. Adelaide: South Australian Dept. of Agriculture / Northfield Research Labs. / International Society for Horticultural Science - ISHS, 1989. p.147-150.

SEINO, H. On the characteristics of hail size distribution related to crop damage. Journal of Agricultural Meteorology, v.36, n.2, p.81-88, 1980.

SONKA, S.T.; CHANGNON JUNIOR, S.A. A methodology to estimate the value of weather modification projects: an illustration for hail suppression. Journal of Applied Meteorology, v.16, n.7, p.677-682, 1977.

SONKA, S.T.; SWANSON, E.R.; TAYLOR, C.R.; VAN BLOKLAND. P.J. An economic analysis of hail suppression. Journal of Applied Meteorology, v.17, n.10, p.1432-1440, 1978. 
SOULAGE, R.G. Scientific bases of hail suppression: the control of atmospheric nuisances: the cases of hail fall. Comptes Rendus des Seances de l'Academie d'Agriculture de France, v.71, n.11, p.1303-1310, 1985.

SPIELER, G. Microsprinklers and microclimate. International Water and Irrigation Review, v.14, n.4, p.14-17, 1994.

STADLER, F. Hail insurance to increase competitive power. Agrarische Rundschau, v.6, p.43-44, 1994.

STADLER, F. Hail insurance in Austria, the EU and the US A. Agrarische Rundschau, v.1, p.32-33, 1996.

STEINBAUER, L. Hail protection: a necessity. Obstbau, v.21, n.2, p.72-74, 1996a.

STEINBAUER, L. Hail nets: costs for kilo and year. Obstbau, v.21, n.4, p.198-200, 1996b.

STEINBAUER, L. Hail nets: developments in Europe. Obstbau, v.23, n.5, p.246-248, 1998.

STEINER, P.W. Predicting canker, shoot and trauma blight phases of apple fire blight epidemics using the MARYBLYT model. Acta Horticulturae, n.273, p.149-158, 1990.

STEINER, P.W. National Association for the Study and Control of Atmospheric Hazards (ANELFA): report of the 1992 campaign: hail control in the world. Bulletin d'Association Nationale d'Etude et de Lutte contre les Fleaux Atmospheriques, n.41, p.3-57, 1993.

STRNISA, T. Investment in apple orchards. SAD, Revija za Sadjarstvo Vinogradnistvo in Vinarstvo, v.7, n.4, p.7-14, 1996.

SUZUKI, H.; KUME, Y.; TAGUCHI, T. Investigation on hail injury of apple fruits in Akita Prefecture. Bulletin of the Akita Fruit Tree Experiment Station n.8, p.6392, 1976.

SZITH, R. Experiences with the control of hail by black nets in apple orchards of the Steiermark. Erwerbsobstbau v.17, n.4, p.53-56, 1975.

TAMBA, R. Hail: active and passive protection. Terra e Vita, v.20, n.28, p.20-21, 1979.

TASSOT, J. Hail control: soon effective? Agri Sept, n.744, p.16-17, 1979. 
THE 75 BIRTHDAY of agricultural mutual insurance companies. Bulletin d'Information du Ministere de l'Agriculture, n.702, p.16-22, 1975.

THE AGRICULTURAL mutual insurance groups participate in the insurance of cooperatives. Agriculture et Cooperation, n.28, p.36-39, 1980.

THE NATIONAL group for the study of atmospheric disasters looks for methods of controlling hail. Lien Horticole, v.18, n.13, p.11-12, 1981.

THROOP, J.A.; ANESHANSLEY, D.J. Apple damage segmentation utilizing reflectance spectra of the defect. In: ASAE ANNUAL INTERNATIONAL MEETING, Minneapolis, 1997. Resumos. Minneapolis: American Society of Agricultural Engineers, 1997a. p.17.

THROOP, J.A.; ANESHANSLEY, D.J. Inspection of processed fruit before and after peeling. In: ASAE ANNUAL INTERNATIONAL MEETING, Minneapolis, 1997. Resumos. Minneapolis: American Society of Agricultural Engineers, 1997b. p.19.

TORGGLER, B. Support framework must not be cut down on. Obstbau Weinbau, v.33, n.2, p.43-44, 1996.

TORGGLER, B. Hail nets should be stable and secure. Obstbau Weinbau, v.34, n.1, p.14-16, 1997.

TREND of the 1992 campaign: hail insurance. Ponte, n.4, p.16-18, 1993.

USE of plastic nets for protecting crops against hail. Mondo Agricolo, v.33, n. 10-11, p.34-35, 1982.

VANNONI, V. A silver umbrella against hail? Giornale di Agricoltura, v.90, n.9, p.49$51,1980$.

VEIT, H.P; LOSCHE, M.; BOCKERMANN, G.; PAUSCH, H.; SPRINGER, P.; BOHMER, S.; MICHEL, B.; HERBORT, M. Insurance that meets gardeners' dema nd. Gartenbau Magazin, v.3, n.10, p.4-26, 1994.

VENTO, D. Situation of the research about active protection against hail. Agricoltura Ricerca, v.6, n.32, p.10-15, 1983.

VENTO, D. At what point is the protection against hail? Informatore Agrário, v.40, n.28, p.22-24, 1984.

VENTO, D. Politics toddles along in the protection against hail. Informatore Agrario, v.44, n.4, p.79-82, 1988. 
VERCAMMEN, J. First experiences with hail nets in Belgium. Fruitteelt Nieuws, v.12, n.11, p.6-8, 1999.

VERCAMMEN, J.; VAN-LAER, P.; VAN-LEEUW, D. Hail control nets in the orchards: first experimentation in Belgium. Fruit Belge, v.66, n.473, p.91-94, 1998.

VRSIC, S. Light permeability of anti-hail net in the grapevine nursery. Zbornik Biotehniske Fakultete Univerze Edvarda Kardelja v Ljubljani, n.61, p.153-159, 1993.

WADSLEY, V. Bear ye one another's burdens: the first 100 years of Farmers Mutual Hail Insurance Company of Iowa. Des Moines: Farmers Mutual Hail Insurance Company of Iowa, 1993. 373p.

WAGENMAKERS, P.; TAZELAAR, M. Resulting light reduction determines the future of hail nets in the Netherlands. Fruitteelt Den Haag, v.89, n.7, p.10-11, 1999.

WEIDNER, G. Hail protection nets in fruit growing. Obst und Garten, v.111, n.5, p.245, 1992.

WEINBERGER, K. An enlarged concept for austrian hail insurance. Agrarische Rundschau, v.2, p.32-33, 1997.

WERNER, C.; KANDIYOTI, D.; MANDEL, R. Household networks and the security of mutual indebtedness in rural Kazakhstan. Special issue: market reforms, social dislocations and survival in post Soviet Central Asia. Central Asian Survey, v.17, n.4, p.597-612, 1998.

WIDMER, A. Shading under hail nets: first results and trends. Obst und Weinbau v.131, n.9, p.231-234, 1995.

WIDMER, A. Shading under white and grey hail nets. Obst und Weinbau, v.133, n.23, p.581-583, 1997a.

WIDMER, A. Light conditions, assimilation and fruit quality under hail nets. Obst und Weinbau, v.133, n.8, p.197-199, 1997 b.

WIDMER, A. Light and fruit quality under different hail net tissues. Rheinische Monatsschrift fuer Gemuese, v.86, n.1, p.8-9, 1998.

WILDERMUTH, A. Which form of crop insurance for Central and Eastern European agriculture? Zemedelska Ekonomika UZPI, v.44, n.3, p.109-113, 1998.

WIRTH, E. Hail prevention in Hungary. Idojaras, v.88, n.2, p.57-85, 1984. 
YE, J. D. On the possibility of artifical suppression of heavy rains. Journal of Nanjing Institute of Meteorology, v.16, n.3, p.373-378, 1993.

ZAVANONE, A. Planes or rockets against hail? Giornale di Agricoltura, v.93, n.20, p.10, 1983. 